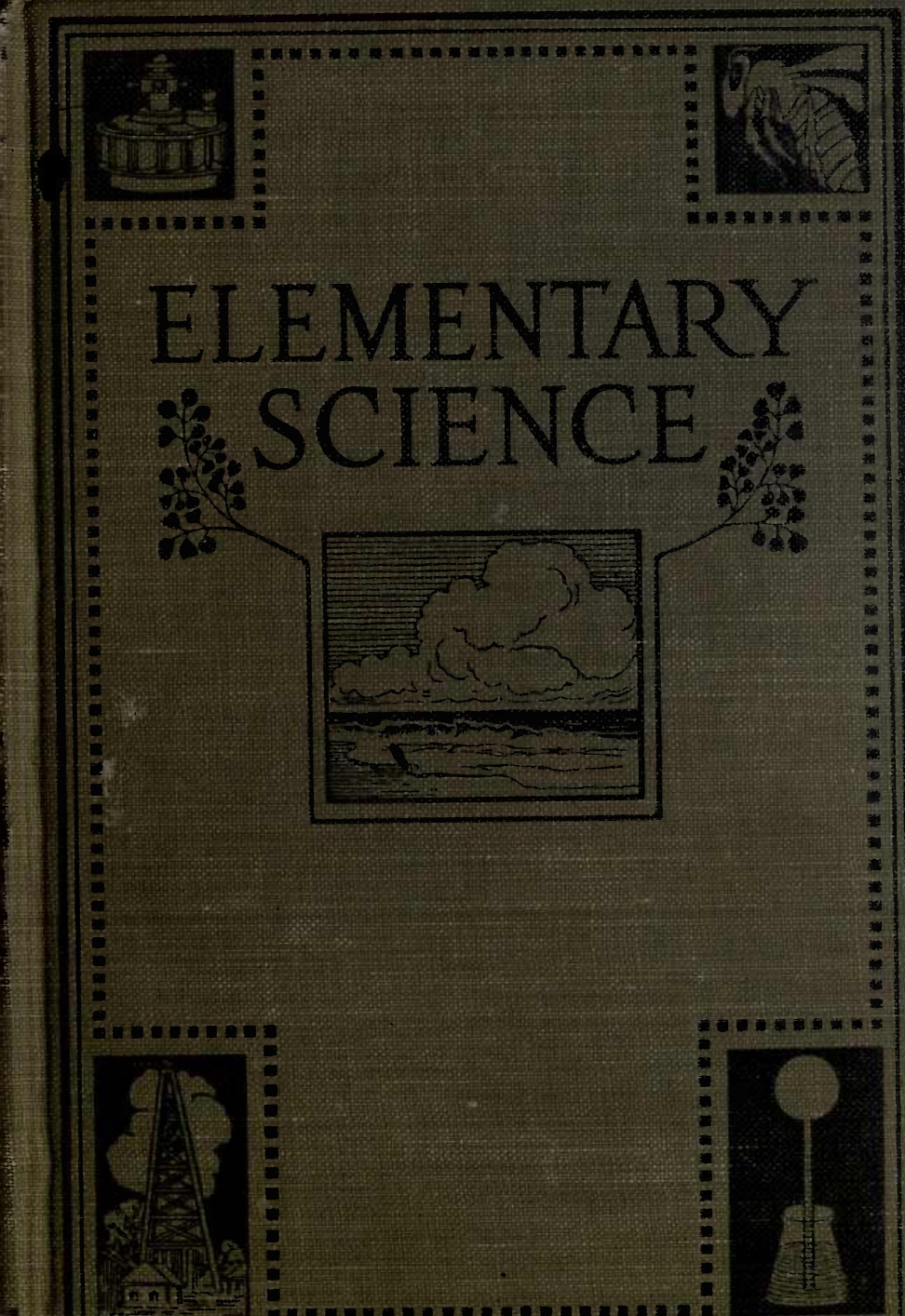




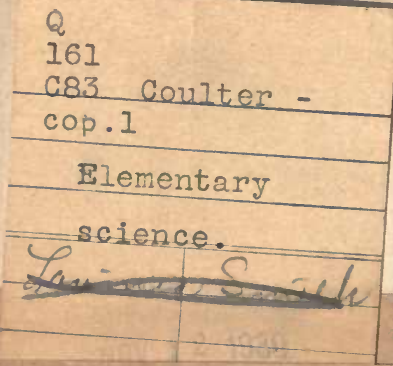

Southern Branch

$$
\text { of the }
$$

University of California

\section{Los Angeles}

Form L-1

Q

$|6|$

C83

cop. 1 


\section{UNIVERSITY OF CALIFORNIA LIBRARY}

\section{Los Angeles}

This book is DUE on the last date stamped below.

\section{SEP $2-1958$}





\section{ELEMENTARY SCIENCE}

BY

JOHN G. COULTER

ILLUSTRATED

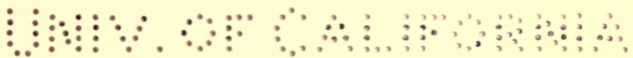

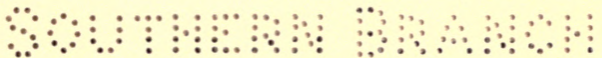

CHARLES SCRIBNER'S SONS 
Copyright, 1917, BY

CHARLES SCRIBNER'S SONS

C

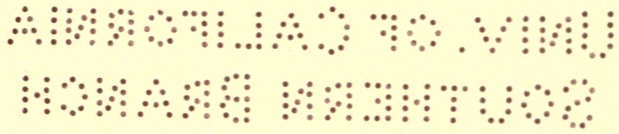

PRINTED AT

THE SCRIBNER PRESS

NEW YORK, U. S. A. 
pends upon the personality of the teacher. No style of presentation is probably best for all. It is hoped, however, that the point of view developed by the material selected, and presented in a way that has been found to be effective, may be helpful to teachers who wish their pupils to realize that one must live in intelligent partnership with nature, and therefore must become acquainted with nature.

John M. Coulter. 


\section{CONTENTS}

CHAPTER

PAGE

I. INTRODUCTION . . . . . . . . . . I

II. Some Relations Between Water AND Light 8

III. The Distribution of Water . . . . . I6

IV. Effects of the Movements of Water - 24

V. Solution . . . . . . . . . . . 40

VI. Man's Supply of Water. The Inside of THE EARTH . . . . . . . . . . 46

VII. The Suction-Pump. Atmospheric Pressure 55

VIII. Archimedes' Principle. Water-Pressure AND WATER-WORKS . . . . . . . 63

IX. Water-Power and Steam-Power . . , 70

X. Water and Agriculture . . . . . . 79

XI. ORIGIN OF Soll . . . . . . . . 86

XII. Kinds of SoIL . . . . . . . . . 94

XIII. Fertility and Soll Life: Bacteria . . IoI

XIV. Mechanical Work: Simple Machines . iog

XV. Work and Energy: Gravitation . . . il7

XVI. Introductory as to Heat: Discovery of FIRE . . . . . . . . . . . . I 23

XVII. Measurements of Heat . . . . . . I 28

XVIII. Heat and Cold . . . . • . . . . I35 
XIX. Some Effects of Heat . . . . . . I4I

XX. The Atmosphere . . . . . . . . 147

XXI. Air and Water Compared. Atoms and EleMENTS . . . . . . . . . . . I55

XXII. Heat and the Atmosphere . . . . . ${ }^{6} 62$

XXIII. The Seasons and the Solar System . . i6g

XXIV. Winds AND Weather . . . . . . . I 78

XXV. Economic Importance of Winds, RaIns,

Cyclones, Clouds, Tornadoes . . . 189

XXVI. Heating and Ventilation . . . . . 199

XXVII. Combustion . . . . . . . . . . 209

XXVIII. Light, Color, And Sound . . . . . 216

XXIX. Some Effects of Light. Photography.

Photosynthesis . . . . . . . . 225

XXX. Food. The Nutritive Cycle . . . . 232

XXXi. Plant Life . . . . . . . . . . . . 242

XXXII. The Story of Seeds . . . . . . . 247

XXXIII. Plant Groups . . . . . . . . . 257

XXXIV. Relations Between Plants and Their Surroundings . . $. \quad . \quad . \quad . \quad . \quad . \quad 265$

XXXV. Animals. Vertebrates . . . . . . 270

XXXVI. INSECTS . . . . . . . . . . . 276

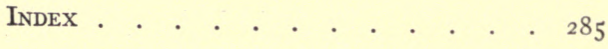


ELEMENTARY SCIENCE 



\section{ELEMENTARY SCIENCE}

CHAPTER I

INTRODUCTION

Air, water, soil, heat, light, plants, and animals - these are the principal things that make up what we call nature. You will find that your life is a sort of partnership with nature. To live in it the best way, you need to understand this partnership as well as you can. You need to know how to do your part in it. Life is the most interesting thing in the world. You want to find out all you can about it so that you can make your own life as happy and successful as possible. A good way to go at this business of finding out about life is to study first the things that are necessary to all kinds of life, plants as well as animals, and see how these things work together to make our own lives possible and pleasant. That is what we shall do in this book. We shall study the seven things mentioned in the first sentence. We shall study the conditions that are necessary for our own lives, and this will help us a great deal in finding out how we ought to live.

For thousands of years men have been finding out more and more about the world. Each year new knowledge is added to the old, and this knowledge of nature is called natural science. You have read about cavemen and other ancient people, and you know that the savage men of long ago had a hard struggle for existence. They did not under- 
stand how to work in partnership with nature, and so nature seemed more of an enemy than a friend. There was much hunger in those days. Famine, wild beasts, and cold weather - these were enemies against which man hardly knew how to protect himself. He lived "from hand to mouth." Only the strong and hardy survived in those perilous times. But since then men have made hundreds of discoveries about nature. These discoveries have made it possible to live much more safely and comfortably, until to-day even poor people have more comforts than had the kings and queens of old.

Sometimes this long process of making life more comfortable and secure is called "man's conquest of nature." But this expression suggests the idea that nature is an enemy that we must fight and try to conquer. That is only a part truth. Man's so-called "conquest of nature" has been rather the learning of nature's secrets; learning how to take advantage of the many ways in which she will help us if we study hard enough to understand her.

Those things that we call inventions are simply newfound ways of developing our partnership with nature. An inventor designs a new type of engine, or a doctor discovers a new way to cure a disease. We call these things men's inventions, but let us remember that they are simply discoveries of new ways of controlling nature. Man discovers how to arrange what we call inventions, but it is nature that does the rest. Nature supplies the materials that man arranges, and also the forces that make all of his inventions work. So you need to study nature in order to understand machinery as well as to understand about the woods, the fields, and the weather. Nature is at work in a steam-engine as well as in plants and animals. Nearly 
all the machinery in the world is run by power that came in the form of sunlight long, long ago, and was stored up in the form of coal. Nature, you see, is the very foundation of man's work, either in city or in country. So, if we are to have a real understanding of our lives we must understand about nature, and our place in nature, as well as about our fellow men and our relations to them.

Let us begin by thinking of the world as a whole, and try to form a picture of it in our minds somewhat as you learned to do in geography. Then we will consider it more carefully, one thing at a time.

There are three parts to the earth. We live on top of two of these parts, and nearly at the bottom of the third. These three parts are the solid, the liquid, and the gaseous parts. Most of the earth is solid rock, the liquid is water, and the gaseous part we call the atmosphere or air. Perhaps you have heard the statement that we live at the bottom of a great sea of air. It lies over the whole surface of the earth, and extends more than a hundred miles above it. It is a huge, soft cover. It flows more easily than water. When air moves so that we can feel it we call it wind. Though it is invisible it has weight. It is much more dense and heavy at the bottom than it is at the top. Most of the atmosphere, by weight, is within four miles of the surface of the earth. Above that it is very light and thin.

Our earth is very old. It has not always been the pleasant place that it is to-day. There was a time when we could not have lived here. There was a time when there were no plants. Before that there was a time when there was no soil. Nearly the whole earth was covered with water. The only land was bare, brown rock. Not one 
green plant grew upon it. Not a bird flew over it. Not a single animal lived there. Everywhere it was very still and very lonely. But in that ancient time, millions of years ago, the earth was slowly changing. Slowly, but surely, it was getting to be more and more like what it is to-day, and the changes that went on then keep going on to-day.

In those days when the earth was young the sun shone just as it shines to-day. It was the heat of the sun that kept things changing then, just as it keeps them changing now. The sun warmed the surface of the oceans and drew water up into the air. Clouds formed. It warmed the air more in some places than in others, and the air stirred and moved about, somewhat as water stirs and moves about when it is heated. Winds blew and carried the clouds over the land. There the clouds were cooled and changed to rain. The rain fell, and the water ran over the land, wherever it could go. The air and the water and the heat worked together and changed the surface of the rock to soil. The streams carried this soil down toward the sea. They made it into mud, and banks of mud were formed along the shores. Then some of the plants that had been living in the water began to live on this mud. As more soil was formed these plants began to spread, until at last the land was covered with green. These green plants made food, and then the land was ready at last for animals to live on it.

Now, with these things in mind you can form a picture of how the earth changed in ancient times, and of how it keeps changing to-day. Light and heat come down to us from the sun. The air is heated more in some places than in others, and this causes movements of the air. 
The clouds move with the air. Heat draws water up into the air, by means of the process we call evaporation. Light, shining on the green plants that cover the land, enables them to make the food on which animals live. Water, moving in clouds and falling as rain, enables the plants to live in the soil in which they are rooted. From the soil and from the air they get the substances that they make into food. Here we see one of the great partnerships of nature. Heat and light and air and water and soil and green plants are the members of this partnership, and the food that sustains our lives is one of the results of their work together.

Of the number of things absolutely necessary to life, food is usually the most difficult to obtain. Air to breathe, water to drink, and enough heat to keep life going can usually be obtained by all living things without much work. But with food it is different. Nature requires that all living things work for their food. Though now you may be getting your food for nothing, somebody else has certainly had to work to provide it for you. Of the money that we spend for really necessary things, more is spent for food than for anything else. It takes a great deal of work to cultivate the plants and to raise the animals that are the sources of human food. If we do not do foodproducing work ourselves, we must pay others to do it for us. So, as we study the working together of the forces of nature, it will be interesting to see how these things are related to the production of food.

Let us go over this matter once more to get the picture clear. Think of the heat of the sun that starts the procession of changes; it starts them by causing movements of both air and water. Think then of the water falling as 
rain, and working down into the soil as well as running off in streams. Then think of the plants whose roots go down into the soil, and whose leaves are lifted by the stems up into the light and air. From air and earth these plants draw materials that are used in food manufacture. These materials come together in the green leaves, and there, with the aid of the sunlight, the food of the world is made. So we see how sun, rain, and wind, soil and roots, and stems and leaves all help make the world a place where we can live. They are all necessary to our lives.

Men have greatly improved the plants which they use for food. The trees in the orchards, and the wheat and corn in the fields are very different from the wild plants that were their ancestors. Long before the written history of man began, our primitive forefathers were learning through experience how to grow plants for food. Many famines in winter taught them how important it is to harvest crops and store them. They found that it was a good thing to grow certain plants in places where they scratched the soil with sticks, which was the first kind of ploughing. They learned that the food plants grew better if other plants were kept from growing near them. So they weeded their little cultivated patches.

So you see that ages ago man began to work as a partner of nature in improving the conditions of life. And we are still engaged in that great work. We have by no means solved the problem. Each year we are finding out new things about nature and about human life. So each year the world becomes a more wonderful and interesting place in which to live. Right now you are living in the most interesting period in the world's history, and to-morrow 
will be even more interesting than to-day. You have an opportunity that no one has had before. You should have a great deal of confidence in the future, and be determined to make the very most of this one life that you have to live. Nature is sure to reward you very richly if you will obey her laws, and her first law is the law of work.

\section{QUESTIONS}

I. What is "nature"?

2. What is "natural science"?

3. Is nature an enemy or a friend to man?

4. What has nature to do with inventions?

5. What are the three great regions of the earth?

6. How is soil formed?

7. How was the first soil formed on the earth?

8. Which lived first, plants or animals? 


\section{CHAPTER II}

\section{SOME RELATIONS BETWEEN WATER AND LIFE}

You have seen that in order to understand the great "cycle of nature" that permits us to live, you must study the following things: air, water, heat, light, soil, plants, and animals. You must study especially the ways in which these things work together in producing the conditions that permit us to live.

We might begin with the study of any one of these topics, and as we studied it we should find ourselves studying all the others, so closely are they related. We will begin with water, because water is the simplest.

Water. - As you look at water in a glass it seems a very simple thing, easy to understand. But when you begin to study the way that water behaves, and the many effects it has upon our lives, you soon find that this is a very large subject indeed. Three-fourths of the surface of the earth is covered with water, and more than threefourths of the bodies of all living things are composed of water. This suggests the idea that life began in the water, and slowly spread from there over the land and into the air. There are many land animals, including man, in which, when they are very young, structures appear that suggest ancestors that lived in the water. However that may have been, it is very certain that water is one of the largest factors in life to-day, and to get a pure water- 
supply is one of the first problems men must solve, whether they live in city or country.

In physiology you learned about digestion. You know that digestion is the changing of food into liquid form. All food must be so changed before our bodies can use it, and the basis of this liquid form of food is water. Nearly all of the weight of blood is water. Plants, in proportion to their weight, need even more water than do animals, especially when they are growing. Their roots are always taking in water from the soil, and from their leaves water is always going off into the air. Water evaporates from leaves just as it evaporates from the surface of lakes and ponds.

When we say "water" we think of a liquid. But we know that water below a certain temperature changes to a solid that we call ice. And above a certain temperature it changes to a gas that we call steam. It may also change into an invisible gas that we call water vapor. This change of water into ice when it is cold, and into steam when it is hot, suggests that heat determines the form in which substances exist. Thus you see you can hardly begin to study one of these topics before you begin to study another. We have just begun to study water and already we need to know something about heat. Just what is heat? That is certainly a question we shall have to answer before we get very far in our study of water.

There are three principal forms in which substances exist: the solid form, the liquid form, and the gaseous form. Scientists refer to all substances taken together as matter, and they call solid, liquid, and gas three states of matter. The "solid earth" on which we walk is the most familiar solid, water the most familiar liquid, and air the most 
familiar gas. Our lives are so very closely related to all three of these that it is impossible to say which one of them is most important to us.

Now let us think of the different ways in which the changes of water from one state to another affect our lives. First, the change from liquid to gas. You know that boiling water gives off steam, and you know that even cool water gradually evaporates, which means that it changes into water vapor. There are at least three ways in which this changing of water from liquid to gas affects our lives. Two very important things in our lives are rain and steamengines. Both of these depend upon the changing of water from a liquid into a gas. Can you explain how?

Every boy or girl probably knows that when water changes into steam it expands, and expands with much force. Probably you have heard about James Watt, the Scotchman who invented the steam-engine about one hundred and fifty years ago. The story is told that once when he was a boy he stuck a cork in the spout of a teakettle, and the steam blew it out. It blew it out so hard that he began to think about the force behind the blow, and wondered if that force could be used in any useful way. That was the idea that led finally to the invention of the steam-engine. In all steam-engines the fresh steam enters a strong cylinder where it can expand only by pushing a piston, just as the steam in the spout of the kettle pushed the cork. One end of a steel rod is attached to the piston, and the other end to a wheel. As the piston is pushed to and fro by the pressure of the steam, the rod turns a wheel, and thus the machinery is operated (see Fig. I). You can see the cylinders and the piston-rods and the driving-wheels on any locomotive. 
The third way in which the changing of water from liquid into gas affects us is by keeping us cool in hot weather. This is not quite so easy to understand, and yet it is a thing that has happened to you hundreds of times. Why is it that it cools your face to fan it? Chiefly because the stirring of the air makes the moisture on your face evaporate more rapidly. As the tiny particles pass into the air,

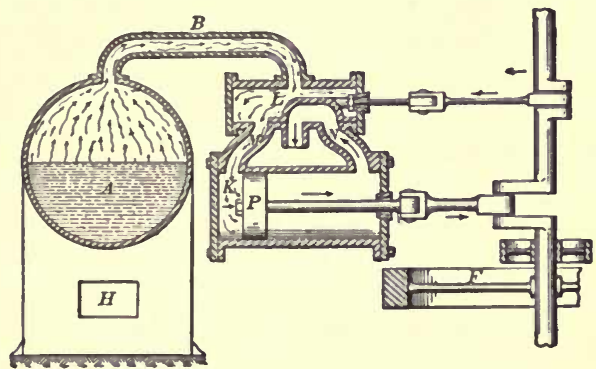

Fig. 1.-Principle of the steam-engine: fire at $H$ heats water in boiler $A$; this produces steam which travels, as indicated, into cylinder $K$, pushes piston $P$, and operates the machinery to which the engine is attached.

they carry heat away with them. Evaporation is a cooling process. This is a matter we shall have to discuss more fully a little later. Here again we find that we cannot study water without studying heat.

Now about the changing of water from liquid to solid. That is what gives us ice, and it would be very inconvenient for us not to have ice. Then there is another interesting thing about the changing of water from liquid to solid, a thing that affects our lives, a thing that seems to be an exception to one of the "rules" of nature. That rule is that heat causes expansion and cold causes contraction. 
Nearly all substances expand when they are heated, and contract when they are cooled. But in the case of water this applies only up to a certain point. Water contracts as it cools nearly up to the point when ice is formed, and then it expands. If it did not, all the fish in our streams and lakes would be killed. Can you see why this is? Suppose ice was contracted water instead of expanded water. Then a cubic foot of ice would weigh more than a cubic foot of water, and all the ice would form at the bottoms of streams and lakes instead of at the surface. As it is, the ice on top really protects the water beneath from becoming cold enough to freeze. If the ice began to form at the bottom, our lakes and streams would all be solid ice before the winter was over. The only inconvenient thing about the expansion of water when it turns to ice is that sometimes this causes the bursting of unprotected water-pipes.

These things that you have been reading about are very easy to see, but they are not so easy to explain. For hundreds and hundreds of years men observed these things and were unable to explain them. But now, in a very short time, you can learn explanations of things that your greatgrandfathers could not explain at all. Take this matter of evaporation that is so important to our lives. You know what it is, but how are you going to explain it? Here is a dish of water. You know that after a while, even when nobody touches it, the water will be gone. It will pass into the air. How did this happen? To understand this you must understand that water and all other substances are composed of very, very small parts, so small that they are invisible. These invisible and very small parts of substances are called molecules. Though they are 
far too small to be seen, scientists have been able to measure the size of molecules. The water molecule is so small that there are millions of them in a single drop. Since they are so wonderfully small, it is not hard to understand that they may fly upward from the surface of a liquid. The surface of a liquid may seem to be very quiet, yet something is going on there all the time.

Think of the surface of a pond on a summer day. The warm sun shines on it. The air above it is dry. A breeze blows over it. Under these conditions evaporation is rapid. But if the air were cold and moist and still, evaporation would be very slow. You see the air can hold just so much water and no more. We say of a sponge that is full of water that it is saturated. Air that has taken up all the water it can is also said to be saturated.

But to go back to our pond. The heat and the wind and the dryness of the air make millions upon millions of invisible molecules keep rising from the pond. Up and up they go, until at last they come where the air is cooler. Then what happens? Then these tiny molecules of water begin to condense. It is as though they huddled together in crowds. These crowds of molecules are tiny droplets, so small that you could not see one of them, and yet when billions and billions of them are near each other they form what we call clouds.

Here for the third time in studying water we have come to heat. Cold means simply less heat, and you have just noted that heat causes water molecules to evaporate, and then less heat causes them to condense again. If it were not for heat, all the water in the world would change to ice, and would remain in that form. Water seems to be quite an active substance, changing constantly as it does 
from one form to another. But, really, water is not active. It is heat that is active. Water is passive, and it is changes in the amount of heat that are responsible for the changes of water. Water is a sort of tool, and heat is the great force that uses that tool. We say that the heat of the sun draws water up. It changes from liquid to gas. Then it changes from gas back to liquid again, and falls as rain. It keeps moving and changing all the time. It goes down deep into the soil and into crevices in the rock, and then again it rises in the air far above the earth. Water is a wonderful traveller. It is in the bodies of plants and animals as well as in the seas and lakes, and it travels from the fields of ice and snow in the far north and south down to the tropics again. Yet with all this movement and changing of form there is always practically the same amount of water in the world. It may change its form and its place, but it is not destroyed.

So, even by studying water alone we learn that we live in a very changing world. Our surroundings are constantly changing, just as we ourselves are constantly changing.

We do not need to travel to see these changes. We can stay where we are and watch day change into night. We can watch the clouds marching across the sky, and the storms as they gather and break. We can feel the wind and the rain in our faces, and can see the rivers running to the sea. We watch the procession of the seasons, winter changing to spring, and autumn to winter again. Each day the country is a little different from what it was the day before. The plants and the animals change as well as their surroundings. Each week of the spring and summer months you will find different birds and insects in the 
fields and woods. Yesterday, when I looked from my window, the whole surface of the earth was green as far as I could see. But to-day it is beginning to turn brown, because the blue grass is ripening.

You saw that it is heat that causes the changes and movements of water. And it is changes in the amount of heat that cause the seasons of the year. You can see that this would be a very still and dead world indeed if it were not for heat.

\section{QUESTIONS}

I. How much of the earth is covered by water?

2. What is the purpose of digestion?

3. What determines the three states of water?

4. What is the force that drives the steam-engine?

5. Why does it cool your face to fan it?

6. How does the size of a substance change when it is heated?

7. Why do water-pipes burst in winter?

8. What are clouds? 


\section{CHAPTER III}

\section{THE DISTRIBUTION OF WATER}

The distribution of water is evidently very important. We must find out about it. What is it that keeps it moving all over the surface of the earth? Does it move of itself, or does something else move it?

There are four things that explain the distribution of water. These four things are evaporation, condensation, air movements, and gravity. Evaporation explains how water gets up into the air. Condensation explains how clouds are formed. Air movements explain why the clouds move about in the sky. Gravity explains why the rain falls to the earth, and why the water goes down to the roots of plants, and why the streams flow to the seas. Here are four things that are at work all the time. Night and day they keep the water moving. Up it goes in invisible mist that changes to visible clouds. Over sea and land the clouds are always moving, and somewhere the water is always falling back to earth again as rain. Always the water that falls as rain is going into the soil and into the streams. In the soil some of it enters the roots of plants, and then it passes out from their leaves into the air again. Without this movement of water through their bodies, the plants would soon wither and die. Water lets them live and grow.

Evaporation. - If you have a bird-bath in your yard, you know that it is hard to keep it filled. The water evap- 
orates. On wash-day wet clothes are put out on the line and presently they are dry. You can't see the water go, but you know that it has gone. How are we going to explain this?

A drop of water is composed of millions of particles. It is impossible to see these particles, but we know that they are there by the way they behave. These particles are always in motion. They move in straight lines. They strike each other, and rebound. At the surface they are always flying off into the air. It is this flying off of the particles of water that we call evaporation. There is always some water in the air in the form of these invisible particles. When there is a good deal of water in the air we say that it is moist or humid.

Evaporation does not always go on at the same rate. Sometimes it is rapid, sometimes slow. The more moisture there is in the air the slower the rate of evaporation. Heat and wind affect it. It is most rapid when the air is hot and dry and the wind is blowing. It is slowest when the air is moist and cold and there is no wind.

Evaporation is a cooling process. As the water passes away, heat passes away with it. On hot days if the air is dry, we are much more comfortable than if it is moist. This is because rapid evaporation of moisture from our bodies keeps us cool. But if the air is moist as well as hot, we are very uncomfortable. Moisture stays on our skin, and heat stays with it.

Evaporation goes on all over the world all the time. All the time water is passing into the air from all the seas and lakes and streams, and from all the leaves of plants. Each year enough rain falls to make a sheet of water between thirty and forty inches deep all around the world, 
and this shows how much water evaporates. For all the water that falls as rain must have gone up by evaporation. There is no other way.

Condensation. - After the water particles get up in the air, a number of things may happen to them. At first they are lighter than the air and keep moving up, somewhat as a balloon moves up. But presently they come to where the air is cooler. The cool air affects them. They begin to crowd together. This is what is called condensation. The particles condense into small drops. You can see how this happens by holding a cool piece of glass in the steam that comes from the spout of a kettle.

We cannot see the particles of water when they evaporate. They are much too small. But after they have condensed into little drops they form clouds. When the sun is shining on them the clouds are white and beautiful. They drift with the wind. When a cloud forms close to the surface of the earth we call it fog.

Sometimes the air just over the earth is moist when evening comes. Then, if the night is cool, this moisture condenses into little drops that we see shining on the grass when the sun comes up. We call it dew. If the night is so cold that this moisture condenses in the form of tiny crystals of ice, we call it frost.

The tiny drops of water that form the clouds are no heavier than the air, so they stay up in the air and float along like tiny balloons. But sometimes they come to where it is cooler. Then they condense more and more, until they form big drops that are heavier than air. The drops begin to fall. The clouds are breaking up in rain. The warmer the air the higher the light clouds go up in 
the sky. The heat keeps the tiny drops from condensing. Then, suddenly, these high clouds may come into air that is very cold, so cold that it makes their drops condense quickly in the form of ice. The drops of ice plunge down to earth, getting bigger as they fall. These drops of ice we call hail.

Air Movements. - Now you understand how the water gets up into the air. The next thing is to understand how it gets carried over the land. The winds blow the clouds, you say. Yes, but what is it that makes the winds blow? Air does not move unless there is something that makes it move. What we want to find out is the cause of air movements.

Air is always moving. It is the most actively moving substance in the world. It may move in any direction. Its horizontal movements we call wind. But there are also up and down movements that we do not feel. As it moves, the air carries with it both heat and moisture. You know how important the circulation of the blood is to your body. The circulation of the air is just about as important for the earth as the circulation of the blood is for your body. It is the beating of your heart that keeps your blood moving. What is it that keeps air moving?

Hot air is lighter than cold air. You have learned about this in geography. You know that the heat of the sun is greater near the equator than it is at the poles. So the warm air near the equator rises and flows away toward the poles, while the cool air from the north and south keeps flowing in toward the equator, under the warmer air. Thus the heat of the sun starts the circulation of earth's atmosphere, just as the heat of a stove starts a circulation of air in a room. 
So the sun explains how the air starts to circulate. But that is not enough. We want to know about the winds that blow from every direction. Sometimes they are very gentle and pleasant, sometimes they are very strong and destructive. What makes the air behave this way?

The air behaves in this way because it is always getting stirred up, and then tries to smooth itself out again. A high wind is just the rushing in of a lot of air to take the place of other air that has moved away. The thing that

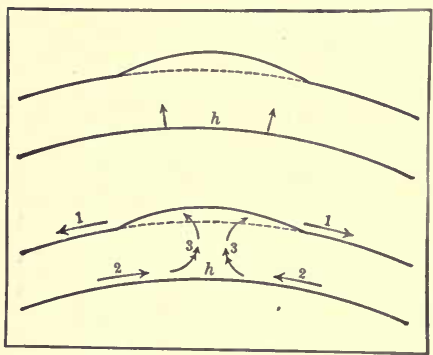

Fig. 2.-Diagram to illustrate how the air becomes heated at the equator and moves upward.-After SALISBURY.

keeps the atmosphere stirred up is the heat of the sun. You know how heat keeps the water in a kettle stirred up. Somewhat in the same way the heat of the sun keeps the air stirred up.

The heat of the sun comes down on the air, and the air catches some of this heat and holds it. The air is a sort of trap for heat. But some parts of the world get more heat than other parts. Also the amount of heat received from the sun varies at different times of day. So, always, some parts of the air get hotter than other parts, and that is what keeps the air moving. For, just as soon as any air gets warmer than the air around it, it begins to move. It begins to move up, because it is lighter than the rest of the air (see Fig. 2). Now, because the air is always stirred up in this way, the amount of air over your head keeps changing. If a 
good deal of the air above us has moved away, we have what is called low pressure, that is, a low pressure of air on the surface of the earth. But if the air is piled up higher than usual in some places, those places have high pressure. Then what happens? It is then that the winds begin to blow. The air seems to try to get evenly distributed again. It rushes from the high-pressure places to the low-pressure places. The greater the difference in pressure, the faster the air will move. It is like water rushing down a steep slope. It may rush so fast that there is a great storm. So the air is always trying to smooth itself out (trying to equalize its pressures), and the sun, by heating it unevenly, is always getting it stirred up again. As a result of these two things, the air is always moving and always distributing heat and moisture over the surface of the earth.

You will learn a good deal more about this when we study the weather. But now you have learned enough to understand how it is that water gets distributed. It is the heat of the sun that does it. It is the heat of the sun that starts evaporation, and it is the heat of the sun that keeps the air moving. So it is the sun that keeps both air and water moving. It is the sun, if anything, that is the heart of the world, and the air and water that the sun moves sustain life just as truly as the blood that your heart moves sustains life in your body.

Gravity. - The fourth thing that explains the movements of both air and water is gravity. It is heat that explains why air and water go up. It is gravity that explains why they come down again. We must understand both of these things and see how they work together. 
Gravity is just as important as any of the other great things that we have started out to study. It has done just as much as any of them in making the earth so that we can live on it.

Gravity is a property or quality of the earth. It is not a thing that we can see or feel; it is a "law of nature." It is the "pull" of the earth upon all things on its surface or near it. It is the power that makes an apple fall to the ground, and makes water run down-hill. It is the power that makes it easier for us to go down than to go up. It is the power that keeps water and air from flying off into space. It is the power of Mother Earth to hold things to her surface.

There is a law of nature that all solid bodies have power to attract other bodies toward them. Thus it is the attraction of the moon that causes tides in the sea. This law is called the law of gravitation. Gravity is simply the law of gravitation as applied to the earth. No one has explained gravitation. Gravitation explains other things, but it does not explain itself. It is one of those things that you will have to accept without any explanation.

This is just a beginning of the study of water. You have learned an explanation of its movement. You have found that heat and gravity are the chief causes of the movements of both air and water. Now we must see what the water does as it moves about on the surface of the earth.

\section{QUESTIONS}

I. How is water distributed?

2. What is "humid" air?

3. When is evaporation most rapid? 
4. Why are we more uncomfortable on moist hot days than on dry hot days?

5. What happens if you hold a cold piece of glass in steam?

6. What is fog?

7. What are dew and frost and hail?

8. How is hail formed?

9. Why does the wind blow?

I0. Define gravity. 


\section{CHAPTER IV}

\section{EFFECTS OF THE MOVEMENTS OF WATER}

You have seen that water is a great tool of nature, and that heat and the force of gravity are the forces that work with this tool. Air is another great tool of nature, and it, too, is moved by heat and by the force of gravity. Up and down, across the surface of the land and under it, these tools keep moving and working. The winds keep blowing, rains keep falling, and water keeps running back to the sea. What effects do these things have upon us?

As air and water move they move other things with them. Things that are loose are shifted about. High winds blow dust and sand from place to place, and high water sweeps along everything in its path that is not firmly anchored. Thus some shifting of the materials of the earth's surface goes on all the time, and running water is by far the most important of the shifters of materials. Water is eighty times as heavy as air; so it can carry eighty times as much. Every muddy stream is carrying a load that will be laid down again somewhere. This is called the wash or the waste of the land. The Mississippi River carries out to sea a million tons of mud and sand each day. (How many freight-trains of fifty cars each would be required to carry this load, allowing five tons to the car?)

Running water plays an important part in the lives of men. It does both good and harm. The rivers carry away to the sea much good fertile soil, but they also bring good soil down from the hills and spread it along their 
courses. In geography you learned of the rich soil of the river-bottoms. This soil is composed of materials carried and distributed by flooded rivers. Rivers in flood sometimes destroy the work, and even the lives of men, but all the time they are turning thousands of water-wheels that do work for him, and they make a highway for his boats. Rivers have been of great importance in the history of man. There was a time when nine-tenths of all the people in the world lived on rivers. This was because of the fertility of the soil there, and because of the ease of travel by boats.

Erosion and deposition are two scientific terms that describe the process of shifting materials on the earth's surface. Erosion means the "gnawing away" of material. We say that acids erode metals; they seem to gnaw them away. So, also, we say that wind and water erode the land, especially the bare, uncovered parts of the land. The waves gnaw away at the shores, and the streams gnaw away at the hills. And all the material that is eroded is deposited somewhere again.

Protection by Plants. - All this sounds as though the world was a very uncertain place in which to live. It sounds as though the land on which we live might be washed away from beneath our feet. Of course this is not true, but it would be true if it were not for the natural covering and protection of the land that is formed by the plants, especially the grass plants. In places where plants cannot grow erosion may be very rapid. Think of the "shifting sands" of the Sahara Desert, or of the "bad lands" in our own country. In these bad lands, where plants do not protect the surfaces, it is plain to see that 
erosion is a sort of gnawing process; the sharp hills look as though their sides had been gnawed. On railroad embankments it is very important to start the growth of tough grass, whose roots hold the soil together, and keep it from washing away. If the plants were gone it would not be long before the whole surface of the land would

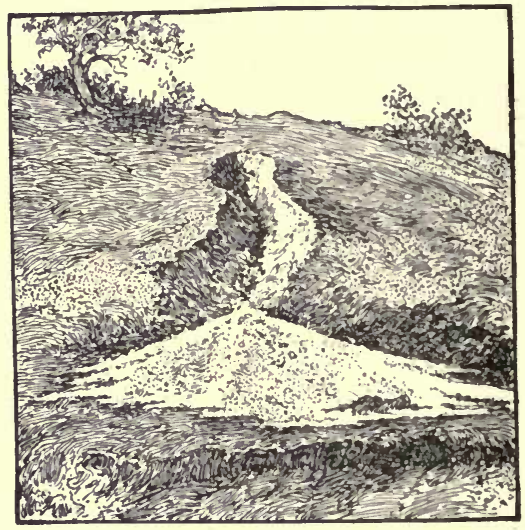

Fig. 3.-Gully cut back into a field by a rain-storm.

begin to look something like the bad lands of South Dakota. As it is, our protected soil is not washed away much except where streams gnaw away at their banks, working under the soil and trees, or where gullies are formed, or where there are steep slopes.

A Picture of the Wearing Down of the Land. - Now, in mind's eye, you can begin to see the way in which water wears down the land. You can see the streams, swollen 
by heavy rains, rushing down the sides of hills and mountains, tumbling the boulders along as they go. You can see the waves of lakes and oceans, beating against their shores, and grinding rock into finer and finer material. After a storm, you have seen the washouts along the roadsides, and the gullies that are cut back into the fields and hillsides (see Fig. 3). You can see, too, that men have

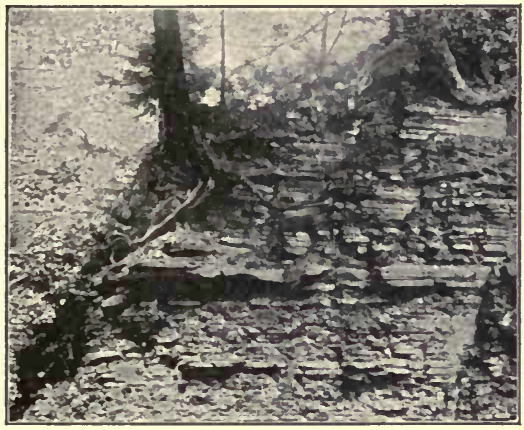

FIG. 4.-View showing how the roots of plants hold the soil and prevent it from being washed away by the rainfall.

done much work to keep the streams in their courses, and to prevent washouts.

Here are two very simple facts. Water runs down-hill, and as it runs, it carries things with it. It is just these simple facts that have determined the forms of the land. Water running down-hill is the great sculptor of nature. Slowly but surely the whole surface of the land is being brought down to sea-level. Of course it is a very uneven process; erosion is much more rapid at some places than at others, but it goes on all the time. Where slopes are steep, 
and heavy rains are frequent, and rock and soil are loose, erosion is rapid. Where the land is level and well covered with plants, erosion is very slow (see Fig. 4). But slow or fast, the result is the same. The land is being worn down to the sea. As long as there is a bit of soil or rock that stands even one foot above sea-level, wind and water
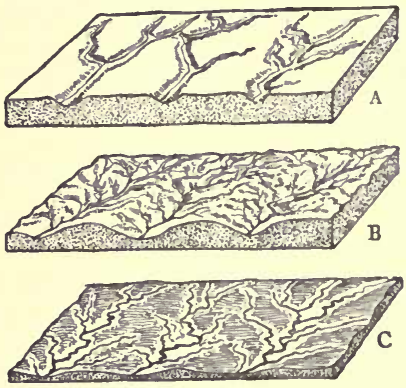

FIG. 5.-Diagram showing how running water cuts into the land and washes it away, until it is finally lowered almost to sea-level.

will attack it. They will work at it till they wear it down (see Figs. 5 and 6).

\section{The Rise of the Land.} "But," you ask, "if all this is true, why have we any hills and mountains left? Why is not the whole surface of the land worn down nearly to sea-level?"

If you have ever felt an earthquake or seen a volcano you can probably guess the answer. Earthquakes and volcanoes show us that inside the earth great forces exist. These forces are strong enough to lift islands out of the sea, or gradually to raise up whole ranges of mountains. They have done this in the past, and in some places they are still doing it to-day. Great though gentle movements of the land seem to be going on all the time.

Some hundreds of years ago an invading army landed on the east coast of England. The town at which it landed is now miles inland, so much has the land risen since that time. There are many such places in the world. Also 
there are many places where the edges of continents have sunk below the sea. This is true near New York City. The valley of the Hudson River is what is called a "drowned valley"; a long time ago it sank below the sea-level, so that now sea-water mingles with the river-water for many miles above the mouth. Careful measurements have

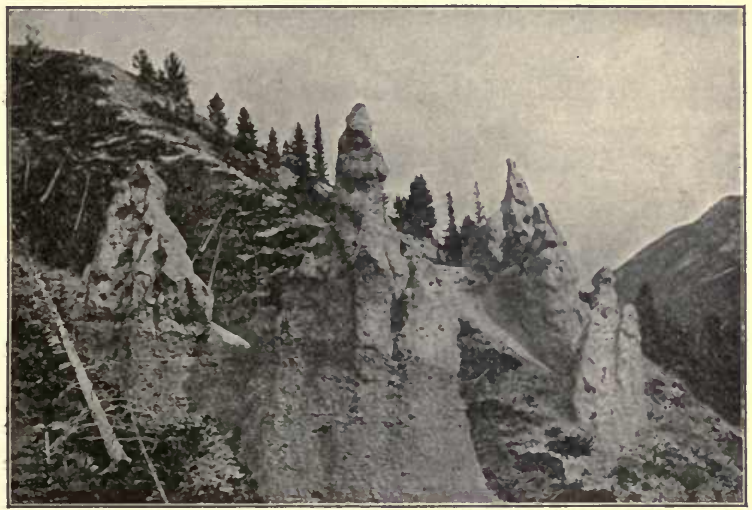

FIG. 6.-Photograph showing how running water cuts away the softer parts of the land and leaves the harder rocks sticking up.

proved that the coast of Massachusetts is sinking very slowly. You have seen how air and water keep moving, and now you learn that the solid part of the earth also keeps moving. Change follows change. All nature is just an endless procession of changes. Not even the hardest rock is quite the same this year that it was last year.

So we see that, while running water keeps wearing the land down, hidden forces inside the earth keep lifting it. The result is that there is just about the same amount of dry 
land to-day that there was when man first began to live on earth. There seems to be no danger of being swallowed up by the sea.

\section{Mountains Worn Down and Seas Filled Up. - Though} the amount of dry land may have changed very little since human history began, we must remember that human history is a very small thing as compared with the whole history of the earth. What we see happening to-day to the surface of the earth is but a trifle compared with what has

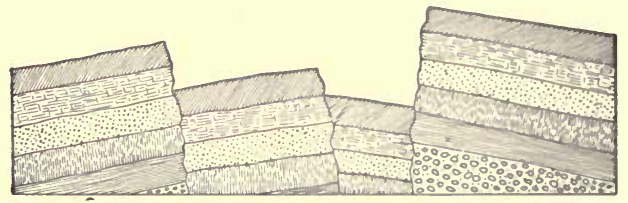

Fig. 7.-Diagram of layers of rock that were laid down in the sea and are now found miles away from the sea.-After SNYDER.

happened in the past. Whole ranges of mountains have been worn down by the ceaseless work of water, and have been carried off, grain by grain, into the sea. Seas and lakes have been filled with this waste of the land, and geologists, who study the rocks and find in them a history of the earth, make maps which show that the continent of North America was once just a series of long and narrow islands. The waste of these islands was carried down into the shallow seas that surrounded them. The mud was pressed down by the weight of more mud. The dead bodies of small animals that lived in that ancient sea were buried in this mud. It hardened into rock. After a great while it was lifted above the surface, so that to-day, hundreds of miles from the sea, we find layers of rocks that were formed 
in the sea (see Fig. 7), and have in them imprints of the bodies of animals that lived in those days. These imprints of ancient animals are called fossils (see Figs. 8 and 9).

The average rainfall of the United States each year is about thirty inches. It is estimated that about one-half of this water evaporates, about onethird of it runs off

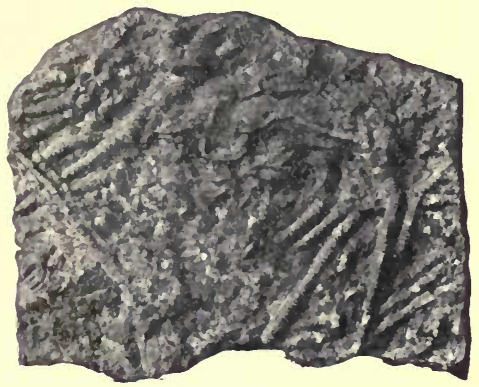

Fig. 8.-Fossils. over the surface, and one-sixth sinks into the ground. Let us think for a while about that one-sixth that sinks into the ground.

Ground-Water.-For at least two reasons, groundwater is very important to man: (I) it nourishes plants;

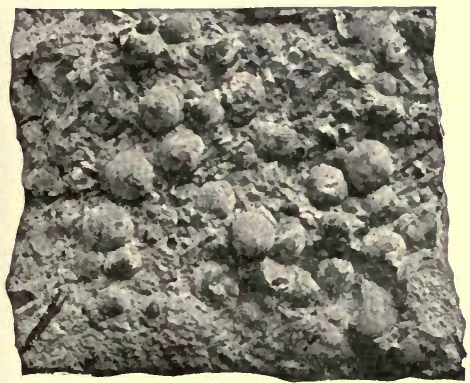

Frg. 9.-Fossils.
(2) it supplies wells and springs. We all get our food from plants, and over half the people in the world get their drinking water from wells and springs.

Rain-water finds its way into all the cracks and pores in the soil, but the 
deeper it goes the smaller are the cracks and pores. At last the pressure is so great that all cracks and pores are closed up. Probably there is no water deeper than a few miles in the earth.

When wells are dug water is sometimes found quite near the surface, sometimes far below it. The level at which water begins to collect in the well is called the ground-

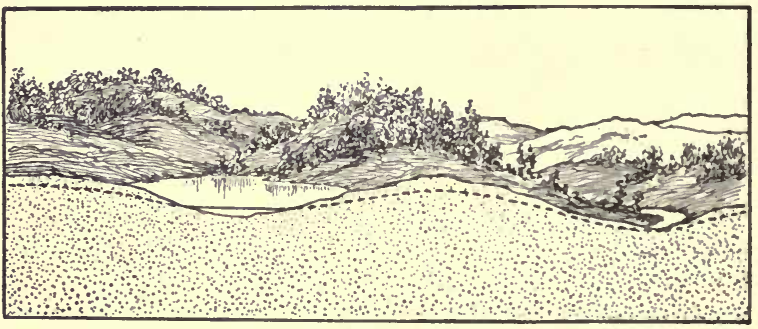

Fig. 10.-Diagram showing how the ground-water level (indicated by the dotted line) follows the curves of the land.

water level, or the water-table. The water-table is the top of the water that is under the ground. The top of the water that is in lakes or streams is level, but the top of the water that is in the ground is not level. It follows the curves of the land, and rises higher than the tops of streams and lakes. This you can understand better by studying the picture (see Fig. Io). Between rains, the water-table sinks, for the ground-water keeps seeping out into wells and springs, into lakes and rivers.

Under the ground the water does not flow evenly in all directions. This is because there are so many different kinds of rock and soil. The different kinds of rock and soil are found usually in layers. These layers are 
called strata. In a layer of sand or gravel the water moves easily, because sand and gravel are full of little openings. They are very porous. But in clay water moves

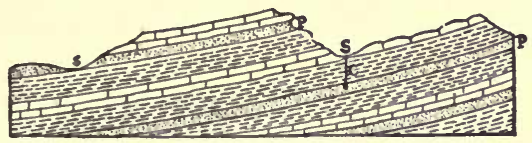

Fig. II.-Diagram illustrating two types of springs; try to explain them; the springs occur at $S ; P$ means porous layer; $C$ is a perpendicular crack in the layers of rock.

very slowly. Clay packs very closely; it is much less porous than sand and gravel. Then there are layers of solid rock that also obstruct the movement of water in the ground. So ground-water moves laterally, more than it moves vertically. It moves along the more porous layers.

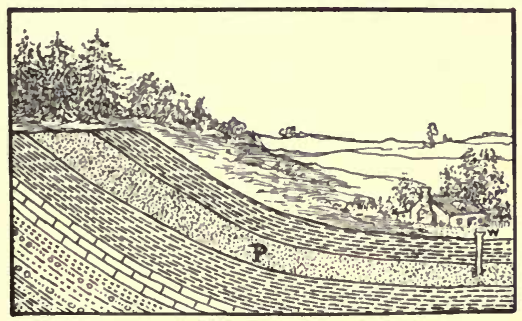

FIG. I2.-Diagram illustrating the artesian well, as explained in the text; $P$ is a porous layer of rock; the well is at $W$.

This explains why there are springs. Where porous layers that have water in them come to the surface, the water runs out and forms springs (see Fig. II). This also explains artesian wells. Artesian wells are wells from which 
the water flows naturally, without pumping. This is because the bottom of the well is in a porous layer that receives water at some place that is higher than the top of the well. The receiving place may be many miles away from the well. Suppose the top of the well is five hundred feet

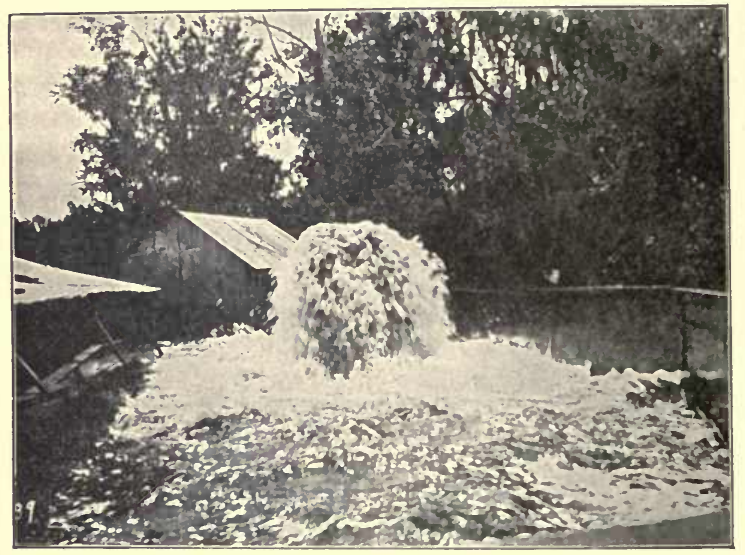

Fig. 13.--Photograph of an artesian well.

above sea-level, and the well is two hundred feet deep. It goes down through layers of clay and rock through which the water cannot escape upward. At last it enters a porous layer that is full of water. Now this porous layer extends for many miles in every direction, but everywhere it is covered by rock and clay except in some hills that are fifty miles away. These hills are formed by the turning up of the underground layers of rock and clay. Here the porous layer comes to the surface, and here it receives 
water from the rain and from the little streams that flow in the hills. This place where the porous layer comes to the surface is one thousand feet above sea-level. Now you can see why water flows out of the top of such a well (see Figs. 12 and 13 ).

Much of the water that sinks into the ground is taken up by the roots of plants, carried up into their leaves, and there it evaporates. Evaporation from leaves is called transpiration. Growing plants need to have water passing constantly through them. Their bodies are chiefly composed of water, and the water that moves through them brings up from the soil substances that they need in their growth. In the growing season thousands of pounds of water transpire every day from an acre of trees. It has been estimated that corn plants transpire about five thousand pounds of water for every bushel of corn that they produce.

Topography means the form of the land. You have learned that the work of water and the movements of the earth's crust are the principal agents in determining the nature of the topography. Upfoldings of the earth's crust have formed the ranges of upland and mountains, and the work of water has deepened the valleys and smoothed the contours of the hills. Together, these great forces of nature have formed the landscapes that to us are so beautiful. We shall find them all the more beautiful and interesting if we know something of the forces which have made them, and something of the long history which lies behind them.

Glaciers. - You have noted the effects of running water. But water in the form of ice has also had a great effect in 
determining the nature of the topography, especially in northeastern United States. Not many thousands of years ago the earth appears to have been a much cooler

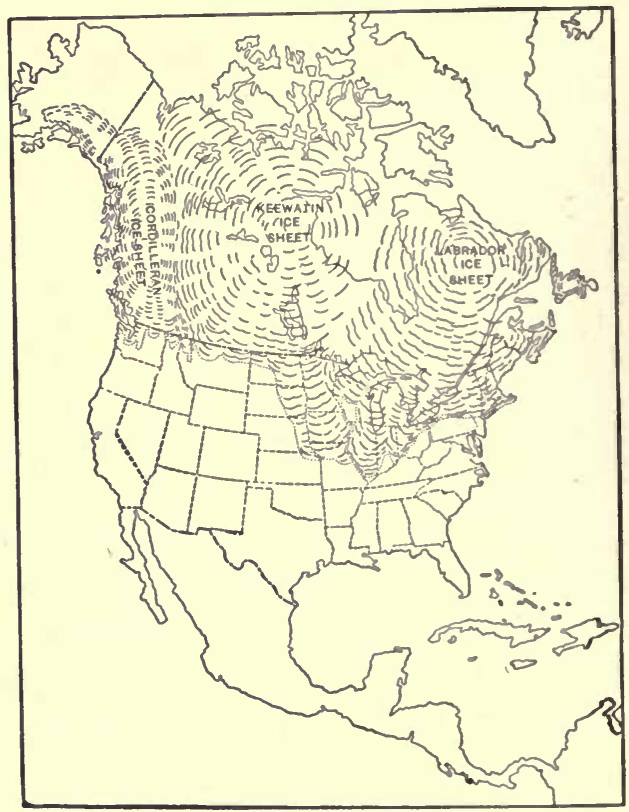

FIG. I 4.-Map showing how a great glacier once covered the northern part of our country.-After CHAMBERLIN.

place than it is now. Picture the effect this would have on the water. Even now billions of tons of water are "locked up" in the form of ice in the polar regions, and only a relatively small amount of this gets into circulation each 
season as liquid. But in those colder ancient days the accumulation of ice in polar regions was much greater. Slowly a great sheet of ice crept southward over the land, ironing the surface as it went. It picked up huge masses of earth and boulders and carried them along. Miles deep

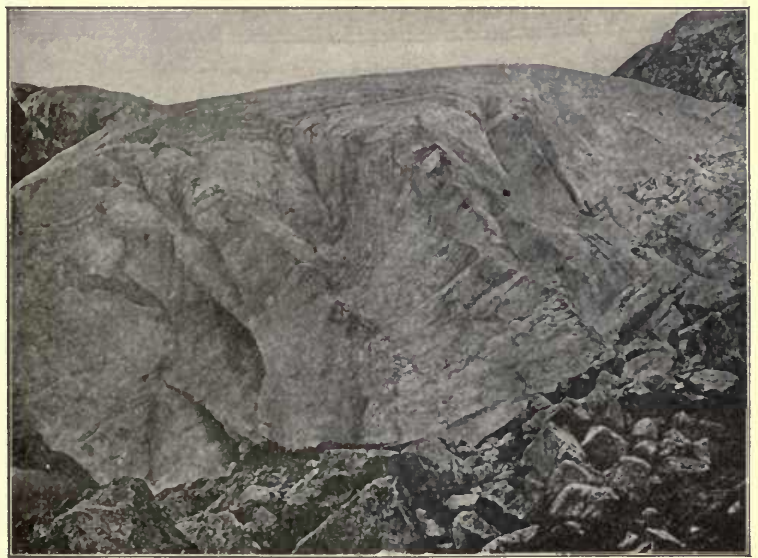

Fig. 15.-Photograph showing a terminal moraine of coarse boulders deposited at the front of a glacier.

the ice accumulated in the north, and it flowed to the south (see Fig. I4). The southern edge of the great ice-field changed with the seasons, and changed as the climate changed. In summer it melted back faster than it flowed forward. In winter it regained the lost ground. Always, as it melted, it kept depositing ridges and sheets of rock and soil. Finally, the climate changed so much that this ice-sheet was melted far back to the north, where it now remains, covering Greenland and other regions. But the 
effects which it produced remain to this day. The ridges and sheets of rock and soil the ice laid down are with us yet. We call the ridges moraines (see Fig. 15), and we call the soil the ice brought down glacial till. It is very fertile.

Even more conspicuous than the moraines and the till are the effects which the ice produced on the hills and

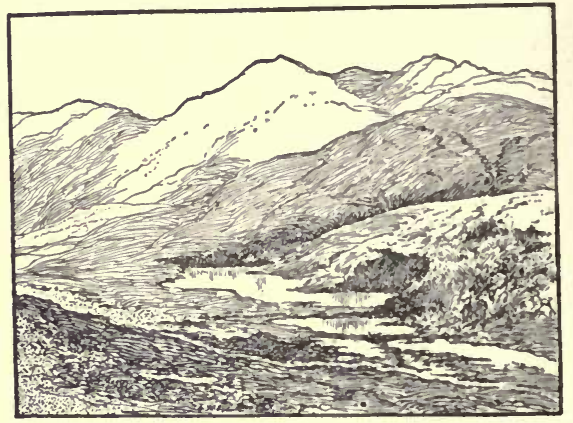

Fic. 16.-Drawing showing hills of which the rough surfaces have been smoothed off by a glacier.

valleys they travelled over. As you look over some of the beautiful landscapes of central New York, you can, in the mind's eye, see the great sheet of ice again, as it flowed with tremendous weight down over the rough surface of the land, and then retreated, leaving as evidence of its visit the soft and graceful curves of hill and valley which now delight our eyes (see Fig. I6). It left, too, many lovely lakes. The basins of these it formed by damming up great valleys with the material it dropped. In once firm-bedded rocks you can see the scratches made by material in the ice as it passed over them (see Fig. 17). 
In many other regions of the world, even in regions now tropical, we find evidence that once there were glaciers.

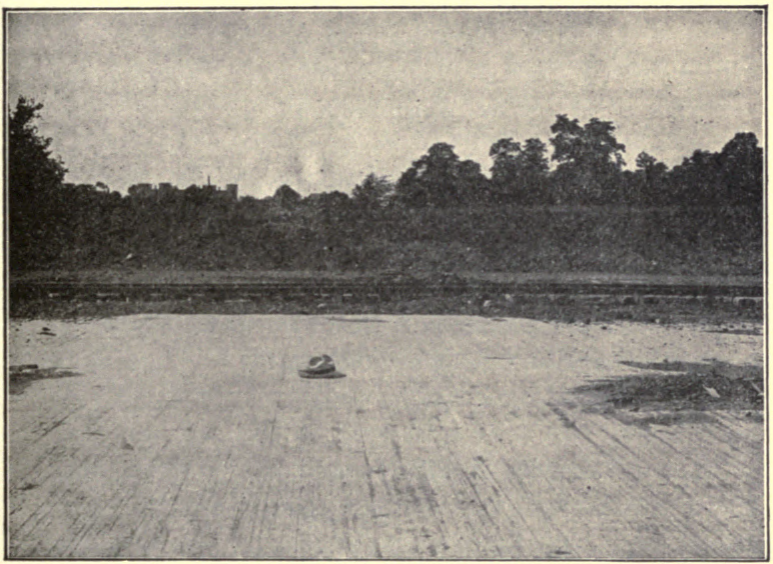

Fig. 17.-Glacial scratches.-After Salisbury.

\section{QUESTIONS}

I. Why did people once prefer to live near rivers?

2. What is erosion?

3. Why is not the whole surface of the land worn down nearly to sea-level?

4. What is a "drowned valley"?

5. How do we know that some rocks were formed in the sea?

6. What becomes of the rain that falls on the earth?

7. Why is "ground-water" important?

8. What is the water-table?

9. In what layers of soil does the ground-water move?

Iо. Explain an artesian well.

II. What is a glacier, and what does it do to the surface of the earth? 


\section{CHAPTER V}

\section{SOLUTION}

Lemonade is a solution of sugar and lemon-juice in water. Sometimes at the bottom of a glass of lemonade you have found some sugar that has not dissolved. The water had dissolved all the sugar it could. Such a solution is called a saturated solution. Now solutions are of immense importance to life. They are among those things without which life could not possibly continue. We must understand them.

The word solution is a little confusing because it is used in two ways. It is the name of a process. It is also the name of a thing. The process of dissolving is called solution, and a liquid after something has been dissolved in it is also called a solution. The liquid in which something has been dissolved is called the solvent, and the substance dissolved is the solute. In lemonade, water is the solvent, and sugar is a solute. Substances that dissolve are called soluble; if they do not dissolve they are called insoluble. Water dissolves more substances than any other liquid, but there are some substances that are not soluble in water but are soluble in other liquids. We rub off paint with turpentine, because turpentine will dissolve it while water will not, and we take out grass stains with alcohol for the same reason.

There are many substances, like sugar and salt, that dissolve in water. This means that when they are put into 
water the invisible particles of which they are composed begin to spread through the water until they are equally distributed. This is the law of solution. Just as a ball thrown up in the air returns to earth in response to the law of gravity, so the particles of a solute become equally distributed throughout their solvent, in response to the law of solution. The lemonade in a glass is just as sweet at the top as it is at the bottom. The particles of sugar are equally distributed throughout it.

Now let us see why solutions are so important in life as well as in lemonade. You know about digestion. You know that it is the process of changing food from solid to liquid form. This means that the food absorbed by our blood is a solution. Blood itself is a solution. In plant life, solutions are just as important as in animal life. All that the roots take in from the soil is in the form of solution, and the nourishing sap that moves inside the plant is simply water with various substances dissolved in it. And, finally, inside the bodies of plants and animals, all the processes that belong to life itself are processes that occur in solutions.

You must distinguish between solution and suspension. When we wash our hands we may say that the soapy water dissolves the dirt, but if the water itself turns dirty, that shows that we have a case of suspension and not of solution. Suspension is the floating in a liquid of fine particles of a solid or of another liquid. Streams that are muddy in flood time gradually become clear. The mud suspended in them is called sediment because it gradually "settles." It slowly sinks to the bottom. But the solutes in solutions do not sink to the bottom. The salt in sea-water never settles. It becomes a solid only when the water evaporates. 
In fresh milk the cream is distributed throughout in the form of tiny droplets. So also droplets of oil are distributed in salad dressing. These are examples of one liquid in suspension in another.

In lemonade you have a solid (sugar) and a liquid (lemon-juice) dissolved in a liquid (water). A solution may also be made by dissolving a gas in a liquid, and this process is also very important in life. It has something to do with the way in which our blood absorbs the oxygen that enters our lungs.

A very important case of gas dissolved in a liquid is the case of air dissolved in water. You have noticed how water may enter the air as a gas. It does this when it evaporates. Now it is important to understand that the reverse of this also takes place. Air enters water. It is dissolved by water. We can easily prove that water, as found in nature, always has air in it. Fishes and other water animals require air to breathe, and their source of air is the air that is dissolved in water.

If you gently heat water in a beaker, or in a porcelainlined vessel, the first change you will note will be the formation of hundreds of tiny bubbles on the bottom and sides of the vessel. These are very different from the large bubbles of steam that form later, when the water has reached the boiling-point. These tiny bubbles appear long before steam arises from the surface. They appear when the water is only a few degrees warmer than the surrounding air. Then if you stop heating the water, and set it aside without shaking, these bubbles remain for a time, even after the water has cooled down to its ordinary temperature. Of course they would not do this if they were bubbles of steam. Steam bubbles would quickly 
change to liquid again as the temperature fell. These tiny bubbles are bubbles of air.

If you have ever fished with minnows for bait, you know that you must change the water frequently to keep the minnows from dying. But if you take a pail of minnows away from the stream, and cannot change the water frequently, they will live much longer if you stir the water frequently. Can you explain this?

Air is not the only gas that is readily absorbed by water. Some gases dissolve in water to a remarkable extent. Thus water can dissolve one thousand times its bulk of the gas ammonia. A gas that is present in air, and is very important in the lives of both plants and animals, is carbon dioxide. This gas is given off from our lungs when we exhale. It is also one of the products of burning. It is used by plants in the manufacture of food. It is readily absorbed by water, and all natural waters contain some of it. Sea-water contains more carbon dioxide than does the air above it. Soda-water is nothing but water charged with carbon dioxide. The water is placed in a metal container, and the gas forcea in to it under high pressure. The container is then firmly sealed. As soon as any of this water is drawn off it begins to fizz and bubble the way you have seen it in a soda-water glass. This is because the pressure is removed, and the extra load of gas is rushing to escape.

We have been calling air a gas. It is time to explain that it is a mixture of gases. Four-fifths of it is a gas called nitrogen, and nearly all the rest of it is the gas called oxygen. Less than half of one per cent of it is carbon dioxide, yet that one-half of one per cent is absolutely necessary to the making of our food. All these gases, as 
well as the water vapor in the air, are perfectly transparent, and are evenly distributed. Just as the substances that make up a solution tend to become equally distributed, so gases that come together tend to become equally distributed. The process by which one gas spreads itself evenly through another is called the process of diffusion.

Water, as we find it in nature, is never perfectly pure. That is, it always contains particles of other substances along with the particles of water. However, these natural impurities do not discolor the water, and may not make it less fit to drink. In fact, the most agreeable drinking water does contain impurities, while perfectly pure water tastes flat and insipid. Any one who drinks distilled water, having been in the habit of drinking well-water, finds it disagreeable at first. Springs that are famous for the health-giving value of their water owe this to the presence in solution of certain minerals or gases, or both.

Hard and Soft Water. - The difference between hard and soft water is that the former contains more of dissolved matter than the latter. There are, of course, all sorts of degrees of "hardness" and "softness" of water, depending upon the varying amounts of matter dissolved in them.

Spring-water is usually regarded as the purest for drinking purposes, because it has been thoroughly filtered by soaking through the soil. This process removes particles which are suspended in the water (as particles of mud), and so renders the water quite clear, but it has no effect on the material which is dissolved in the water. In fact, this process of soaking through the soil is the very process by which water becomes hard. It dissolves certain soil materials as it goes along and carries them with it in solution. 
Hard water is not good for washing. When you use soap with hard water a dirty sediment is produced. This prevents the formation of a lather, unless a good deal of extra soap is used. When hard water is boiled, some of the mineral matter in it is deposited on the sides and bottom of the boiler or kettle. You may have noticed this formation ( $f u r$ ) on the inside of a teakettle. It sometimes forms what is known as boiler-scale on the inside of the pipes in steamboilers, and renders them useless until they have been cleaned, which is an expensive process.

River-water is usually soft, though it contains some mineral matter, and may carry a good deal of soil in suspension, thus giving it a muddy appearaince. Lake-water is softer than well or spring water, but usually harder than riverwater. Rain-water is very soft, and hence is collected in cisterns for use in washing. Though best for washing, it is not best for drinking. It contains impurities washed from the atmosphere and from roofs, and its taste is less agreeable than that of other kinds of water.

\section{QUESTIONS}

I. What is a solution?

2. Why do we use paint?

3. Do fishes breathe air? Explain.

4. Why do bubbles form in heated water before it is hot enough to boil? How could you prove that these were not steam bubbles?

5. What is soda-water, and why does it fizz?

6. What is the composition of the air?

7. What is the difference between hard and soft water?

8. Why does "fur" form on the inside of a teakettle? 


\section{CHAPTER VI}

\section{MAN'S SUPPLY OF WATER. THE INSIDE OF THE EARTH}

The Sources of Water-Supply. - Where does the water that you use in your own house come from? Probably all you have to do to get it is to turn on a tap and let it run. Think now where it comes from and how it gets to you.

Lakes, rivers, springs, wells, and cisterns are the sources from which men get the water they need. Nearly all great cities were originally located on lakes or rivers; these were important for water-supply as well as for transportation. But when homes had to be made in the country, away from lakes and rivers, springs were looked for and wells were dug. No house was built unless there was near it a convenient supply of water. Wells are very ancient. The Old Testament and other books of ancient history tell of their important part in the life of the people.

A well is just a hole dug in the ground with water in it. A deepened spring is a sort of well. We may say that the reason a well has water in it is because the hole has tapped an underground spring. So there is no absolute difference between a well and a spring. There is water in the ground. When this water comes to the surface of its own accord, we have a spring (see Fig. II); when we dig for it, we have wells. Whether we strike water or not when we dig depends a good deal on chance, but not so much as it used to. Modern science furnishes information which enables ex- 
perts to tell with a good deal of certainty what to expect in the way of well-water. But in the old days, when a well was to be located, it was quite customary to employ a "water-witch." A water-witch was a person supposed to have mysterious power to locate favorable spots for wells. This was done with the aid of "divining-rods." A favorite form of such rod was a forked branch of hazel, or peach. The rod was held by the forks, the main stem pointing straight forward. Then, as the holder passed over water, the main stem was supposed to twitch downward. It has never been possible to prove that this is so, and it seems absurd, yet there are many people to-day who still believe there is "something in it." In support of their belief, they point to wells which have been located in that way. Does this prove anything? Yet many things which people believe to be true are founded on no better evidence than this. The great work of science is to find out what is true and what is false.

The Inside of the Earth. - We cannot think of underground water in wells and springs and hidden streams without thinking of the inside of the earth. Have you not wondered about this mysterious region? Have you not wanted to explore caves, and to see the stalactites like rock icicles (see Fig. I8) whose pictures you have seen in geographies? Scientists, too, have done a good deal of wondering about the inside of the earth, but they have not found out very much. The deepest mines are but mere scratchings when you think of all that is beneath them. It is more than eight thousand miles through to China, and the deepest borings of man go down only a few thousand feet. And yet these borings, and other things, have given 
a good deal to go on, so that we feel fairly certain of the following things:

I. That the earth, as a whole, is solid, and the deeper you go the more solid it gets. The pressure increases and

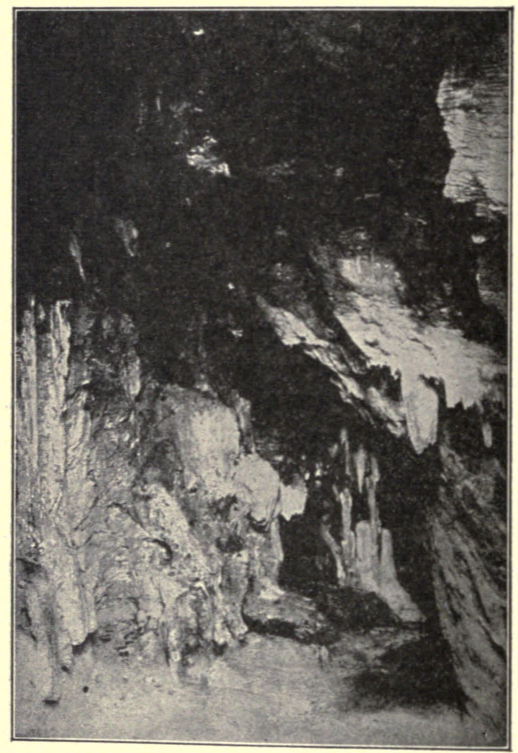
FIG. 18.-Photograph of limestone cave, showing rock
icicles (stalactites).

becomes so tremendous that the real inside of the earth is as firm as steel.

2. Yet some underground regions are fluid. They are also very hot. Volcanoes prove this (see Fig. 19). The 
"molten lava" they throw out when they are in eruption comes from the depths of the earth. So it seems that, as you go down, the heat increases as well as the pressure. Judged by conditions in deep mines, the thermometer goes up at the rate of about one degree for every hundred feet of depth. This varies a great deal with different localities, and for the first hundred feet or so it usually does not apply at all. In fact, cellars and caves are usually much cooler than the air above. Why is this so?

3. The earth was once very hot; so hot that nothing at the surface was solid. It was all either liquid or gas. The coolingoff process and the

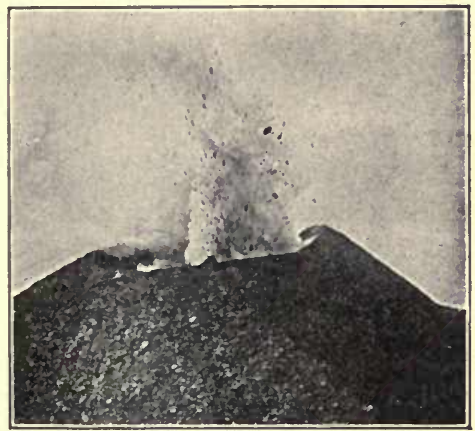

Fig. 19.-Volcano. formation of solid rocks probably required millions of years. The changes that have occurred to the land areas since they were solidified have been produced chiefly by running water, and by movements of the surface that have changed sea to dry land and dry land back to sea again. To-day we find far inland, and often deep under the surface, sure evidence that the sea was once there. We find accumulations of sea-shells, and formations of limestone that were undoubtedly made from sea-shells (see Fig. 9). We also find under the surface deposits of coal, and coal is a formation due to the accumulation of the 
bodies of plants, probably in swamps. These accumulations subsequently underwent changes which were largely due to pressure. Hard coal (anthracite) has been subjected to greater pressure than soft coal (bituminous).

4. The outer part of the earth is largely composed of layers called strata (singular, stratum). Its stratified nature may be observed in many mountain regions where the upfoldings are sharp and broken. Sometimes it may be seen on the sides of railway cuttings, and always, when deep wells are dug, the boring passes through different layers, as of clay, gravel, and rock,* of which there are many varieties.

The early geologists were much puzzled by these strata and brought forward many interesting theories as to their cause. But as knowledge grew, it became easy to understand that they are due simply to the surface movements and water work that you have been considering. For example, a layer of deep mud might have formed over the bottom of a shallow sea, not far from the land. Then by a shift of the surface (a slow and gentle earthquake) this region may have become deep sea, far from land. The wash of the land may have reached it no more, but the shells of tiny marine animals, for long ages, accumulated on top of the mud. Then, due to another shift, came a period in which sand was the chief thing laid down. So these changes went on. Due to the pressure of new layers, and to chemical and other physical changes, the older layers became hardened into rock. Then at last there may have come a great disturbance, due to an adjust-

* Rock means any hard part of the earth's crust. It does not need to be broken. When you say you pick up a rock, it would be more accurate to say a piece of rock. 
ment of differences between the forces of heat and of pressure. As a result, these layers, and others, may have been forced up, pressed together, broken and distorted, and the result was a new range of mountains (see Fig. 7). And in such mountains to-day we may see what was once mud changed to a kind of rock called shale, what was once

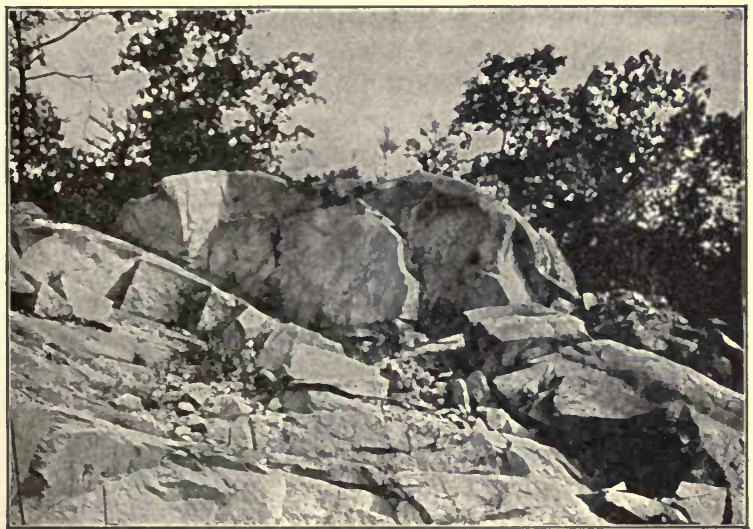

FIG. 20.-Igneous rock; a granite quarry.

a layer of shells changed to limestone, and what was once sand changed to sandstone.

5. As to their origin, all rock or formations of rock may be classed as igneous or sedimentary. Igneous means related to fire (ignis, fire), and igneous rocks are those whose substance was once molten. They have come to their present state through cooling, pressure also usually having a good deal to do with it. Granite is an example of igneous rock (see Fig. 20). Sedimentary rock is rock 
whose material once was sediment; that is, it was laid down in water. Limestone and sandstone are sedimentary rocks (see Fig. 7).

6. The strata or formations of the earth's crust are very different with respect to their relations to water. Some are much more soluble in water than others. Limestone is especially soluble in water. Sandstone is composed of grains of sand held firmly together by a sort of cement. Water may act on the cement and leave loose sand. Large caves occur in limestone regions and are due to underground water having dissolved and carried away particles of the rock. The stalactites are due to dripping water which, at the point of drip, deposited certain solutes they had been carrying (see Fig. I8).

7. Clay, gravel, and sand, and mixtures of these with each other and with organic substances, form what we call soil and subsoil. They are the latest geological formations. Gravel and sand, being loose formations, can hold a good deal of water. Clay, whose particles are very small, packs down into a firm formation which water penetrates very slowly. Some of the best wells are made by boring into formations of wet sand or gravel down below layers of clay. The water may have entered the strata of sand or gravel many miles away where they outcrop at the surface (see Fig. II). It may have soaked through them, being hindered in working upward by the dense layers of clay above. So, in northern Illinois, many of the best wells tap a layer of sand whose outcrop is far away in Wisconsin. Springs are caused by the outcropping of layers which have received water somewhere else. Artesian wells (so called because first found in Artois, France) are those whose water rises to the surface without pumping, 
sometimes with sufficient force to form a natural fountain. This is because the well-boring has tapped water which is under pressure, due to its intake being at a greater altitude than the mouth of the well (see Figs. 12 and 13 ). Or, in some cases, the pressure is due to the confinement of the liquid between two deep-placed layers which it cannot

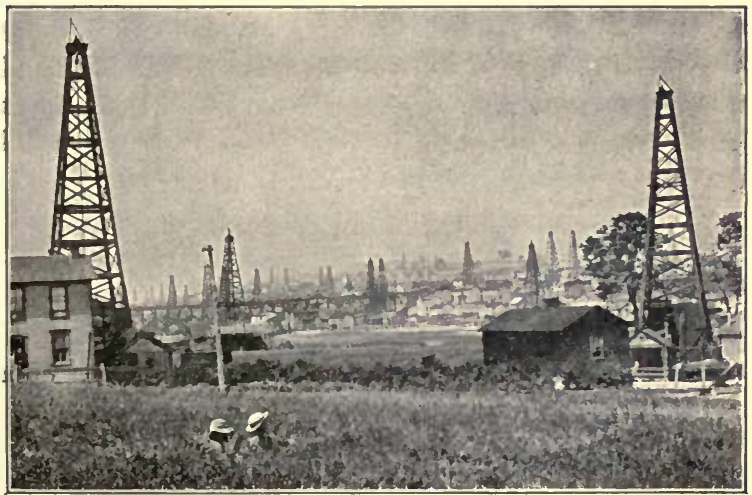

Fig. 21.-Oil-wells.

penetrate. This is the explanation of gushing oil-wells (see Fig. 2I). When formations of oil and natural gas are tapped, the gas naturally comes to the surface first. Gas and oil are found in the earth both together and separately. Both are believed to have an organic origin, that is, they have resulted from extensive chemical and physical changes in accumulations of organic substances. By organic substances we mean those derived from the bodies of living things (plants and animals); all other substances are inorganic. 
This chapter began to tell of man's supply of water, and then, to explain about wells and springs, it went clear back to the start of things. It told a little of the history of the earth. This may seem like getting away from the story. But you will find it is always so in studying the story of nature. In order really to understand the little things, you have to go back to the big and ancient things. 'It is a continuous story, but it continues out and back in every direction rather than in a straight line. To understand what we see to-day, we must understand these great forces which have shaped the earth since it began, and which still govern it and its tiny creatures.

\section{QUESTIONS}

I. Why does a well have water in it?

2. How was coal made?

3. What is meant by "sedimentary" rock?

4. Describe an ordinary well, a spring, an artesian well, and a gushing oil-well. 


\section{CHAPTER VII}

THE SUCTION-PUMP. ATMOSPHERIC PRESSURE

You have noted that man discovered a very long time ago that a good way to get pure drinking water is to dig for it. But having dug for it and found it, he had a good deal of trouble in getting it out of the hole. The ancient way was to lower a pail, and then to pull it up. There was considerable danger of falling in while you were doing this. So they built curbs about the wells. Then some bright person discovered that you could pull the pail up more easily by winding it up on a revolving bar which

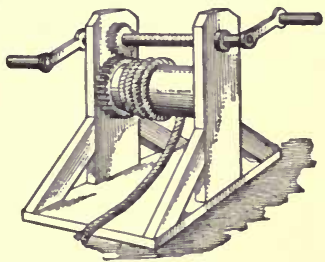

Fic. 22.-The windlass. you turned with a handle. This was the invention of the windlass (see Fig. 22). But it was a long time after windlasses were invented before any one happened to get the idea of a pump.

To understand how a pump works you must understand atmospheric pressure. Atmosphere is simply another word for air. You may have heard that air at sea-level exerts a pressure of fifteen pounds to the square inch. This atmospheric pressure is due to the fact that this mixture of gases we call air extends for some miles upward from the earth, and that this great sea of air, at the bottom of which we live, has a certain weight. It is so evenly distributed about us, and whe so used to it, that we are not con- 
scious of it at all, any more than fish are conscious of the weight of water in which they swim. Though we are not conscious of this weight of air through our sensations, yet it is a very real thing, and it does a great deal of work which is for our advantage.

You take advantage of air-pressure every time you suck lemonade through a straw. As the straw stands free in the glass, the air-pressure within it and the air-pressure outside of it are equal, and the lemonade stands at the same level within and without the straw. But the instant you put your lips to the straw and draw into your mouth the air which is in it, what happens? The lemonade immediately follows the air up to your lips. Why does it do this? It is because you have removed the air which was holding it down. The air outside is pressing down on the surface of the lemonade, and it is this pressure which makes the lemonade go up the straw. Suppose there was an air-proof cover over the glass except where the straw protruded. Could you still suck up the lemonade? Try it and see. Have you ever tried to pour liquid out of a can with only one hole in it? Why is it necessary to have two holes in order that the liquid may flow readily out of one of them?

Now it is this very principle which operates when a pump works. The surprising thing is that it was so long before any one thought of taking advantage of it in this way. But we should remember that things which seem simple and easy to us now were not at all simple and easy for our ancestors. If we had been in their place we should have done no better than they, for they were quite as bright as we. But we have the great advantage that we may learn quickly and easily what mankind learned very 
slowly and with great difficulty. For this we should be truly grateful. We should accept our wonderful "heritage of knowledge" with an understanding of all the toil and all the time it took to build it up. For what we know there is little credit to ourselves. About all we have to do is to open a book and read.

The most important thing about a pump is the piston (see Fig. 23). It works up and down in a cylinder. When you push the handle of the pump down, the piston comes up in the cylinder, and does the same thing that you do when you suck a straw. It removes the pressure on the water just below it. The pressure of air on the water in the well forces the water in the pipe to follow the piston up the cylinder. Of course the piston must be air-tight, and there must be a valve in it which will let the water come through but will not let it get back. So when you force the piston down again, the water which has entered the cylinder

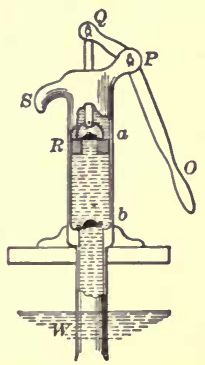

FIg. 23.-The suction-pump; try to explain the different parts. will pass through it (the piston) and be in a position to run out of the spout. Also there must be a valve at the point where the pipe joins the cylinder. Why? All this you can understand better by studying the figure and explaining it. When a pump has a leaky valve, you can sometimes make it work by priming it, that is, by pouring in water at the top. Can you explain this?

If the distance between the surface of the water in the well and the piston in such a pump as we have been describing is greater than about thirty-two feet, the pump will not work. This should not surprise you when you remem- 
ber that atmospheric pressure is not an unlimited thing. It is limited, as you have noted, to fifteen pounds to the square inch. Of course it will not force a column of water up an indefinite distance. About thirty-two feet is the limit.

Atmospheric pressure is well illustrated by the siphon (see Fig. 24). The siphon has been used since ancient times for drawing liquid from a higher level to a lower level over the side of the higher vessel. The tube must be filled with the liquid in order to start the process. As long as the distance from $a$ to $d$ is less than the height

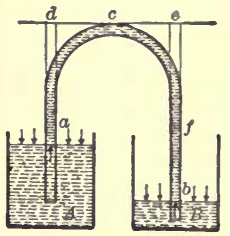

FIG. 24.-The principle of the siphon. at which atmospheric pressure will hold a column of water, and as long as the tube remains filled with water, it will continue to flow from the bottom of the tube. For as fast as it flows down and away, it is replaced by water rising to the top of the arch on account of the atmospheric pressure.

What effect should you expect atmospheric pressure to have upon the boiling-point of water? Will it take less heat or more heat to make water boil at the top of a mountain? Amateur campers in the mountains have found that the water may all boil away without cooking the beans, or whatever it is they are trying to boil. Why is this?

Measuring Atmospheric Pressure. - An aneroid barometer is an instrument much used in mountain travel. It enables you to estimate how high up you are, and it does this by recording the atmospheric pressure. There is a little metal box with a vacuum inside, that is, a space from which the air has been withdrawn. The pressure of the air outside causes imperceptible movements of the metal 
sides of this box. This is because there is no pressure within the box. These imperceptible movements are magnified by a contrivance which records them by movements of a hand on a dial. Since certain pressures correspond to certain altitudes, the hand and dial show the altitude as well as the pressure (see Fig. 25). However, since airpressure varies with local conditions, as in storms, you can see that an aneroid record of altitude is not always exact. The word aneroid means without fluid. Fluid barometers are also used. A mercurial barometer is one in which changes of pressure are recorded by the rise or fall of a column of mercury. As you already know, the rise and fall of a column of mercury, in the instrument we call the thermometer, records changes of heat. But note this important difference. In a thermometer the mercury is in a closed tube and is not sensitive to

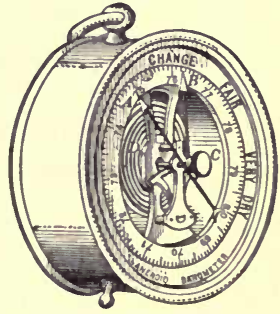

Fig. 25.-The aneroid barometer. changes in pressure. But in a mercurial barometer the mercury must be exposed at some point to the air so that it will be sensitive to changes in pressure; also there must be sufficient room for expansion of the mercury outside the tube so that changes in its volume due to heat will not seriously affect the reading of changes due to pressure (see Fig. 26).

Standard atmospheric pressure is the average pressure at sea-level. You have noted that this is a pressure of fifteen pounds to the square inch. This was determined by measuring at sea-level the height of a column of mercury held up in a mercurial barometer; this height is about, 
thirty inches. Since mercury weighs a half-pound to the cubic inch, it follows that the standard atmospheric pressure amounts to fifteen pounds to the square inch. Similarly, in barometric readings, thirty inches is taken for the

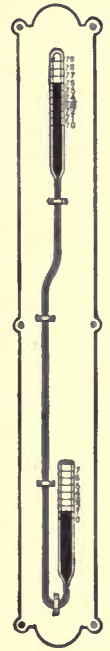

Fig. 26.The mercurialbarometer. standard. Pressure which the barometer records by standing at over thirty inches is said to be high; pressures recorded at less than thirty inches are said to be low. You already know that a barometer is used to foretell weather, and weather is largely due to states of atmospheric pressure. If the conditions of atmospheric pressure over a large area are known, the weather about to follow can be foretold with a good deal of certainty.

The standard of atmospheric pressure (fifteen pounds to the square inch) is also used as a standard in measuring other kinds of pressures; it is referred to as a pressure of one atmosphere. Thus the pressure of water may be measured in atmospheres. Water at thirty feet below its surface has a pressure of one atmosphere, etc. Evidently this is a matter of importance in under-water constructions, as in building of submarine boats. Careful allowance must be made for the pressures which are to be withstood.

Atmospheric pressure was first measured by a famous experiment known as Torricelli's (tor-ri-chelly) experiment. Torricelli (1608-47) was a pupil of Galileo, the famous Italian scholar of whom you have already read. Galileo himself noted that suction-pumps were unable to lift water more than about thirty-two feet, and he probably suspected that this rise was due to atmospheric pressure. 
You see pumps were used long before they were explained. It remained for Torricelli to explain them, and also to demonstrate the limits of atmospheric pressure. He did this by means of an experiment with mercury, which, being a much heavier liquid than water, does not require so long a tube to measure the atmospheric pressure against it. This experiment may be repeated as follows (Fig. 27): Fill with mercury a strong glass tube closed at one end. The tube should be about thirty-two inches long. Invert the tube, closing the open end with a finger (A). Immerse this end in a dish of mercury and then remove the closing finger. The mercury then falls, leaving a vacuum at the top $(B)$. But if the experiment is well performed, the mercury will fall only a short distance. It will stop at about thirty inches above the surface of the mercury in the dish. This thirty-inch column of mercury is, then, a measure (in mercury) of at-

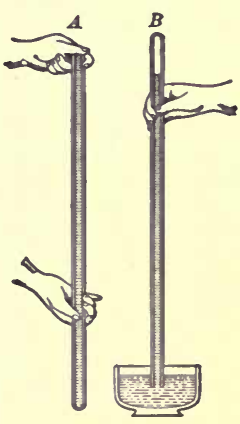

Frg. 27.-Diagram illustrating Torricelli's experiment. mospheric pressure. Thus you see that the Torricelli experiment is actually the construction of a mercurial barometer.

Pascal, a great French mathematician $\left({ }_{16} 6_{23}-62\right)$, reasoned that if the mercury in the Torricelli experiment is really supported by atmospheric pressure, then the column should become shorter at a higher altitude. So he performed the experiment at the top of a high tower in Paris and found a decrease in the column which corresponded to his computations. Soon afterward this principle was confirmed by performing the experiment on a mountain. 
In this way it was found that the height of a column of mercury could be used as a measure of altitude above sealevel.

\section{QUESTIONS}

I. Explain what happens when you suck up lemonade through a straw.

2. Why can't you pour liquid out of a can with only one hole in it?

3. Explain how a pump works.

4. Explain how a siphon works.

5. Explain how an aneroid barometer works. A mercury barometer.

6. Why is the barometer important for the "weather-man"? 


\section{CHAPTER VIII}

\section{ARCHIMEDES' PRINCIPLE. WATER-PRESSURE AND WATER-WORKS}

Archimedes $(287-2$ I 2 B. C. $)$ was the greatest of the ancient mathematicians. He lived in Syracuse on the island of Sicily. The king of Syracuse in Archimedes' time once ordered of a goldsmith a crown of pure gold. It was delivered to him. It looked like pure gold and it had the proper weight. Still the king had reason to suspect that the goldsmith had cheated by melting up silver along with the gold. He asked Archimedes to discover a method of proving the fraud. A modern chemist could have solved the problem in a minute, but chemistry in those days was unknown. So the mathematician put his wits to work. He was sorely puzzled. One day, while in the public bath, he noticed that the part of his body under the water was much lighter (more buoyant) than the part above it. He got to thinking about this. Suddenly he jumped from the bath like a crazy man (so the story goes), rushed into the street without waiting to dress, and ran home shouting "Eureka! Eureka!" which means "I have found it."

Now what had occurred to Archimedes was this: $\mathrm{He}$ knew that gold and silver are different as to their buoyancy in water, or, as we say now, as to the specific gravity. So taking a weight of gold equal to the weight of the crown; and comparing it with the crown as to buoyancy, he could prove whether the crown was pure gold or not. 
Whether Archimedes discovered the goldsmith to be a fraud or not is not important. He had made a discovery far more important than that. He had discovered what is known even to-day as Archimedes' principle: the principle that $a$ body immersed in a liquid is buoyed up by a force equal to the weight of the liquid that it displaces.

If the body weighs more than the amount of liquid displaced, it will sink; if less, it will float. A floating body sinks to such depth in the liquid that the weight of the liquid displaced equals the weight of the body. This application of Archimedes' principle you can easily prove. Take a piece of wood coated with paraffin to prevent its absorption of water. Fill a pitcher with water until it overflows at the spout. Then float the wood in this water and catch all that runs out of the spout. The water thus obtained and the piece of wood should weigh the same. Try the same thing with a piece of ice, making allowance for the melting of the ice. Is it true that seven times as much of an iceberg is under water as above it?

By means of Archimedes' principle we may also compute the volume of solid objects of any shape. Weigh the object in air, and then weigh it under water. The difference in the two weights represents the weight of the water displaced. Suppose this difference be ten grams. We know that ten grams of water by weight is ten cubic centimeters of water by volume. We also know that the volume of water displaced is identical with the volume of the object submerged. Therefore, the volume of the object is ten cubic centimeters. In other words, the difference in grams between the weight of an object in air and its weight in water is equal to the volume of that object in cubic centimeters. 
Water-Pressure. - The pressure of a liquid is exerted equally in every direction against the sides and bottom of whatever contains it. Suppose there is a tank of water at the top of a house, with a pipe leading down from it and branching off to different rooms. Now if you turn on the water at a tap directly below the tank, will it run out with any greater force than from a tap many feet away to one side? You know that it will not. This illustrates the principle stated above.

It is possible to take advantage of this principle in performing various kinds of work. Since liquids thus transmit pressure equally in every direction against the walls of their containers, it is possible to use water as a means for multiplying the area of pressure. Thus in the hydraulic press (see Fig. 28)

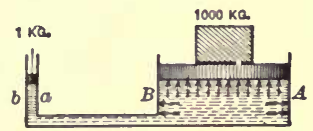

FIG. 28. - Diagram illustrating the principle of the hydraulic press, as explained in the text. a pressure applied at $a b$ will be equally exerted by the surface at $A B$, as well as by all the other contained surfaces. If there is a pressure of one pound at $a b$, there will be a pressure at $A B$ of as many pounds as the area of $a b$ is contained in the area of $A B$. This is what is meant by multiplying the pressure. If $A B$ is ten times as large as $a b$, then one pound laid on $a b$ will balance ten pounds laid on $A B$.

Thus we have a multiplication of pressure, but this must not be confused with multiplication of work. If the piston $a b$ is pushed down one inch, will the piston $A B$ rise one inch? Certainly not. For one thing, there would not be enough water to fill such an addition to the space. The piston $A B$ will rise only in proportion to the difference between its area and the area of $a b$. If it be ten times as 
large as $a b$, and $a b$ be forced down one inch, then $A B$ will be forced up one-tenth of an inch. The pressure at $A B$ is ten times as great as the pressure at $a b$, but it works through only one-tenth of the distance, thus fulfilling the law of conservation of energy. You have heard of the law of the

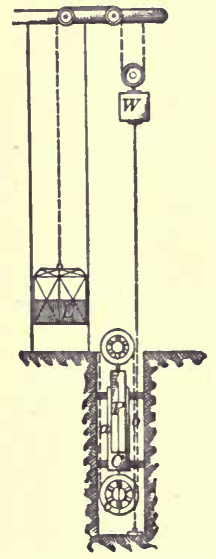

Fig. 29.-Diagram of hydraulic elevator. indestructibility of matter. You know that matter may be changed, but it cannot be produced or destroyed. So energy or work can be changed; the area over which it operates can be multiplied. But the work done cannot be multiplied. Energy like matter can be changed in form, as from electricity to light, but, like matter, it can neither be produced nor destroyed. However wonderful a machine may be, the amount of work it does is never greater than the amount of energy it takes to make it work. The work taken out cannot be greater than the work put in.

Water-pressure is used in the operation of elevators (see Fig. 29). Water forced into the cylinder $C$ drives back the piston and produces a pull on the cable. The elevator gaes up. The operator stops the car by closing the valve that shuts off the water from the water-main. He lowers it by opening a valve that permits the water in the cylinder to run off into the sewer. City water-power is also commonly used to operate pumps which pump soft water into tanks at the top of houses.

Water-Works. - By water-works we mean constructions for the collection and distribution of water for towns and 
cities. A surprising amount of water is needed for this purpose. The daily consumption of water per person for certain cities has been estimated in gallons as follows: New York 79, Chicago 140, Philadelphia 132, St. Louis 72, Boston 80, Washington 187. In European cities it is much less, because of restrictions. The question of watersupply is often one of the most serious questions which a city has to face.

The purity of water is just as important to a city as its amount, for many of the commonest and most serious diseases, especially typhoid fever, are caused by impure water. In many cities the death-rate has been much lowered by purifying the water-supply. Thus in Chicago after the opening of the drainage canal, which purified the supply of water from Lake Michigan, the rate of death from typhoid alone was reduced by two-thirds. This represents a saving of nearly a thousand lives a year.

Ancient Rome had an elaborate system of water-works. Portions of its aqueducts still stand; they were very excellent constructions (aqua, water; duco, lead). These aqueducts were for the purpose of leading water across valleys and lowlands from its source in the highlands. Such a system is called a gravity system; it depends wholly upon the force of gravity to secure the desired flow of water. Gravity systems of water-works are largely used to-day. However, it is not necessary to build high aqueducts across valleys as it was in the days of ancient Rome. The water may be carried across valleys and under rivers in iron pipes, which rise and re-enter the aqueduct on the opposite side. As long as the rise is not higher than the head of the water-supply, the water will continue to flow, however deep its plunge. The ancients could not use this plan on ac- 
count of their limited knowledge of iron-working. The High Bridge over the Harlem River in New York City was built to serve as an aqueduct as well as a bridge.

The pipes which convey water through city streets are called mains. The smaller pipes which enter the houses are called service-pipes. Water-meters are installed in the houses to record the amount of water used. The point at which a service-pipe goes through the foundation wall of a house is often the point of greatest danger from freezing. So it is desirable to have the service-pipe enter the house on the sunny side. It is also desirable to have the pipes protected by wrapping where they are most exposed to cold. The depth at which service-pipes must be laid to prevent bursting from freezing depends on the climate and the nature of the soil. Loose, gravelly soil freezes much deeper than more compact soil.

In low and level country stand-pipes are commonly used in order to give gravity flow. The water is pumped up into them. But in cities with high ground near them, the water is pumped into high-lying reservoirs instead.

When the water comes from a river, or from some other source of doubtful purity, filters are used to remove the impurities. A filter is a construction of porous material through which the water is strained. Sand, gravel, charcoal, and porcelain are substances used for filters. Even filtered water, however, may contain disease germs, and when there is any doubt about its purity, it should be boiled. This destroys the germs. 


\section{QUESTIONS}

I. What is Archimedes' principle?

2. Explain the principle of the hydraulic press.

3. If the smaller surface on a hydraulic press is two inches square, and the larger surface is a foot and a half square, how many pounds pressure must be exerted on the smaller surface to balance a weight of fifty-three pounds laid on the larger surface? If the piston at the smaller surface were pushed down twelve and one-quarter inches, how much would the weight on the larger surface rise?

4. What is meant by "conservation of energy"?

5. Explain how a hydraulic elevator works.

6. How would you construct a city water-system?

7. What is a filter? 


\section{CHAPTER IX}

\section{WATER-POWER AND STEAM-POWER}

The power of falling water has long been used by man to do various kinds of work. The grinding of grain was one of the most tiresome of early occupations. No wonder that some tired grinder put his wits to work to find a way of getting out of this endless job. Grain was ground in ancient times between stones, as it is even to-day in some primitive countries. So the grinding together of stones by a waterfall may have been the thing that suggested having the water do this work. Water-wheels were devised, and set up in places where falling water could be easily diverted to run over them. Dams were built to impound the water and make its flow over the water-wheel constant. The revolving shaft of the water-wheel turned the grinding stones of the early mills (see Fig. 30).

Many American cities are where they are because they grew up around old mills. Along the Connecticut River in New England there are many manufacturing cities. They are there simply because the many falls and rapids of the river furnish the power which runs their mills. To-day, however, men have learned to transform waterpower into electric power, and thus to transmit it over wires to cities many miles away. So mills no longer need to be near the falling water which furnishes power to operate their industries. Niagara Falls is the source of the power that runs the street-cars of cities hundreds of miles away. 
The Mississippi River, by means of the great dam at Keokuk, Iowa, is made a source of power for St. Louis and many other cities. Do you know any other examples of falling water that has been "harnessed" by man so that it is the source of energy that does work many miles away?

When you were studying the movements of water, and its many changes from one form into another, you learned what is meant by the indestructibility of matter. Now, in thinking about the various ways in which waterpower may be used, you can see that a similar principle is at work. Energy, which means the power to do work, is a thing that can be changed, but it cannot be destroyed. Matter and energy are the two great things that make up the world and neither of them can be destroyed. They keep changing all the time, but they are not used up. Suppose you carry a trunk up-

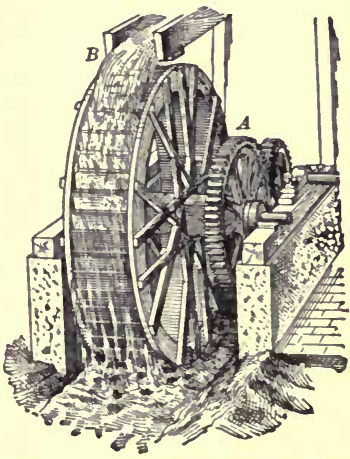

FIg. 30.-Diagram illustrating how the water-wheel works. stairs. You may think you have used up a good deal of energy in doing this. But the energy that you used in carrying that trunk up-stairs still exists, as you would see if you let the trunk slip and it fell down-stairs. In other words, energy, like matter, may be easily transformed (as water-power into electricity), but it cannot be destroyed. You may not be able to understand this completely now, but you will see more and more illustrations of it as you go on with your work. 
Water-power may be defined as power derived from falling water and converted (by means of motors) into useful work. A motor is any apparatus which changes

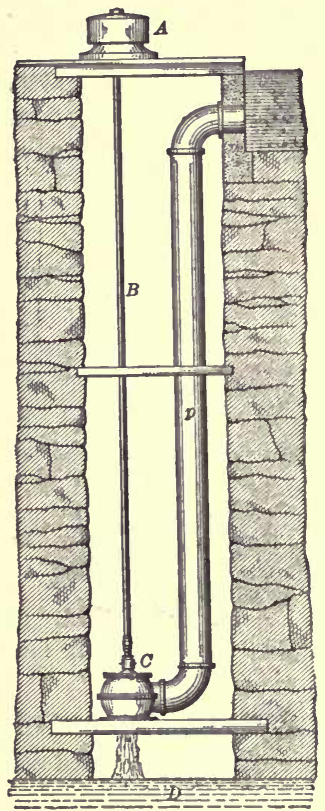

Fic. 3r.-The turbine in action. (transforms) one form of energy into another. Steam and gasolene engines, windmills, and electric dynamos, as well as water-wheels, are forms of motors.

It is quite simple to compute the amount of power which may be generated by water at a given point. The number of pounds of water that flows in a given time is multiplied by the number of feet of the fall. This gives the theoretical amount of power. From this amount, of course, deductions must be made, for there is always considerable loss of power in the processes of transformation and transmission. By transmission is meant the sending of the power. This may be done by geared shafts, or by belts, or, in the case of electricity, by means of wires.

The power-plant at the famous Keokuk dam illustrates quite simply the most modern and scientific method of getting power from falling water. This is the turbine method (turbo, whirl). In a turbine motor the falling 
water enters a cylinder in streams that strike the blades of a revolving shaft in such a way that nearly all the power of the falling water is utilized in spinning the shaft (see Figs. $3 \mathrm{I}$ and 32 ). By this means only about twenty-

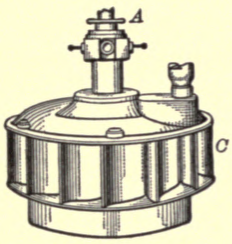

(b)

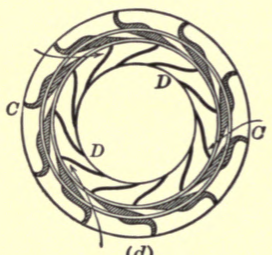

(d)
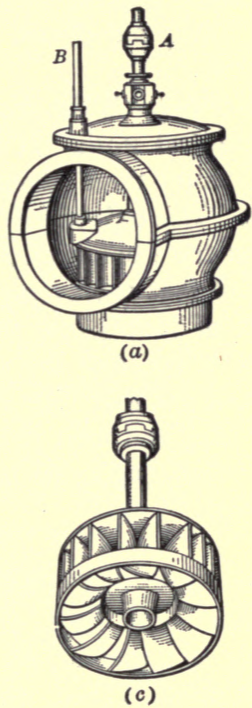

Fig. 32.-The machinery of the turbine.

five per cent of the theoretical energy is lost, which is much less than the amount lost in the use of the older types of water-wheels. Turbines are also used in generating power by means of steam-pressure. Many modern steamships use turbine motors.

It has been estimated that the rivers of the United 
States can furnish about two hundred million horse-power, while the amount utilized now is less than two million. Rapid development of this water-power is being made. Each year many factories, for the sake of economy, close down their own steam-power plants and buy electric power, which is delivered to them from plants like the one at Keokuk.

A horse-power is the standard unit in measuring the rate of mechanical work. It is the amount of work done in raising thirty-three thousand pounds one foot in one minute. This unit was devised by Watt from observations made on the amount of work done by strong dray-horses. He found that the average dray-horse is able to work at the rate of twenty-two thousand foot-pounds per minute, foot-pound meaning the amount of work done in raising one pound one foot. He arbitrarily increased this amount by one-half, and used it to measure the power generated by the steam-engine he had invented. It has been used ever since.

Water-Power and Gravity. - You have noted that the work that water does, or can be made to do, depends upon the fact that it falls. Now before anything falls it must be lifted. Then, when it falls, it falls with precisely the same force as was required to lift it. Here we have a statement of the law of gravity, by which we mean the tendency of bodies to fall toward the center of the earth. (Gravitation means the tendency of all bodies to attract each other. Thus gravity, which is the most familiar example of gravitation, is a case of gravitation in which the earth is the principal body involved.)

This law of gravity has been of great aid to man in many 
of his devices. It aided him in his first defenses against his enemies. He climbed trees to escape from those of his enemies that could not, by climbing, overcome the law of gravity. Then he built stockades and walls over which his human enemies could not climb. $\mathrm{He}$ carried large stones to the tops of walls where they could be conveniently dropped upon the heads of those who came to attack him. Thus he used the force of gravity to crush his enemies.

But nowadays falling water is much more important to man than falling stones. In ancient days slaves did the work of carrying up the stones. What does the work of carrying up the water? What is the force that takes the water from the seas and lakes and carries it up to the hills, whence it runs back to the seas again, and, in running, turns the wheels of ten thousand mills? Evidently we must think again of that great water cycle of nature described in Chapter III. And we must ask ourselves what is the force behind evaporation? We noted in Chapter I that increase of heat hastens evaporation. Now can it be that it is the heat of the sun that does this great work of lifting water up? Is it the sun that we have to thank for getting the water in such position that its fall does work for us? Does the sun then serve us somewhat as the slaves of old served their masters when they carried stones up to high places? We shall see.

Steam-power is like water-power in that water (in the form of gas) is used. It is used to push against something. In the case of steam-engines this pushing or pressure is the pressure of steam in a cylinder against a piston (see Fig. I). The compressed steam forces the piston through the cylinder, then this steam is released. Other steam imme- 
diately admitted on the other side, by means of valves, forces the piston back. Thus a powerful motion is produced. Thus locomotives are driven at high rates of speed and draw heavy trains. You have seen the rapid motion of the shaft of locomotives which runs from the cylinder to the great driving-wheels. The force which turns the wheels comes from that cylinder in which the piston moves rapidly to and fro, the pressure of steam against it being controlled

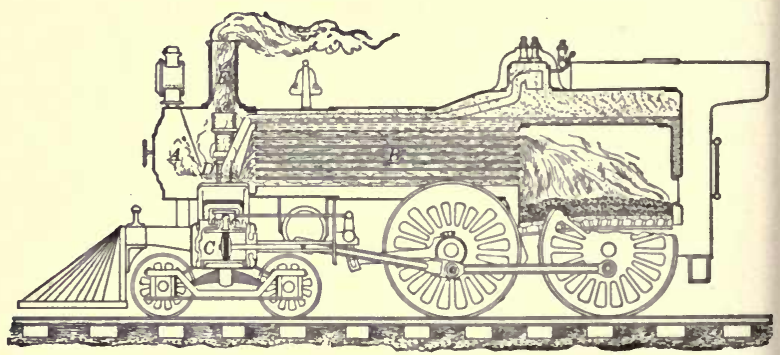

Fic. 33.-The locomotive.

by the engineer. You have seen the used steam as it escapes, hissing, from the ends of the cylinders. Some of it goes up the stack and escapes with the smoke. Study Fig. 33 .

A steam-engine may be defined as a machine for converting heat energy into mechanical motion through the medium of steam. It consists of the fire-box and boiler (where the steam is generated) and the engine proper, where the steam acts on a piston, producing motion. Machines in which the steam acts on blades set on a rotating wheel instead of on pistons are called steam-turbines, which you have already noted, 
Water-Power and Steam-Power Compared. - They are alike in that they both use water. But let us note an apparent difference as to the force behind. You have noted that the force behind water-power is the force of gravity. There is no water-power unless the water falls. Thus it is gravity, acting on water, that is the real force that turns the turbines, that spins the generators, that generates the electricity, that lights the electric lamp by whose light, even now, you may be reading these words.

In steam-power, however, it is heat that is the force behind. It is heat that expands the water into steam, and then expresses itself in pressure if this steam is confined. This heat, in turn, is generated by the burning of fuel. Whether the fuel be coal or wood, its source is plants, for coal is a formation of ancient plants (see page 49). Now since we can release it by burning, there must be energy in the wood and coal. Where did they get it? They got it from the sunlight which once shone on the leaves of the plants of which they were a part. So, if it be that the wire from your electric lamp runs to a steamoperated electric plant, it is the force of the sunlight of ancient days which is now expressing itself in the light you read by. Think, then, how these two ancient forces, gravity and sunlight, serve us to-day. Whether it be the light by which we read, the trains by which we travel, the wires over which we send our messages, the automobiles in which we ride, or any one of a thousand other of our modern conveniences, we can trace all back to the source of their power, and find it in one or the other of these great servants of mankind, the pull of this old earth we live on and the sunlight which shines upon it. Yet we should remember that before the "pull of earth" can act on water, 
and thus give us what we call water-power, the water must be lifted to the high parts of the land from which it flows down. The force which does this is, as has been suggested, the heat of the sun. So it is to the sun, to its heat in one case and to its light in the other, that we must finally go back when we are seeking an explanation of water-power and of steam-power. Thus we see that here, as everywhere in nature, we have an endless chain of causes and effects, and that the sun is the great original source of the energy we see displayed on earth.

\section{QUESTIONS}

I. Explain why waterfalls are useful.

2. Where did the energy that runs your watch come from?

3. How would you compute the power that could be generated by Niagara Falls?

4. How is power transmitted?

5. Explain the turbine. Why is it better than the old-fashioned water-wheel?

6. What is a horse-power? A foot-pound?

7. What originally furnished the energy of the waterfall?

8. Explain the steam-engine.

9. What is the difference between a water-turbine and a steamturbine?

Io. What put the energy into coal?

II. Where did all energy come from originally? 


\section{CHAPTER $\mathrm{X}$}

\section{WATER AND AGRICULTURE}

The Importance of Water to Plants. - You know how important water is to plants and also that water has great effect in determining where men live. This is due to the need of it for agriculture (food-production) quite as much as to the need of it for direct use by man, and in connection with transportation. Good crops depend upon water, soil, and climate. Soil and climate suitable for agriculture are much more wide-spread than suitable watersupply. Hence water-supply is the chief factor in modern times in determining the location of farms. Until quite recently the availability of a market for the crops was quite as important a factor, but the modern development of transportation has very largely solved this problem.

To insure good crops of hay and grain, a water-supply equivalent to at least ten inches of rainfall a year is needed. Also this supply must be distributed throughout the growing season of the plants; it will not do if it all comes at once in heavy rains followed by long periods of drought.

It is easy to demonstrate that water evaporates from the leaves of plants. Place a bell-jar over a potted geranium, covering pot and soil with sheet rubber; or a tumbler over a single leaf whose end is in covered water. Droplets or a film of moisture will soon collect on the glass. This is evidently a result of plant-evaporation, a process which is technically called transpiration. 
The amount of water transpired by growing crops has frequently been estimated. It has been found that in the production of one ton of well-dried hay, over three hundred tons of water are used. Corn which produces fifty bushels to the acre uses, during its life, an acre of water ten inches deep.

Irrigation. - Agriculture does not depend for water on rain alone. Doubtless you have heard of irrigation. It is the process of watering land by artificial means. It is an ancient art. It was practised in the Nile Valley in the days of the Pharaohs, even before the pyramids were built, and even to-day we find highly developed irrigation systems built and operated by savage tribes. They are found in mountainous regions where agriculture requires the building of terraces as well as the conveyance of water by ditches.

The modern development of irrigation in the United States is very extensive. We have in the West vast areas of desert land; the climate is excellent for agriculture and the soil is usually fertile. All that is lacking to make these lands "blossom as the rose" is water; water supplied throughout the growing season. To thousands of such acres in some Western States, water has been supplied. It has been supplied by ditches from rivers and from mountain reservoirs, and now some of this irrigated land is the most fertile and valuable land that we have; often when developed it sells for more than a thousand dollars an acre. In Arizona and California you may see orange groves, or rich and beautiful fields of alfalfa, while just over the fence from them is the desert, whose only plants are sagebrush and cactus and the like. The soil is the same. 
The sunlight is the same. The heat is the same. The only difference is the "magic touch" of water (Figs. 34 and 35 ).

Irrigation projects frequently involve the expenditure of great sums of money on the necessary dams and ditches. It may be necessary to bore tunnels to carry the water

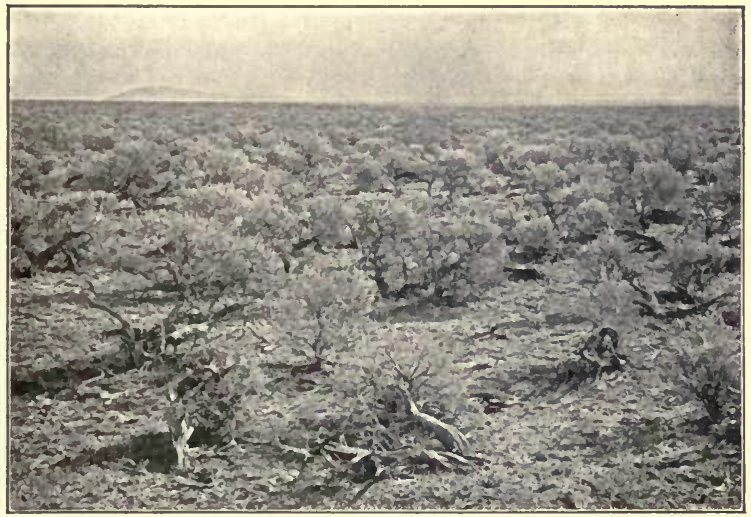

FIG. 34.-Some of our Western land which has not been irrigated.-After U. S. Reclamation Bureau.

from the mountain reservoir to the thousands of acres which it may reclaim from the desert. This great expenditure of money, combined with the fact that the land to be reclaimed is in most cases government land, makes it natural that we have in the United States a government Reclamation Service. This important branch of the government makes the careful preliminary surveys which are necessary, and then proceeds, as funds are made available by Congress, to build irrigation works at what 
seem the most desirable places. The land which is made fertile by such works is then sold to settlers.

Between 1902 and I9I5 more than three million acres were reclaimed by the government by irrigation. Plans have been completed and part of the work done to reclaim thirty million more. In $\mathrm{I}_{9} \mathrm{I} 4$ homesteaders of seven hun-

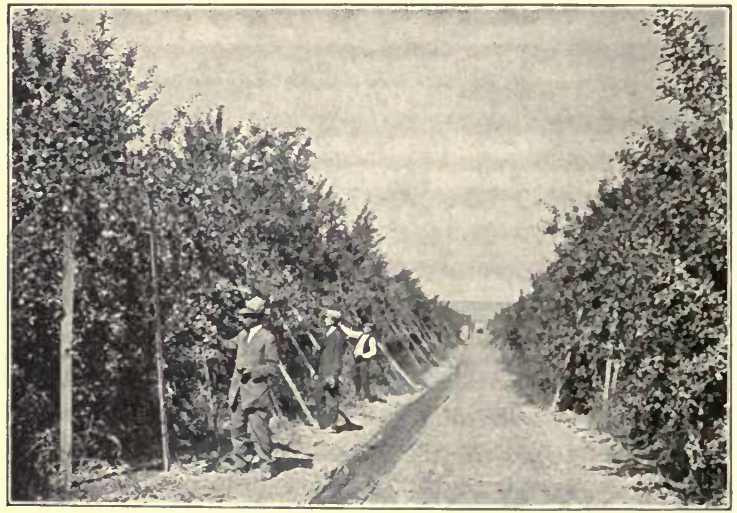

Fig. 35.-The same sort of land as in Fig. 34 after irrigation.-After U. S. Reclamation Bureau.

dred thousand acres of this land got average crop returns of twenty-five dollars per acre. The average cost of the perpetual water-right is forty dollars per acre, the homesteader being given twenty years in which to pay this in instalments without interest. Complete information concerning the Reclamation Service may be obtained by writing to the United States Geological Survey at Washington.

Why is it called the Reclamation Service and not the Irrigation Service? This is because it does not reclaim 
land by irrigation alone. There is much land in the United States which is rendered unfit for agriculture not by too little water, but by too much water. Such land is reclaimed by drainage. We have more than one hundred million acres of swamp-land, most of which by drainage can be made fit for farms. The soil is very fertile, once the excess of water is removed. In Florida thousands of acres have been reclaimed by drainage, and smaller drainage projects are found practically all over the United States.

Drainage. - We note then that though water is necessary to plants, there may be "too much of a good thing." So scientific farming involves, among many other things, the effort to secure for crop plants the optimum (best) water-supply. It is for this reason that good farmers lay tiledrains in their fields where there is need for them. Let us note, however, that such drains benefit the plants in other ways than merely by carrying off the excess of water. In the excess of water they carry off excretions from the roots of previous crops which, if not removed, make the soil less fertile. They also indirectly permit more air to get into the soil, which is important to plants. The increase in the porosity of the soil caused by draining off the excess of water also permits heat to penetrate it more rapidly; the warming up of the soil in spring is especially important in connection with the germination of seeds. These incidental benefits of drainage are so important that it has been found desirable to provide artificial drainage even for irrigated farms.

Water in the Soil. - The amount of water which is held by soil depends on what kind of soil it is. More specifically, 
it depends on the size of the soil grains. Clay has greater retentive capacity for water than sand because its grains are much smaller. Liquids have a tendency to adhere to the surface of substances with which they are in contact, even in opposition to the force of gravity. So each soil grain holds to its surface a film of water; this is known as the water of adhesion. Therefore, the greater the number of soil grains in a given volume of soil, the greater the total area, and the greater the amount of water of adhesion. The total surface of a cubic foot of the tiny grains of clay is very much greater than the total surface of a cubic foot of the much larger grains of sand.

In your study of wells (see page 46), you learned that a layer of clay is often very important as a barrier which prevents the escape of water through it. Now let us note that if this clay is moist, which it inevitably is, if in contact with another water-containing stratum, then it becomes much more impenetrable to water than if it were dry. Due to the minuteness of its grains, and its consequent high powers of surface tension, it holds the water that gets into it with greater tenacity, and nothing is more impervious (impassable) to water than a layer which is already filled with water.

Roots and Water. - You have just noted that the fineness of soil grains multiplies the water-retaining capacity of soil. Similarly, the increase of water-absorbing surfaces multiplies the water-absorbing capacity of roots. This increase of water-absorbing surface roots secure by means of root-hairs. On the roots of seedlings, such as those of corn or radish, these hairs are so dense that they form a fuzz, as you may have seen (see Fig. 36). When you 
pull up a plant by the roots, you do not find these hairs. They are so delicate and so closely adherent to the soil grains that they break off and remain in the soil. You can see that the absorptive surface of roots is multiplied very many times by these millions of hairs.

You should also note that roots, in their growth, are positively attracted by water; they grow toward it, and when the water-supply is deeper than usual plants may develop an unusual depth of roots. In fact, the growth of roots seems to be chiefly a sort of groping and searching in the soil for water. If you sprout seeds in a suspended wire cage containing damp moss, the rootlets that grow down
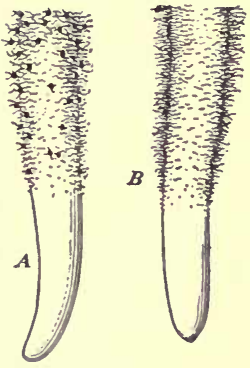

Fig. 36.-Young root-tips with root hairs; $A$ shows how the soil particles become attached.-After J. M. Coulter. through the bottom of the cage will turn and grow up again toward the water above them.

\section{QUESTIONS}

I. How can you prove that water evaporates from leaves?

2. What is irrigation?

3. What kinds of work are done by the United States Reclamation Service?

4. Why can't you grow a plant in a bucket of water?

5. What kind of soil holds the most water? Why?

6. What are root-hairs, and of what advantage are they to the plant? 


\section{CHAPTER XI}

\section{ORIGIN OF SOIL}

Importance of Soil. - As life depends on food, so food depends on soil. We know how necessary food is to us. It takes but little thought to show that soil is likewise necessary to food. Fish and other sea-foods we might have, if there were no soil, but what would life be worth if our only food was food from the water? It is the soil, with the sunlight and heat on it and water in it, that makes life possible for our crop plants, and it is these crop plants that make life possible for us.

The soil covers the rocks and holds, firmly and nourishingly within itself, the roots of plants. It is of the soil we think when we say "Mother Earth," for it is the soil which permits Earth to be "Mother" of us all, plants and animals alike. It is in the soil that man worked in the long ages in which his civilization was slowly developing. It is from the soil he drew his strength; from it he gained the foundation of his wisdom. To-day more than onethird of the human race are workers of the soil, and upon their work all the rest of us depend. It is not surprising that those of us who live in cities are glad sometimes to "get back to the soil," to go to the country and see things growing in the fields, to make a garden of our own, when spring comes, or to plan to buy a farm. All this seems but a response of our nature to a sort of instinct; a sort of instinct implanted by that long intimacy with the soil that our forefathers had. So, however far from farms 
our work may take us, we still feel more or less the instinct to go and work in the earth for our living, and find pleasure in the following of that instinct.

Formation of Soil. - You have learned that all substances are either organic or inorganic; and the sciences are often divided into those which treat of organic things

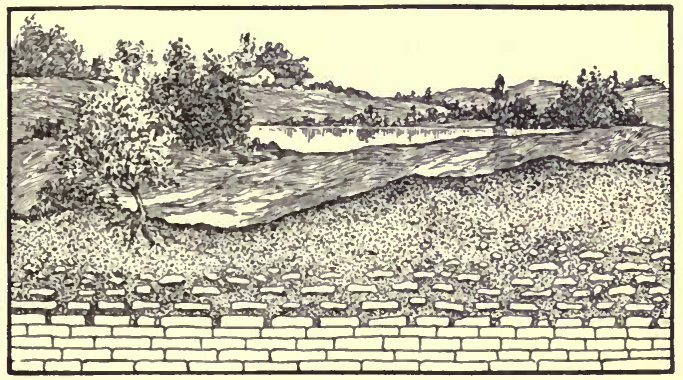

FIG. 37.-A section of the soil, showing its relation to the underlying rock.

and those which treat of inorganic things. But soil, more than anything else in the world, is a thing in which the organic and inorganic meet and merge. It is composed of mineral (inorganic) matter derived from the rocks beneath, and of organic matter derived from the organisms which live on and in it. So whether you are studying geology, an inorganic science, or botany, an organic science, in both you must study the soil.

That soil is a mixture, a mixture in which organic and inorganic materials "meet and merge," is quite evident when we consider its origin, or look at it from top to bottom (see Fig. 37). Where streams are eroding steep 
banks, or where there is a freshly made railroad cutting, you may see, as in the picture, how the underlying rock and subsoil gradually merge into the soil which covers them. In such places you may readily see how soil is made in part by the decay of plants above and in part by the decay of rock beneath. The death of things helps produce it, while it, in turn, helps to produce new living things again; it nourishes the plants; they draw from it materials which they use in growth, and which they transform from what was lifeless and inorganic into what is living and organic. You have learned in geography that the wealth of countries depends a good deal upon their "mineral resources," an expression which makes you think of gold and silver and iron and other valuable metals. But the most valuable mineral resource of all is the soil.

To understand how soil has been formed, we must think of the earth as it was before there was any soil. It is believed that at one time water and rock formed the entire surface of the earth. There was no soil and there was no vegetation. But this condition could not continue long. There are forces constantly at work in nature which cause even the hardest rock to crumble at the surface, and thus the formation of soil begins. The operation of these forces on rock is called rock weathering, and soil has been called "rock-meal" or "rock-flour" because it is chiefly composed of substances which were once hard rock. The organic material in soil, which comes chiefly from the decay of fallen leaves and twigs, is called humus or mould. it is dark-colored. Rich surface soil, especially in forests, is largely composed of humus.

You have learned that rock means any hard, inorganic part of the earth. So the loose rock (gravel, sand, etc.) 
which covers the surface is called mantle rock. It forms a sort of mantle over the solid rock beneath.

The weathering of rock, which leads to the formation of soil, is caused by various things, and it proceeds at various rates in different places. Some of the principal factors in rock weathering are the following:

I. Water. - You have already noted what a large part running water plays in the distribution of soil. It also reduces pieces of rock to sand and clay by grinding them together. This is quite evident to any one who has watched the effects of water when streams are running swiftly or waves are pounding on the beaches. But there is quite another and an earlier part which water plays in the origin of soil, a part in which movement of the water is not necessary. You know that water expands when it freezes. It expands about one-tenth of its volume. In this expansion it exerts great force. You have seen how this force may cause the bursting of pipes. Similarly, it may cause the bursting of rocks. Crevices in rock may be filled with water. A freeze comes and the water changes to ice. The expansion that results may have force enough to enlarge the crevices, splitting the rock still farther. After a thaw, more water runs in. Then the process may be repeated. So, with alternate freezings and thawings, great masses of rock may be broken up, and this process will be effective wherever water can get into crevices. Evidently it will be most effective where changes from water to ice, and the reverse, are most frequent. So in some regions this process produces much larger effects than in others.

II. Expansion and Contraction. - You know that in general heat causes substances to expand while cold causes 
them to contract, the expansion of water into ice being a conspicuous exception to a general rule. Now where rocks are exposed, as on the sides of cliffs and in deserts, and especially where there are considerable changes in temperature between day and night, the alternating contraction and expansion causes the outer layers of rocks to break and scale off (Fig. 38). The surface of the rock, when the sun is shining on it, becomes hotter and more expanded

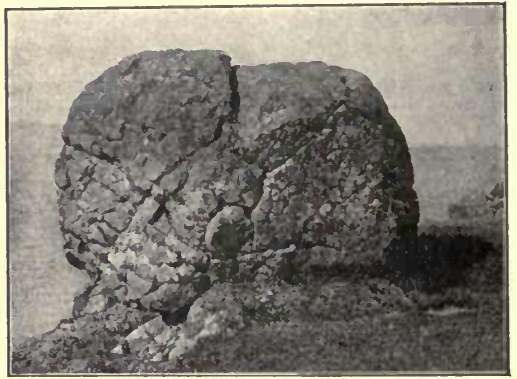

FIG. 38.-Photograph showing how rocks may crack and scale off, due to changes in temperature.

than the interior. This causes a strain in the rock, and starts the process of breaking. Then, at night, the surface may become colder and more contracted than the part just below it. This causes more strain and more breaking, so that as a result it is common to find that cliffs have much loose rock on their surfaces, and the fallen pieces accumulate in great heaps at the bottom. Such accumulations of broken rock at the foot of cliffs are called talus (see Figs. 39, 40). The talus at the bases of large mountains is sometimes hundreds of feet deep. This shattering of rock by alternate heating and cooling 
is more conspicuous at high altitudes than at low ones. Why?

III. Chemical Action. - The changes in rock just described are physical changes. There are also certain chemical changes constantly occurring which also contribute to the reduction of rock to soil. Chief of these is the proc-

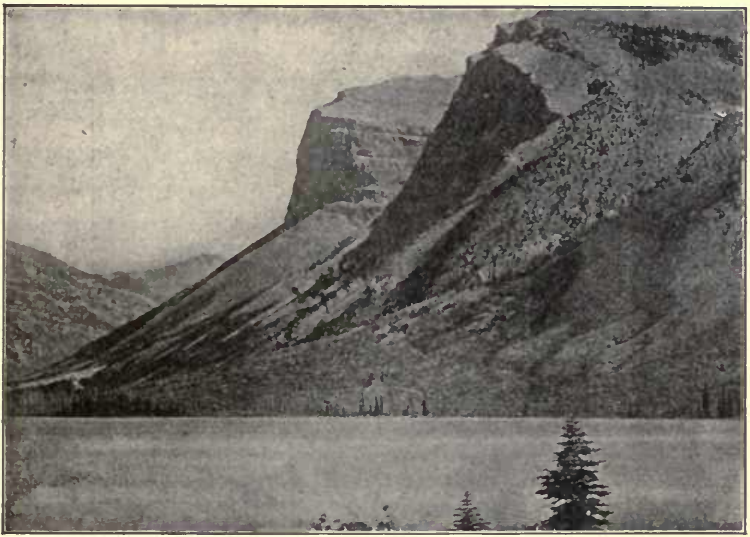

Fic. 39.-Talus slope.

ess of oxidation, which is the chemical union of oxygen with any other substances. Similarly, hydration is the chemical union of water with any other substance. The rusting of iron includes both oxidation and hydration. Now many rocks contain iron. When this iron is exposed to the atmosphere, especially to a damp atmosphere, it becomes changed to iron-rust, and this tends to make the rock crumble.

You have learned (see page 52) how water may "act on" 
limestone and sandstone. This action is a combination of solution and hydration. You have noted its effects. Similar effects are produced by the oxidation and hydration of iron in rock; the rock becomes weakened and presently crumbles. Thus we see how a chemical change may also produce physical change as one of its results.

Other chemical changes produce similar results. Some of the substances which result from chemical changes in

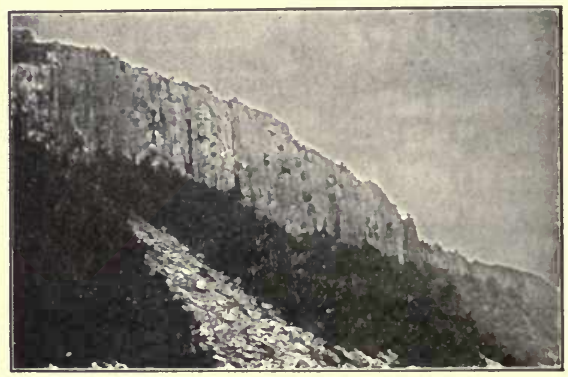

Fic. 40.-Talus slope.

the rocks are thereby rendered soluble in water, while other minerals are soluble without chemical change. So we see that the combination of chemical change and solution is one of the most important of the causes of the breaking down or disintegration of rock. As rock breaks down, soil builds up; in other words, rock disintegration is soil formation.

IV. Organisms. - You have learned that plants and animals contribute directly to soil formation, their dead parts forming humus or mould. But they also contribute indirectly by being an important factor in this great process 
of "rock weathering." Their disintegrating effects upon rocks are both chemical and physical. Roots may enter crevices of rock, and by the great pressure of their growth crack these rocks apart (see Fig. 4I). Burrowing animals produce important effects; their burrows increase the aeration (exposure to air). Earthworms are particularly important in increasing fertility of soil by stirring it up and improving its aeration. The roots of plants

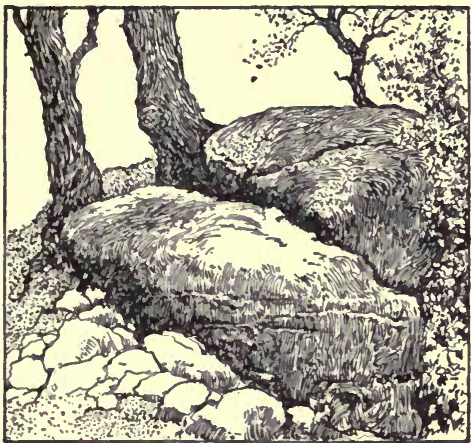

Fig. 41.-Showing how the roots of trees may split huge rocks.

excrete substances which produce corrosive effects upon rock, especially limestone.

V. Glaciers. - The very important action of glaciers upon rock and soil has already been described (see Chapter VIII).

\section{QUESTIONS}

r. What is soil made of?

2. What is our greatest mineral resource?

3. What is humus?

4. Name and explain the different factors in rock weathering.

5. What is "talus" and how is it formed?

6. How does water act on limestone? 


\section{CHAPTER XII}

\section{KINDS OF SOIL}

Soil may be classified in various ways. Thus we may classify it on the basis of its origin, that is, on the basis of how it was formed. Or we may classify it on the basis of the materials which principally compose it and give it a certain character. Both of these methods of classification are important. The former is much simpler, but the latter is more important when it comes to considering agricultural possibilities.

As to method of origin, the kinds of soil are comparatively few, for the ways in which soil is formed are comparatively few. But as to the nature of its contents, the kinds of soil are very many, for, as you have seen, soil is a mixture, and the substances which enter into this mixture are numerous and their proportions are various.

You have learned that the various inorganic substances of which soil (and rock) is composed are called minerals. Thus clay is largely composed of the mineral called feldspar, while sand is chiefly made up of quartz. There are many different kinds of minerals and each kind has a definite nature of its own. One kind may have a very beneficial effect upon the fertility of soil, while another kind, if present in large quantities, may have an injurious effect; or the mineral nature of the soil may make it favorable to the growth of certain kinds of plants, but unfavorable to the growth of other kinds. 
Thus we can see why it is said that to the farmer each field has a problem of its own. The fertility of a field depends largely upon the physical and chemical nature of its soil; it may be good for some crops, but poor for others; it may be good for a certain crop one season, but poor for that crop the next season, because of the changes in the soil which that crop produces. Many crops gradually "poison," or reduce the fertility of soil for crops of the same kind. So we hear of what is called rotation of crops; by changing his crops from season to season the farmer really changes his soil and so helps ta keep up its fertility. The changes which one kind of crop makes are counterbalanced by the changes which another kind makes; one kind will succeed another kind better than it will succeed itself. This is because the materials which one kind of plant takes from the soil may be different in amount from those taken by another kind, and the changes which one kind produces in the soil may also be different from those produced by another kind.

Soil as to Origin. - As to origin, there are evidently two great kinds of soil. There is the kind which has been formed just where you find it, and there is the kind which was formed somewhere else, and then moved, usually by water, to the place where you find it. The former is called residual soil; the latter, transported soil.

The fertility of residual soils varies more than the fertility of transported soils; some residual soils are fertile, others are sterile; this depends chiefly upon the nature of the parent rocks from which they were formed. Transported soils, on the other hand, are much more uniformly 
fertile; this is because of the thorough mixing of materials which occurs in the process of their formation; the result is usually a complex mixture which is very good for the growth of plants. Residual soil whose parent rock was sandstone is sandy and generally infertile. Residual clay comes from shale, and is generally more fertile than very sandy soil, but it is usually heavy and difficult to till. (Tillage means the working of soil for crops, as by ploughing, harrowing, etc.) Residual soil derived from limestone is usually fertile and tillable; a certain amount of lime in the soil is very desirable for plant growth.

Transported soils may be subclassified on the basis of the transporting agencies. Thus we have alluvial soils, which are composed of materials (sediment) transported and deposited by rivers. These soils are highly fertile and easily tillable, both on account of their texture and the levelness of their surface. So it is not surprising to find that agriculture and civilization first developed near the mouths and along the lower stretches of great rivers, such as the Nile in Egypt and the Hwang Ho in China. For along these ancient rivers there are great areas of alluvial soil, very excellent for farming, and capable of supporting a dense population. Such rivers, where they flow through level country, develop flood-plains, that is, plains which have been levelled over and built up by the wide floods of the river (see Fig. 42). "Ancient civilizations were confined so generally to rich flood-plain soils that the period before 800 B. C. has been called the Fluvial Period" (Salisbury). In the United States the rich "bottom-lands" of river-valleys are famous for their fertility, and are of high value, though subject to the risk of loss by flood of fences, houses, and livestock. 
Wind has played and continues to play a far more important part in the transportation of soil than one is likely to think. However, if you recall the sand-storms of the desert of which you have heard, and then think of the enormous stretches of time through which this agency has been at work, you can understand how great results

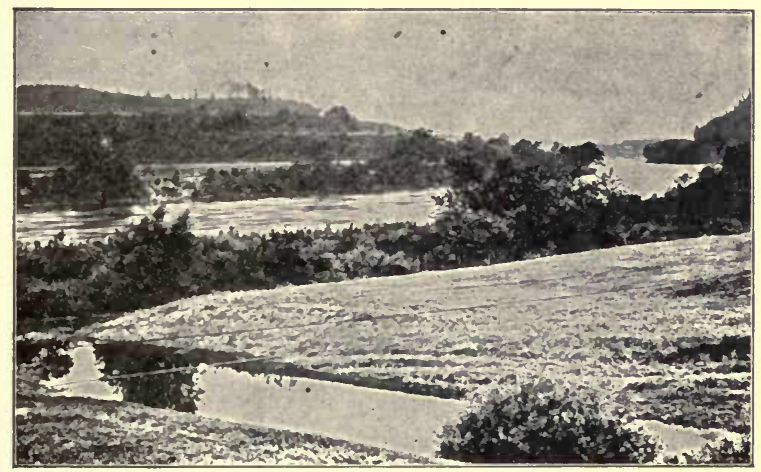

FIG. 42.-Flood-plains.

have been accomplished. Soils composed chiefly of sand or dust which was once blown where they are, are called eolian soils.

Sand-dunes (see Fig. 43) are formed by the winds. Of course, while the sand is still being blown about, there is little chance for plants to gain a foothold. But gradually, on dune-forming shores, the beach moves seaward or lakeward as the sand accumulates; and the farther a dune gets from the beach, the less it is exposed to the wind. So plants begin to cover it, their roots holding it together, and presently we may have a dense vegetation growing 
upon this strictly eolian soil, as along the east coast of Lake Michigan. The "sand-hill region" of western Nebraska is a great tract which is practically useless for agriculture because of the strong winds which blow the loose sand about.

Eolian soil that contains more of dust than of sand is called loess (pron. lus). Soil which is partly sand and

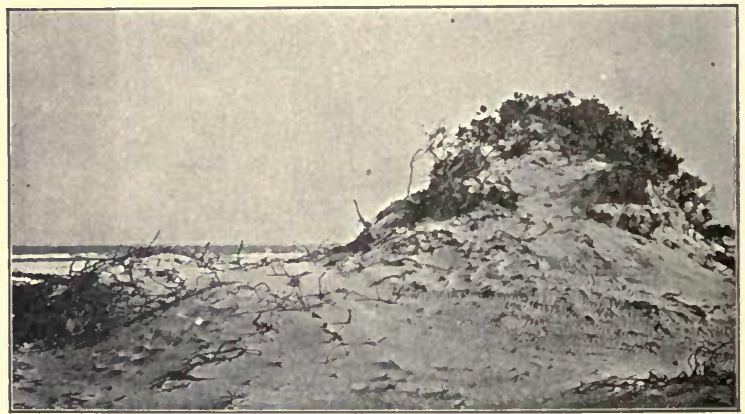

Fic. 43.-Sand-dunes.

partly clay (and usually partly humus) is called loam. So we see that loess is eolian loam. Some of the richest agricultural regions are regions of loess. There is much of loess in the Mississippi and Missouri river-basins. Loess formations in China are famous for their depth, and many of those in Europe for their fertility.

Ice was (and to some extent is to-day) a third great factor in the transportation of soil. You have read of the glaciers and of the great effects they produced, especially in northeastern and north-central United States (see chapter VIII). You know that the material deposited by 
glaciers is called till or glacial drift, and that the soils affected by glaciers are usually quite fertile.

Soil as to Nature. - The classification of soils as to their chemical nature is much too complicated a subject to take up in a book of this kind. But we should note that this is a very important matter in scientific farming. By means of chemical analysis it is possible to discover in what mineral and organic substances a given soil is rich or poor, as the case may be. The substances which crops need being known, it is evident that such analyses give the farmer a scientific basis upon which to determine what kinds and amounts of fertilizers should be applied to his fields. Without such analyses, the use of fertilizers is largely a matter of guesswork. We mean by fertilizer anything used to improve the fertility of soil. Lime, rock-phosphate, bone-dust, potash, and manure are examples of fertilizers; all of these contain substances which are very necessary to the growth of plants.

The classification of soil as to its physical nature depends chiefly upon the size of the soil grains. Thus, sand has much larger grains than clay, while loam, as you have noted, is a mixture of the two. You have also learned (see page 83 ) how important a part the size of soil grains plays in the matter of water retention by the soil. Generally speaking, for agricultural purposes, sand is too porous; it lets the water escape too readily. Clay is too dense; it holds water too tenaciously and is too difficult to work. Loam is a "happy medium" between the two, especially if its richness be increased by a quantity of humus.

Of course soils vary exceedingly as to the relative pro- 
portions of sand and clay, but the following rough classification may be made:

\begin{tabular}{|c|c|c|}
\hline & SAND & CLAY \\
\hline 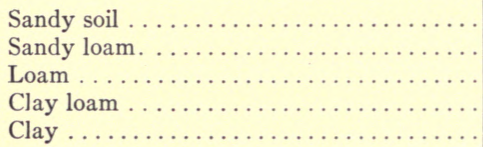 & $\begin{array}{l}80 \% \\
60-70 \% \\
40-60 \% \\
10-35 \% \\
10 \%\end{array}$ & $\begin{array}{l}10 \% \\
10-25 \% \\
15-30 \% \\
30-50 \% \\
60-90 \%\end{array}$ \\
\hline
\end{tabular}

Summary: Soils may be classified as follows:

As to origin. - Residual soil.

Transported soil.

Alluvial soil.

Eolian soil.

Glacial soil.

As to nature. - Chemically, on the basis of chemical analyses of its constituents, or Physically, on the basis of the size and texture of its grains (see table above).

\section{QUESTIONS}

I. What are the different kinds of soils?

2. Why do we "rotate" crops?

3. Why does the fertility of residual soils vary more than the fertility of transported soils?

4. In what respects are the following residual soils good, and in what respects are they bad: sandy soil, clay soil, limestone soil?

5. What are alluvial soils? Are they good or bad?

6. What are eolian soils?

7. What are the various things that transport soil?

8. What are fertilizers? How do we learn what fertilizers to use?

9. What is the best kind of soil, and why? 


\section{CHAPTER XIII}

\section{FERTILITY AND SOIL LIFE: BACTERIA}

Soil Fertility Dependent on Bacteria. - The fertility of soil depends upon certain things which you have already learned. But it also depends upon another thing which we have not mentioned. That thing is the hidden life within the soil. This "hidden life" to which we refer is not the life of the roots of plants whose stems and leaves grow up into the air and sunshine. Nor is it the life of animals which, like earthworms, burrow in the soil, though they, too, affect soil fertility. It is life which is hidden not only because it is in the soil, but because, even when we do uncover it, we cannot see it. The individuals which compose it are too small to be seen by the naked eye. They are microorganisms (mikros, small); organisms so small that they can be seen only with the aid of a microscope.

These micro-organisms are mostly plants, but they are not green plants, and their life habits are very different from those of green plants. They are not capable, as green plants in sunlight are, of making their own food; that is, they cannot take inorganic materials from soil and air and transform them into organic materials. None the less, their way of life appears to be very successful, for they occur in teeming millions. Rich soil is as full of invisible life as is stagnant water. Forest soil, especially, supports within itself a population more dense than the population of our most crowded cities, and the plants which grow up 
from such soil are greatly affected by the hidden life which swarms among their roots, and finds its nourishment in rotting branches and decaying leaves.

Chief among these micro-organisms of the soil we should note the bacteria, which, as you may already know, are very abundant else-
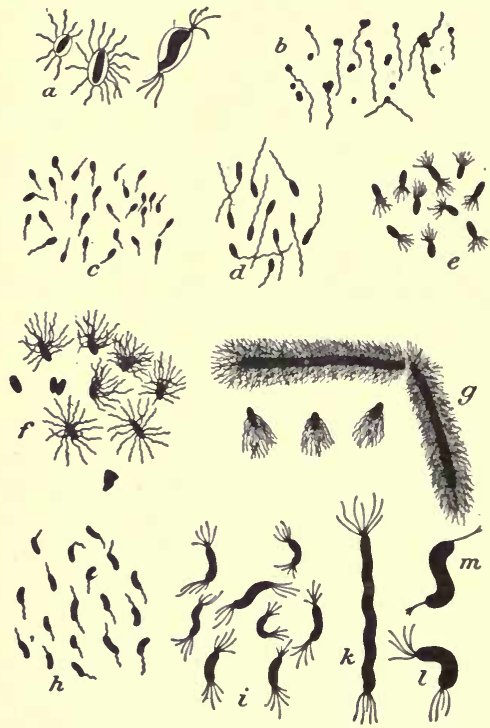

FIG. 44.-Various kinds of bacteria. where as well as in soil (see Fig. 44). Doubtless you have heard that bacteria cause disease, and perhaps you naturally think of them as the enemies of mankind. It is true that many diseases are caused by bacteria; it is also true that most of these diseases might be prevented by careful living. And yet the benefits which bacteria confer on mankind are quite as important as the harm they do. It is the green plants which make our food; but it is the bacteria, chiefly, which reduce the dead parts and bodies of organisms to a condition in which they can be built up into food again. Just as we depend on the work of green plants for 
food, so it appears that green plants depend upon the work of soil bacteria for materials out of which they make food. Thus we see that the changing of materials from the inorganic to the organic condition and back again occurs in a sort of cycle. At the beginning of this cycle we have the work of green plants. At the end of it we have the work of bacteria and other micro-organisms, which change the complex dead organic substances into simpler substances which green plants can use. Green plants cannot use these materials until they have been so changed.

Importance of Nitrogen to Plants. - Bacteria increase the amount of nitrogen in the soil which is available for the use of green plants, and this is very important. By available nitrogen we mean nitrogen in such condition that plants can use it. Nitrogen is necessary to plant life. Four-fifths of the air is nitrogen, as you have learned. In the air then there seems to be an inexhaustible supply. But green plants cannot use this atmospheric nitrogen at all; they cannot use it any more than we can use sea-water to drink. Shipwrecked sailors might have a whole ocean of water about them, and yet perish of thirst for lack of available water to drink. So with green plants and nitrogen; the nitrogen to be available for them must be present in certain compounds (nitrates) which are very different from the free nitrogen of the air.

Certain bacteria, sometimes called the nitrogen-fixing bacteria, have the power to use the nitrogen of the air, and they change it into the compounds that can be used by plants. This is not the only method by which such compounds are produced in nature, but it is a very important one. 
Farmers realized that clover improves the fertility of soil long before they found why this is so; later it was found that clover enriches the soil in these nitrogen compounds that are used by plants. The reason why clover and other of its plant relatives produce this result is that "nitrogen-fixing" bacteria live and thrive in abundance

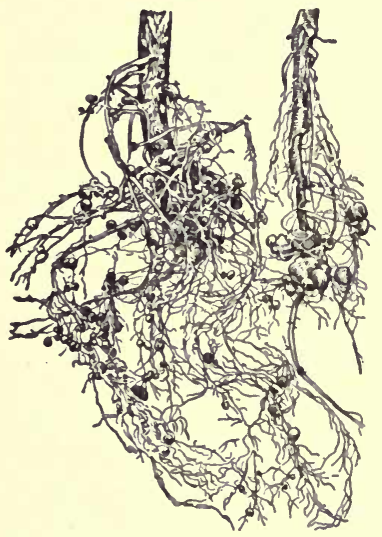

FIG. 45.-Root-tubercles. on the roots of these plants. They live in little swellings of the roots called nodules or tubercles; these nodules are produced by the activity of the bacteria which live inside the roots (see Fig. 45). There is air, as you know, in the soil, and the bacteria in these nodules absorb nitrogen from this air, and combine it with other substances. The clover hay is cut, and the roots left to decay in the soil, thus making it much more fertile. Note that clover and bacteria are both necessary for this process. When the nitrogen-fixing bacteria are not abundant, the clover crop is much poorer than when they are. Sometimes fields are artificially "inoculated" with the desired bacteria. Soy-beans, cow-peas, sweet clover, and alfalfa are some of the relatives of clover which also bear nitrogen-fixing bacteria and root-tubercles abundantly. These plants all belong to the same family, the legume or pea family. 
You have learned what is meant by "rotation of crops" (see page 95). To grow corn or wheat for two years and then clover for one is a common example of rotation. Various benefits arise from such rotation, but probably the principal one is the enrichment of soil in nitrogen in the way indicated. Soy-beans are sometimes grown by farmers and then "ploughed under," the sole value of this crop being to enrich the soil in nitrogen for other crops.

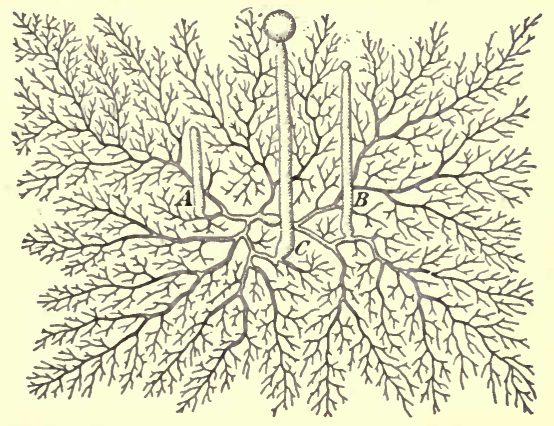

Fig. 46.- One of the fungi.

Besides the bacteria, which are the smallest of the micro-organisms, there are hosts of other kinds of lowly organisms which live in rich soil and affect its fertility. There are, for example, many kinds of colorless plants (fungi) which grow underground in the form of spreading threads, more delicate even than the threads of cobweb (see Fig. 46). Occasionally, when the conditions are just right, a mass of such cobwebby threads will produce a structure much larger than itself which grows up above the surface; these structures contain millions of almost invisible, pow- 
der-like spores, which reproduce the plant. Toadstools, mushrooms, and puffballs are examples of such structures (see Fig. 47).

The effects which such plants produce upon the fertility of soil are not well understood, but it is known that their threads penetrate everywhere in soil that contains organic matter, and they certainly produce many chemical changes in such soil. Some of them form felt-like coat-

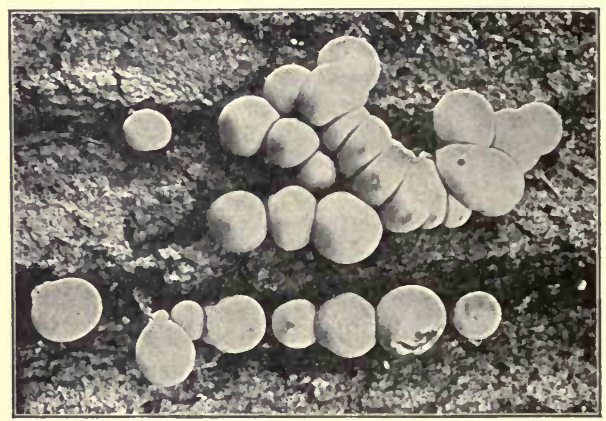

Fig. 47.-Puffballs.

ings on the tips of the roots of certain plants, and seem to be of benefit to such plants (see Fig. 48).

Enough has been said to prove to you that soil is a very complex thing. Except where it is quite bare of plants, like bare sand, it contains more or less of organic material, and this organic material furnishes food for hosts of microorganisms. These micro-organisms, along with the physical and chemical nature of the soil, and its relations to water, air, and heat are all factors in determining fertility or infertility. 
Fertilizers. - Formerly it was thought that when fertilizers were added to soil; the plants simply used the fertilizers directly as "food." But now we have found that fertilizers may produce their good effects without acting as food at all. They may cause the destruction of poisonous substances which are in the soil, or they may stimulate the growth of micro-organisms which are essential to its fertility, or they may simply change the chemical condition of the soil in a way that is favorable to plants. Thus fertilizers benefit the soil in various ways, and probably will be used even more in the future than in the past. In the future, however, we may expect that the exact effects which they produce will be better understood, and this will lead to a more scientific and more economical use of them.

\section{Soil Fertility and Food-Supply. -} The whole question of soil fertility is of huge importance to every one of us; the

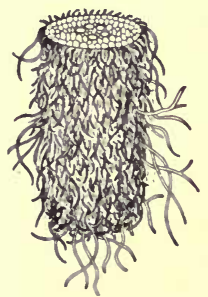

Frg. 48.-Fungi growing on a root. future welfare of the human race appears to depend upon it more than upon any other single thing. As the years have gone by, the fertility of many of our greatest agricultural regions, especially in the United States, has been decreasing; the amount of crop per acre has been getting less. Meanwhile each year the population of the world increases. Each year there are more mouths to be fed, more hunger to be satisfied. Are we sure that each year there will be more food? Most of the fertile land in the world is already under cultivation, and if fertility continues to decrease while food-consumption continues to increase, 
the outcome is evidently going to be very bad for the human race.

However, there is no real danger if the farmers will use better methods of agriculture. Science has shown how to prevent loss of the fertility of the soil, and scientists continue each year to make new discoveries which are of the greatest importance to agriculture. They have proved how certain fertilizers and certain methods of farming increase the crops, and they have found and developed new races of plants which will yet further increase the food production of the world. But the difficulty is to get the farmers to heed the facts of science. Usually they do not like to take the trouble to change their methods, and generally they stick to the old wasteful ways even in the face of positive evidence that other ways are better. So our hope lies chiefly in the next generation, of which you are a member. It is to be hoped that your training in science will be thorough enough to make you fully appreciate all that science offers of improvements, both in agriculture and in other great human activities. Whether you will heed what science teaches or not, that is another matter, a matter for you yourself to determine.

\section{QUESTIONS}

I. What are bacteria?

2. Why are bacteria useful in the soil?

3. Can green plants use the nitrogen of the air? How is nitrogen made available for them?

4. Why does clover improve the fertility of the soil?

5. Why do we rotate crops?

6. What are fungi, and what good are they in the soil?

7. What things do fertilizers do? 


\section{CHAPTER XIV}

\section{MECHANICAL WORK: SIMPLE MACHINES}

Work may be classified into that which is mechanical and that which is mental. Man's work is, or should be, a combination of both. A man is generally paid for his work in proportion to the amount of brains he puts into it. That is, mental work is usually more highly paid than mechanical work. A "day-laborer" is usually expected to do only mechanical work, which any healthy and sane man can perform. Brain-workers, however, are not so common. Those who can do really high-grade mental work are comparatively few, and command high prices, if there be a demand for their kind of work.

There has always been plenty of work for man and there always will be. When we hear of scarcity of work it really means scarcity of money to pay for it. There is no danger of the work itself giving out. The kinds of work to be done will change, but work itself we shall have always with us. Though labor-saving inventions enable one man to do work formerly requiring many, new needs for work almost keep pace with the inventions. But this important thing should be noted. As the world grows older, it is the opportunities for brain-work which are increasing, while the opportunities for mechanical work are decreasing. It is easy to see that machines may presently do nearly all the purely mechanical work, and to be sure of profitable work, one must learn to do things which require skill and brains. 
So it is equally clear that, as the world grows older, the need of its young people for education becomes greater. The education which was good enough for your grandfather may not be good enough for you. Times have changed. You must stay in school as long as you can to make sure of earning a living. The modern world into which you are going demands, above all things, minds which are trained and well-informed. Mere strength and smartness count for little in the world's work of to-day, and they will count for less and less as time goes on.

The progress of man may be measured by the extent to which he has put brains into his work. Indeed the progress of man may be defined as the process of putting brains into work. It is the process of thinking in connection with doing, the process of making behavior a fulfilment of careful thought. This defines the progress of the individual as well as of the race. It is a goal toward which we all strive.

Man's first use of labor-saving devices was probably not reasoned out. It was more or less instinctive. He felt his way, rather than thought his way to the doing of certain things in certain ways. He learned by experience rather than by reason. Thus the first primitive men who pried up large stones with sticks, or threw small ones in slings, probably did these things without thinking much about them. There is a scientific explanation as to why it is easier to pry up a stone than to lift it, but a small boy will do it without having any idea of the explanation. Similarly such things were done in the childhood of the race. The explanations came later. These explanations were the beginnings of science. 
Mechanical Work. - The work which this chapter discusses is mechanical work. It is the kind of work which can be measured in foot-pounds or horse-power. It is the kind of work done for us by animals and by machinery.

An ancient legend illustrates the principle which man has chiefly used in his simplest and oldest labor-saving devices. A king had six sons. He decided to bestow his kingdom upon the one having the most intelligence. To test this he gave to each a bundle of sticks, and asked them to see who could break his bundle in two. Five of them tugged and strained and did their best to break the bundles by main strength. But the sixth untied his bundle and broke the sticks one by one. On him the father bestowed his kingdom.

This simple principle of doing things gradually explains many of our simple machines. Let us see how it applies. Why is it easier to climb a steep hill by a crooked path than by a straight one? Why is it easier to roll a heavy barrel up a tilted board than it is to lift it straight up to the same height? Both of these are cases of doing things gradually, cases in which the principle used is called the principle of the inclined plane. If a barrel weighing three hundred pounds is to be lifted to a height of one foot, three hundred foot-pounds of energy must be used. If it is lifted straight up all this energy must be applied at once. But if it is pushed up an inclined plane three feet in length, and the pushing power is applied parallel to the plane, then only one hundred foot-pounds need be applied at once. In other words, we have to move the barrel three times as far, but, as compared with lifting it up straight, we have to work only one-third as hard while we are doing it. 
Take the case of winding up a well-bucket on a windlass (see page 55). Suppose the circumference of the circle described by the handle of the windlass when it is turned is five times as great as the circumference of the axle on which the rope is wound. Then, for each foot that the bucket ascends, your hands pushing the handle must move five feet. In other words, the work of lifting the bucket one foot is distributed through a five-foot effort, rather than concentrated in a one-foot effort, as it would be if you pulled up straight. So it is just five times as easy to push the handle one foot as it would be to pull the bucket up one foot. It is just like breaking five sticks one at a time instead of trying to break them all at once. What you may not be able to accomplish by one great effort, you can accomplish by a continuation of small effort, and this in the end accomplishes as much as some stronger person might be able to accomplish all at once. The amount of work done is the same whether it be done all at once or gradually, with the great advantage in favor of the gradual method that it enables us to do things which by direct methods we cannot do at all.

Take the case of prying up a heavy stone with a stick or a crowbar. In order to get a purchase you place a piece of wood or stone under the crowbar, near the thing to be pried up. The crowbar is a lever. The thing that gives the purchase is the fulcrum. Now suppose it is one foot from the fulcrum to your hands, and four inches from the fulcrum to the thing you are prying up. Then for every inch that the lower end of the bar rises, your hands at the other end must push down three inches. If you put all your strength and weight on the end of the bar, and move it down three inches, that strength and weight is multi- 
plied three times as applied to lifting the heavy stone one inch. Do you see that the same principle is involved?

Take the case of a pulley (see Fig. 49). The object to be lifted is held up by two lengths of rope, one of these being fastened to the hook under the upper pulley, the other passing over it and down to your hands. Now do you see that to lift that object one foot you must pull the rope two feet? This means that your effort as applied to lifting the weight will be doubled, though it will operate through only half the distance that you pull the rope. By arranging a third pulley, the strength of the pull

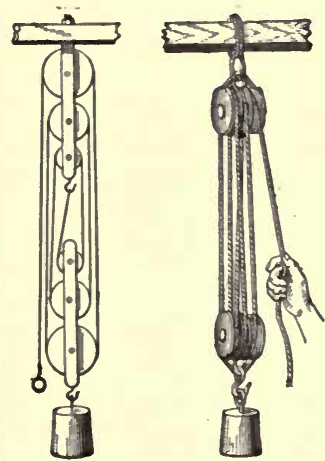

Fic. 50.-Compound pulleys. on the weight may be trebled, the distance through which the pull must be

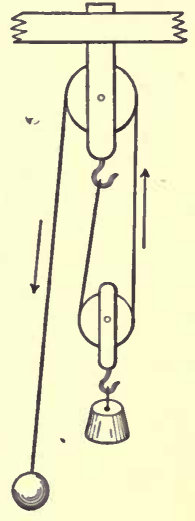

FIG. 49.-The simple pulley. made being, of course, also trebled. You may have seen houses moved by a combination of windlass and pulleys, and you must have noted that the horses turning the windlass move much faster than the house which they are moving. It is the same principle at work. The more you increase, by extra pulleys, the power applied to the object to be moved, the longer must be the pulling done at the other end (see Fig. 50).

This principle may be expressed mathematically. The 
power expended multiplied by the distance through which it is expended is equal to the weight moved multiplied by the distance through which it is moved. In other words, the work done is equal to the force expended multiplied

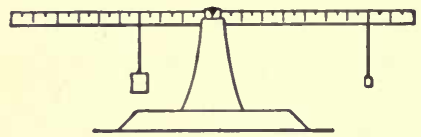

Fig. 51,-Principle of the scales. by the distance through which that force acts.

A lever, of which you have seen the crowbar to be an example, is evidently a device which increases power at the expense of speed, which is another way of saying that the job is done gradually. Evidently, also, three things are essential to a lever; namely, the point at which the power is applied, the point at which it is exerted, and the point of purchase (the fulcrum). These points may be variously arranged with reference to each other, and on this basis levers are divided into three classes.

A lever of the first class is one in which the fulcrum is between the applied power and the resistance. The crowbar is a lever of this type. So is a pair of scales on which your weight is counterbalanced by a much smaller weight at the end of

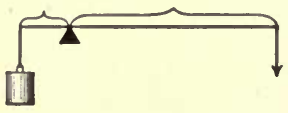
a bar. Another weight slides to

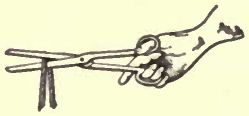

Fig. 52.-A lever of the first class. and fro on the bar. The heavier you are, the more weight it takes to bring down the bar (see Figs. 51 and 52 ).

In a lever of the second class the resistance is between the applied power and the fulcrum (see Fig. 53). This is well illustrated by the nutcracker, which also well illustrates 
the gradual application of power. You apply power gradually to a nutcracker so that the shells will not fly on the floor and the kernels be crushed. A wheelbarrow is another lever of this class.

In levers of the third class it is the applied power which is between the fulcrum and the resistance (see Fig. 54).
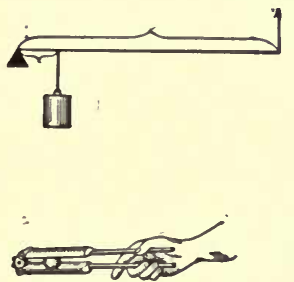

Fig. 53.-A lever of the second class.

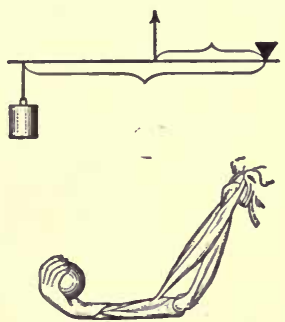

Fig. 54.-A lever of the third class.

This class of lever you can illustrate by straightening out your arm and then raising your hand to your shoulder. Your elbow is the fulcrum, and the weight of your forearm is the resistance. The power is applied at that point in front of the elbow at which the tendons of the muscle of your upper arm (biceps) are attached to a bone of the forearm. You lift the forearm by contracting the upper arm, but the power is applied just in front of the elbow.

\section{QUESTIONS}

I. Explain the principle of the inclined plane.

2. Why is it easier to lift a thing with a windlass than by hand?

3. If a two-hundred-and-forty-pound stone were on the short end of a lever, eight inches from the fulcrum, and if the long end 
of the lever were four feet from the fulcrum, how much strength would it take to lift the stone by means of the lever?

4. Explain the pulley.

5. Explain the difference between levers of the first, second, and third classes.

6. A ton of coal must be raised twelve feet. The force which can be applied is one hundred and fifty pounds. What is the shortest inclined plane which can be used for this purpose?

7. In what class of levers do the following belong: the drawbridge, the teeter-totter, the spring-board, the can-opener? 


\section{CHAPTER XV}

\section{WORK AND ENERGY: GRAVITATION}

Energy Defined. - Behind work lies energy. Work is what is done. Energy is what does it. Energy is that by means of which anything moves or changes other things.

The word force has a meaning similar to that of energy, but there is a difference you should note. Energy is a more general word than force. By force we usually mean a specific kind of energy. Thus we speak of the force of gravity rather than of the energy of gravity. Energy is a quality which all forces possess. Forces differ in their nature. Energy is the quality which is common to them all.

Forms of Energy. - Doubtless you have heard the expression "forms of energy." Heat, light, electricity, and the fall of bodies are manifestations of different forms of energy. We call them forms of energy, and we find that they can be transformed into each other. This you have learned, as in the case of transforming water-power into electricity (see page 70). You have also learned of the law of conservation of energy (see page $7 \mathrm{I}$ ). This law may also be stated as follows: no form of energy can be increased or diminished except when some other form of energy is diminished or increased. The same quantity of energy is present in the world to-day as existed ages ago. You cannot increase this total amount of energy and you cannot take from it. Whenever energy is expended 
it is either transmitted to some other body or transformed into some other form.

Take the case of the windlass and the well-bucket (see page 55). Suppose, by winding, you have raised the full bucket up to the axle on which the rope is wound. The energy you expended in pushing the handle of the windlass is now transmitted to the full bucket at the top of the well. The elevated position of the water in that bucket, as compared with the water in the well from which it came, is an investment of energy. All you have to do to prove this is to drop the bucket. What happens? Down it plunges, and round and round the handle of the windlass spins, far faster than you turned it in the opposite direction. Thus the energy which was transmitted to the full bucket by the winding of the handle is rapidly transmitted back again whence it came. Part of it is expended in the force by which the axle unwinds, and part of it in the force with which the bucket hits the surface of the water in the well.

Two Kinds of Energy. - Here evidently are two kinds of energy. The full well-bucket at the edge of the curb had energy because of its elevated position. The handle, when you were turning it, had energy because of its motion. Energy possessed by a body because of its position or condition is called latent or potential energy. Energy possessed by a body because of its motion is called kinetic energy. The former may be readily changed to the latter, as when you dropped the bucket from the brim of the well. A brick at the top of a building possesses an amount of potential energy directly proportional to its weight and its height above the surface of the earth. If the brick 
be shoved off, this energy at once becomes kinetic. If it falls in the mud, it expresses itself in the depth of the hole made in the mud. If it hits some one on the head, the pain it gives him will be a rough measure of its energy. So we see that energy when merely potential accomplishes nothing. It may lie unexpressed for ages. But once it becomes kinetic, something happens. Kinetic energy is the energy that does things.

The kind of energy you have just been considering is due to the operation of the law of gravity. You know that energy may be also due to the operation of the laws of heat, or of light, or of electricity, but, whatever the law of nature involved, or the form of energy under consideration, the principle of kinetic and potential energy always applies. Thus in coal there is much potential energy, irrespective of its position. This energy is due to condition. It expresses itself in heat when we burn the coal. Heat is a kinetic form of energy. It comes from the coal, because the molecules of coal are in such condition that, when burning, they unite rapidly with oxygen, and give off heat in connection with this process.

Gravitation. - Later we shall discuss those manifestations of energy known as heat, light, and electricity. But let us now consider the law of gravitation. We have already considered many manifestations of energy which are due to its operation. One of these is the fact that water runs down-hill. This is one of the first great facts whose effects you were asked to consider. You have noted its effects. Now let us note its cause.

Whether it be the fall of water or the fall of an apple, the same principle is at work. As you may have heard, 
it was the fall of an apple which set that great scientist Sir Isaac Newton $\left(1642^{-1727}\right)$ to pondering on this problem; the problem of why the apple falls. The great conclusion which he reached is known as Newton's law of universal gravitation. It may be stated as follows:

Every mass of matter in the universe attracts every other mass with a force which is directly proportional to the product of these masses, and is inversely proportional to the square of the distance between their centers.

According to this, you see, the apple attracts the earth as well as the earth attracts the apple. But the apple is so very, very small as compared with the earth that its effect is not noticed.

It is surprising how many things the law of gravitation explains. You have learned that the tides are explained by the mass attraction or gravitation of the moon acting on the water of the seas. But a far greater thing is the fact that the paths of the heavenly bodies are explained by gravitation. You have heard of the "stars in their orbits." By orbit is meant the path or course which is determined by effects of gravitation, or "pull" of heavenly bodies upon one another. The moon is held in its orbit by the mass attraction of the earth, and the planets (of which earth is one) are held to their orbits around the sun by the attraction which its mass exerts upon them. So, also, the stars in their courses are believed to be suns around which other planets wheel in response to the same law.

Weight. - But to come back to earth. We can see now that the weight of any object is nothing more than the effect upon it of the law of gravitation. Weight is an expres- 
sion of the tendency to be drawn to the center of the earth. Every particle of matter has this tendency. The denser an object is, the greater its number of molecules and, hence, the greater its weight.

At the poles of the earth, the distance to the center of the earth is less than at the equator. Hence, an object, according to Newton's law, at one of the poles should weigh less than the same object at the equator. Actual measurements show this to be the case.

We must not forget that this law of mass attraction works both ways. That is, the smaller object attracts the greater as well as the greater the smaller, though the only visible effect may be the effect on the smaller object. The level of the ocean along the west coast of South America has been found to be higher than its level at other places. This is believed to be due to the mass attraction of the huge range of the Andes Mountains. The attraction of the earth as a whole tends to keep the oceans at the same level, but the mass of the Andes above the waterlevel is sufficiently great to cause in its neighborhood a measurable variation of that level.

Why does oil ascend the wick of a candle? This is due, at least in part, to the effect of the mass attraction of the wick upon the molecules of oil.

Note that the explanation of facts by the law of gravitation is a very different thing from explaining gravitation. That is a thing which no one has explained. This is one of those great laws of nature which, in elementary work at least, we do not attempt to explain. We simply call these laws causes and seek to see the connection between such causes and their effects. It is very important to realize that given causes do inevitably produce certain 
effects. But to attempt to explain the cause of the causes is philosophy rather than science.

\section{QUESTIONS}

I. What is the difference between potential energy and kinetic energy?

2. What kinetic energy and what potential energy are involved in a watch? a cannon? a dynamo? a piece of coal?

3. State Newton's Law of Universal Gravitation.

4. Why does the earth move around the sun, instead of flying off into space?

5. Would a piece of lead weigh the same at the top of Pike's Peak as at sea-level? 


\section{CHAPTER XVI}

INTRODUCTORY AS TO HEAT: DISCOVERY OF FIRE

What Is Heat? - We know how to measure heat and we know how to feel it. But what is it?

It is easy to prove that our feeling of heat is not a scientific means of measuring it. What seems hot to one person may seem cool to another. If you come into a room after a brisk walk on a winter day, it may seem uncomfortably warm to you, while it may seem uncomfortably cool to a person who has been in it for some time. If you place one hand in hot water and the other in cold, and then transfer both to lukewarm water, the lukewarm water will feel cool to the hand that has been in hot water. After you have been eating ice-cream, does ice-water "taste" as cold as it did before? A piece of wood and a piece of marble may be of just the same temperature, and yet the marble will feel much cooler than the wood. Why is this?

A little of this sort of thing is quite enough to prove that the feelings of a human being for heat and cold are not a safe guide to the actual facts as to heat and cold. One of the characteristics of science is that it deals with facts rather than feelings. Therefore scientific instruments are needed for recording precisely the facts as to heat and cold. With one of these, the thermometer, you are already familiar. It records the intensity or degree of heat. The degree of heat is called temperature, so, to speak exactly, the ther- 
mometer is a measure of temperature rather than of heat. The amount of heat in a substance is another thing. That may be measured by another instrument, the calorimeter, of which more later.

The thermometer was invented by Galileo, in 1593, one hundred and one years after the discovery of America. Before that there was no science of heat; men judged of it solely by their feelings. When men began to study heat with the aid of the thermometer they discovered a number of things about it which they could not discover by their feeling alone. Thus the thermometer shows that the temperature of boiling water does not increase however long it continues to boil, a thing that was not discovered when the temperature of objects was judged by fingers instead of thermometers. Thermometers also show that, when heat is applied, the temperature of some substances rises much more rapidly than the temperature of others. Thus mercury is thirty times easier to heat than water; it requires only one-thirtieth as much heat to raise the temperature of a given quantity of mercury one degree as it requires to raise the same amount of water one degree.

Such facts gave the early scientists much more light on the subject of heat than they had had before. Their theories as to heat had to be revised in the light of new evidence. This sort of thing is constantly happening in science. Investigators are constantly discovering new facts which require the recasting of old theories. Now as to heat, men have had a number of interesting theories. It was once supposed to be due to the presence of a mysterious fluid known as caloric. And as to fire, the ancient Greeks believed that it was due to the presence of another 
mysterious thing which they called phlogiston, a thing which every inflammable substance was supposed to possess. In the process of burning, the phlogiston was supposed to escape.

The Kinetic Theory. - But the modern explanation of heat is based upon the kinetic theory. You learned in the last chapter that the theory of gravitation explains many things. But you will find that this kinetic theory is even more remarkable as to the number of things that it explains. You have just learned that kinetic energy means energy at work. Now the kinetic theory is a theory of motion. You have learned that all substances, whether gaseous, liquid, or solid, are composed of very small particles. A single drop of water is composed of many millions of these particles. They are called molecules, and the kinetic theory is the theory that molecules are in motion. That is to say, they move as much as conditions permit them to move. In a solid substance this motion is, of course, very limited, while in a gas it is not so limited. This kinetic theory helps us understand why gases diffuse so rapidly. It also helps us understand why liquids evaporate; molecules at the surface are continually flying off into space. This theory is too complex for full explanation in this book, but even a very general idea of it will help you understand many common phenomena.

If heat is due to the activity of molecules, then the process of heating a substance is simply a process of making its molecules move more rapidly, and the rise in temperature of the heated substance is one of the results of this acceleration (increase in speed) of its molecules. So we may say that heat is one of the results of molecular 
motion. The motion of the molecules is a cause, of which heat is one of the effects.

If we explain heat as a phenomenon of molecular motion, it is easy to understand that it is a form of energy. This is further evident when we consider what results from the transmission of heat to the water in the boilers of a steamengine. We know that the heat in the boiler of a locomotive, by means of the pressure of the steam it produces, can be changed into motion. We also know that motion can be changed into heat again. We change motion into heat every time we strike a match; even a slight rub develops enough heat to set fire to the sensitive chemicals that compose the "head" of a match. Even safetymatches require a slight rub on the specially prepared surface, and this rub increases the heat just enough to make the match ignite. This principle is also evident when a train gets a "hot box." We know that this heat is a result of friction. We know that lubricants (oil, graphite, vaseline, etc.) must be used in machines wherever there is danger of overheating on account of friction. Friction is the rubbing together of two bodies. Evidently, there can be no friction unless there is motion. It was probably by means of friction that man first obtained fire. We do not know this to be true, but it seems probable.

Think then of the surprise and terror of that ancient savage who first discovered fire! Picture him as he may have squatted in the sun on some hot beach. About him lay plenty of driftwood, dry as tinder, as you yourself may have seen it on lake or ocean beaches. He rubbed the sides of two pieces briskly together, perhaps to fashion one into a shape he wanted, perhaps just to be doing something. As he rubbed hard and fast, suddenly he noted a 
little curl of smoke arising. This was interesting, but not perhaps alarming. Anyhow, he kept on rubbing to see what would happen. Suddenly there came a spark, and then a burst of flame. The dry wood caught and blazed. When this happened, the discoverer of fire probably howled in terror and ran for his life. We can almost see him jabbering in his excitement to his family, telling of the new devil he had discovered. Perhaps the next day they visited the place, and, since no harm came of that, they may have repeated the experiment. But in the nature of things it must have been a good while before they found out how to use this new discovery for their own. comfort and convenience.

Bonfires probably warmed them on cool days long before they discovered the art of cooking. However, it is easy to see that the discovery of fire ultimately made a great difference in the ancient world. For fire is the means by which the wonderful energy of heat is placed at man's service. Sometimes it escapes his control and works with destructive violence. Men doubtless saw fire coming from volcanoes before they learned how to produce it for themselves; doubtless they thought of it as some terrible thing which, if liberated from earth's interior, would destroy them all. Perhaps the first discoverer of fire thought he had liberated it. In any case, it is not difficult to understand why there were fire-worshippers in those days.

\section{QUESTIONS}

r. What is meant by "cold"?

2. Why do we "strike" matches?

3. How did men obtain fire before matches were invented?

4. What is a "hot box"? 


\section{CHAPTER XVII}

\section{MEASUREMENTS OF HEAT}

You learned in the preceding chapter that thermometers and calorimeters are instruments for the measurement of heat. A thermometer measures temperature, which is the degree or intensity of heat, while a calorimeter measures its amount. Both instruments are extremely useful.

The Thermometer. - The most familiar form of thermometer is the mercury thermometer, to which you gave some attention when studying the barometer (see page 58). It consists of a glass bulb and a tube of very small caliber arising from the bulb (see Fig. 55). Mercury fills the bulb and rises and falls in the tube as variations in the intensity of heat cause it to contract or expand.

Since we have noted that increase of heat is associated with increase of the activity of molecules, it does not surprise us to find that this involves expansion of the substances heated. But changes of temperature produce other effects besides expansion and contraction. They may change the state of a substance, as from solid to liquid to gas, as in the case of water. Or they may produce changes in its quality which are not so obvious. Thus, in tempering steel, the quality given to the steel depends upon the temperature changes to which it has been subjected. All such changes are due to changes in the nature of the molecules, 
But to go back to the thermometer, and the expansions and contractions which it records. If increase of heat causes expansion of substances in general, then we may expect that the glass of the thermometer will expand when the mercury expands, and contract when it contracts. And it does. Evidently, if the glass expanded and contracted at the same rate as the mercury, the thermometer would be valueless. But it does not. The glass expands and contracts only one-seventh as much as the mercury. Hence, what a thermometer actually records is the difference between the expansion and contraction rates of mercury and glass, and its value as a recording instrument depends on the fact that there is such a great difference between these rates.

In the manufacture of thermometers mercury is poured in at the top of the tube (then open) until it fills the bulb and part of the tube. Then heat is applied until the mercury has expanded to the top, and the top is closed by melting (fusing) the glass at that point. Then the bulb is surrounded by finely broken ice. When the mercury has stopped falling (contracting) the point at which it stands is marked on the glass.

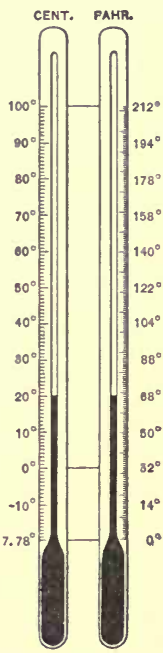

FIG. 55.-The mercury thermom. eter. That point is called the freezing-point-the freezing-point, that is, of pure water; different substances have different freezing-points. The next thing is to mark the boilingpoint. This seems a perfectly simple thing to do until you remember that the boiling-point of water is not always the same. You recall that water boils at a much 
lower temperature on mountains than it does at sealevel; that its boiling-point depends upon the atmospheric pressure. Evidently, it is desirable to mark thermometers with reference to the boiling-point of water at a fixed and known pressure. So the unfinished thermometer is placed with its bulb and thread of mercury completely enveloped in steam which rises from perfectly pure water, the atmospheric pressure being known to be standard. The point at which the mercury stops rising is marked; this is the boiling-point.

The next thing to do is to graduate the thermometer; that is, to mark it off into degrees. The number of degrees to be marked off between the freezing-point and the boiling-point depends upon what kind of thermometer it is to be. If it is to be a Centigrade thermometer, there will be just one hundred degrees between these two points, the freezing-point being zero. (Centigrade means "hundred degrees.") The degrees below freezing are indicated by a minus-sign.

But if it is to be a Fahrenheit thermometer, the freezing-point will be marked $32^{\circ}$ and the boiling-point $212^{\circ}$, the interval between these two points being marked off into 180 equal parts, each part representing one degree. Similar divisions are made both above the boiling-point and below the freezing-point. The zero on the Fahrenheit thermometer is the lowest temperature obtainable by using a mixture of ice and salt, such as is used in freezing ice-cream.

The thermometers in ordinary use in America are Fahrenheit, but in nearly all scientific work and generally in Europe the Centigrade is used. The Fahrenheit is used by the United States Weather Bureau and by physicians. Fahrenheit is named from Gabriel Fahrenheit, a Ger- 
man scientist, who introduced the use of mercury in thermometers in 1720 , and established the scale which bears his name. The Centigrade instrument was introduced by Anders Celsius, a Swedish astronomer, about 1742 ; it is sometimes called the Celsius thermometer. F. is used as abbreviation for Fahrenheit, and C. for centigrade.

At $-38.8^{\circ}$ C. mercury freezes. Obviously, then, a mercury thermometer cannot be used for reading temperatures lower than this. Some substances with a still lower freezing-point must be substituted. Alcohol does not freeze until $-\mathrm{III}^{\circ} \mathrm{C}$. is reached. So alcohol thermometers are used on arctic expeditions or whenever very low temperatures are to be recorded.

The thermometer which Galileo invented in

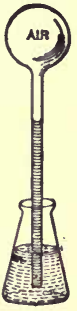

FIG. 56.Galileo's thermometer. I 593 (see page I24) was quite a different instrument. It depended on air-pressure to maintain the column from which the reading was made. The bulb was at the top of the tube instead of at the bottom, and was large instead of small. The tube was open at the lower end, and that end was immersed in some colored liquid (see Fig. 56). To start this apparatus the air in the bulb was heated. Then as this air cooled down to the temperature of its surroundings, it contracted, and the force of atmospheric pressure caused the ascent of the liquid in the tube. (Compare with the action of a suction-pump.) Evidently, the liquid in the tube would rise as the air above it cooled, and would descend as this air became warm, thus reversing the action of a mercurial thermometer. The temperature was read by means of a graduated rule placed alongside the tube. Such a thermometer is unsatisfactory 
to record large changes of temperature, but it is very sensitive to small changes and is frequently used to-day in experimental work.

The importance of the thermometer in connection with the study of weather is obvious. It is also an invaluable instrument for the physician. The normal temperature of the human body is $98.4^{\circ} \mathrm{F}$. Variations from this temperature indicate disease. Especially in the case of fevers, careful records of the temperature of the patient must be kept in order to guide the physician in his treatment. In commercial processes such as the refinement of oil or sugar, or the manufacture of steel, temperature readings are of the highest importance, since they indicate physical changes which greatly affect the character of the product. Scientific kitchen management also calls for frequent use of the thermometer to show the heat of an oven or for other purposes.

The Unit of Heat. - The unit of heat, measured as to its amount, is the calory. It is that amount of heat necessary at standard pressure to raise the temperature of I cc. (cubic centimeter) of water $\mathrm{I}^{\circ} \mathrm{C}$. It is also the amount of heat which I cc. of water gives off when its temperature falls $\mathrm{I}^{\circ} \mathrm{C}$., which is what we should expect to be the case, according to the law of conservation of energy. In other words, the amount of heat which a substance acquires when its temperature rises a certain amount is identical with the amount it gives off when its temperature falls by the same amount. This has been proved many times by actual measurements.

The number of calories needed to raise the temperature of a substance $\mathrm{I}^{\circ} \mathrm{C}$. (or the number which it gives out 
when its temperature falls $I^{\circ}$ C.) is called the specific heat of that substance. You have already learned that some substances "heat up" more rapidly than others, which goes to show the fact that substances vary as to their specific heat. The lower the specific heat, the more quickly a substance heats up. Thus mercury, whose specific heat is low, heats up thirty times as quickly as water; that is, to raise I cc. of mercury $\mathrm{I}^{\circ} \mathrm{C}$. requires the application of only one-thirtieth of a calory.

With the exception of hydrogen, water has the highest specific heat of any known substance. Since, therefore, water absorbs more heat than other substances as its temperature rises, it follows that it gives out more heat as its temperature falls. So we perceive why water is so useful in heaters, in hot-water bags, or in foot-warmers; no other substance could be used which would give out so much heat. Have you ever noticed how much more likely you are to burn your mouth with hot chocolate than with hot coffee or tea? What is the explanation of this?

The calorimeter, which measures the number of calories in substances, does this by measuring the amount of heat which they give off to a given amount of water. There are various types of calorimeters. The simplest is a metal vessel covered with some non-conductor (usually felt) to prevent the loss or gain of heat from the surrounding air. In this vessel there is a quantity of water of known volume and temperature. The substance to be tested is put into the water and the change produced in the temperature of the water carefully noted. From this can be estimated the number of calories which have been added or subtracted by the substance introduced. 
By the same means we can test substances of equal temperature to determine which contains more actual heat than the other. Thus if equal amounts of iron and lead be tested at equal temperatures it will be found that the iron gives off over three times as much heat as the lead; that is, the specific heat of iron is three times as great as that of lead.

Calorimeter tests are especially important in determining relative values of fuel, especially of different kinds of coal. They are also important in determining the "fuel-value" to the body of various kinds of heat-producing foods. But such tests as these require a more complicated apparatus than the one described. They require that the substance to be tested be actually burned under water. This is done in a closed vessel by means of electricity and compressed oxygen. The heat which they impart to the water is then computed. Of course this is very delicate work, since it is absolutely necessary that all foreign sources of heat gain or loss be either eliminated or else known so accurately that they can be allowed for in the computations.

\section{QUESTIONS}

I. Explain the principle of the thermometer.

2. How are thermometers made?

3. What is the difference between Centigrade and Fahrenheit thermometers?

4. What kind of thermometer is used on arctic expeditions, and why?

5. Explain Galileo's thermometer.

6. What is the calory?

7. What is "specific heat"?

8. Describe the calorimeter. 


\section{CHAPTER XVIII}

\section{HEAT AND COLD}

What Cold Is. - Darkness is lack of light. Black, as you may have heard, is not really a color. It is lack of color. Similarly, cold is lack of heat. It is not a positive thing. It is a negative thing.

Yet we are in the habit of thinking of heat as one thing and of cold as another. We speak of cold as a positive cause of certain effects, when the cause, strictly speaking, is withdrawal of heat. One may say on a cold day that the cold "gets into the house," or "gets into one's bones," when really it is heat that gets out. Ask any one why icecream freezes, and he is likely to say that it is "because the cold of the ice gets into the freezer," when really it is because the heat of the cream gets out of the freezer.

It is not important to correct such inexactness of speech, but it is important to correct an inexactness of ideas which may lie behind such speech. That is, there need be no objection to speaking of cold in the way we do, if we understand the real facts involved. Many such inaccurate forms of speech have come into such common and general use that it is practically impossible to correct them. So, in such cases, it is not so important to say what we mean as it is to know what we mean when we say it; the form of speech may be inaccurate, and yet through usage and general understanding, it may have come to convey an accurate meaning. So in this chapter we shall use the word cold when we really mean lack or low amount of heat. 
Freezing. - Let us take first the case of the freezing of ice-cream by means of surrounding it with a mixture of ice and salt. This seems a simple process, yet when we stop to analyze what happens and why it happens, we find that it is by no means as simple as it seems. We also find that an understanding of this process helps us to understand many other phenomena of nature.

As we turn the handle of the freezer we note that the mixture of salt and ice begins to melt. It melts more rapidly than it would if we did not stir it somewhat by our turning. Evidently, the stirring stimulates the action. Similarly, we saw that stirring stimulates the absorption of air by water. Now if, after some turning, we place our hand on the metal cylinder which contains the cream, we find that it is very cold, colder even than ice. Why is this and how has it happened?

What has happened is that heat (a form of energy) has been withdrawn from the contents of the freezer. Now heat is a result of the motion of molecules. Therefore, reduction of the heat of a substance means reduction of the motion of its molecules. You have noted in the case of water that increase of heat, if we start with ice, involves the change of water from a solid to a liquid and finally to a gas; in other words, change of the rate of molecular motions in a substance involves, if carried far enough, changes in the state of that substance. Now if we reverse this process, subtracting heat instead of adding it, we may rightly expect the changes in the state of a substance (liquid, solid, and gas) to occur in reverse order. What has actually happened in the case of the cream in the cylinder of the freezer? We started with it as a liquid; we note that now it is being gradually transformed to a 
solid. We do not have to look at it to tell this; it is indicated by the fact that the handle of the freezer gets harder and harder to turn. Evidently, then, the withdrawal of heat, which means the reduction of molecular motion, also involves the transformation of this liquid into a solid.

Heat Conduction. - But how did this heat get out through the wall of the metal cylinder? You may accept the idea of heat being due to molecular motion, but it may be a little difficult to see how heat, if this be its nature, is transmitted through such a solid substance as the metal of this cylinder. But did you ever sting your hands by striking a baseball with a bat? Or suppose that your body were protected by tight-fitting metal and some one were to strike you hard with a ball or with a bat. Wouldn't you feel the effect of the blow? Then think of the millions of millions of blows which the molecules of a liquid or a gas are constantly striking against the walls of any vessel which contains them. These walls, like the wood of a ball bat, are capable of transmitting the effects of blows struck upon them, and the phenomenon of the transmission by solids of molecular blows struck upon them is called the conduction of heat. Some substances are better conductors of heat than others; that depends upon the nature of their molecular construction. Wood is a poor conductor of heat, while metals are good conductors. You would have a great deal of trouble in freezing ice-cream if a wooden cylinder were substituted for the metal one. Why do teakettles and coffee-pots usually have wooden handles?

But what becomes of the heat that passes out through the metal cylinder? Evidently, according to the law of the conservation of energy, something must happen to 
this heat. It cannot be lost, and certainly there is no evidence that energy in the form of heat is passing into the air around the freezer. What actually happens to it is that it is absorbed by the liquefying salt and ice. The heat energy which was present in the liquid which you put into the cylinder is now present, in another form, in the liquid which has formed outside the cylinder.

You started with a liquid inside and with solids packed around it. But you end this process of freezing ice-cream with a solid inside and with a good deal of liquid outside. The heat which was in the liquid cream has now gone into the liquid water and salt, and as a result you have the solid ice-cream, which was what you wanted.

But what, you may ask, is the need of the salt? Why is a mixture of salt and ice (a freezing-mixture) a better heat extractor than pure ice? This is because more heat is absorbed in the melting of ice and salt together than is absorbed in the melting of ice alone; there is the heat which is absorbed by the melting ice plus the heat absorbed by the melting (or dissolving) salt.

That salt absorbs heat when it dissolves, you can prove by a very simple experiment. Immerse the bulb of a thermometer in a tumbler of water. When you are sure that the mercury is stationary, add quickly a spoonful of salt. How much does the mercury drop? Of course the mercury presently goes up again to its original mark because the water absorbs from the air the heat which it gave up to the dissolving salt. But the heat absorbed by the salt is still there, there to remain until the salt solidifies again and gives it up.

The same principle is involved in the fact that the freezing-point of salt water is much lower than the freezing- 
point of fresh water. Ice forms in the ocean only at much lower temperature than in fresh water. Solutions in general have lower freezing-points than their solvents taken alone. In other words, the act of dissolving is in itself an absorber of heat, and in solutions this extra heat must be overcome before freezing occurs.

Here again we have a set of phenomena which are clear and understandable only if we keep the kinetic theory in mind. Let us remember that molecular motion (a form of energy) is much greater in liquids than in solids. Therefore, a substance in changing from a solid to a liquid must thereby acquire more of this form of energy, $i$. e., of heat. And when it changes from a liquid to a solid, it must give up heat.

In the study of geography you probably learned that a large lake has an important effect in winter in warming the air which is over it. This is due to the principle you have just been studying; as the water is changed from liquid to ice a great deal of heat is given out, enough to produce a marked effect on the weather of the surrounding region. Thus, Chicago in winter, solely on account of being on Lake Michigan, is often many degrees warmer than other cities farther inland, and even much farther south. It is common in very cold weather to place tubs of water near vegetables stored in cellars. The heat given out by the freezing water may be enough to keep the vegetables from freezing.

Also in considering the phenomena of heat and cold, or, more accurately, of more heat and less heat, let us constantly remember that our own feelings of heat and cold are purely relative, and are not at all accurate indicators of the real state of a substance as to heat. Heat is 
molecular motion, but what we commonly call heat is simply that degree of molecular motion which we happen at the time to feel, but there are vast amounts of heat all about us which we never feel at all. Heat is a great phenomenon of nature of which our senses alone enable us to perceive only a tiny fraction.

\section{QUESTIONS}

I. What is cold?

2. Explain conduction of heat.

3. Explain how ice-cream is frozen.

4. Why does the water of the ocean not freeze at the same temperature as the water of the Great Lakes freezes?

5. Why is Chicago warmer in winter than cities farther away from the lake? 


\section{CHAPTER XIX}

\section{SOME EFFECTS OF HEAT}

You have noticed that the principal effect of "change of temperature" upon substances is to change the volume. The rule is that increase of heat causes expansion, and decrease of heat causes contraction. Change from solid to liquid or gas means expansion, with the exception of the change of ice into water. The kinetic theory helps us very much in explaining why changes in heat involve changes in volume. You have found that increase in heat means increase in the rate of the movements of molecules; that is, the hotter a substance is, the more rapidly its molecules are moving. And the more rapidly its molecules move, the larger the space they tend to occupy. Thus, the heating of water "speeds up" the movements of its molecules; they fly off at the surface more abundantly (evaporation), and thus we get. a rapid transformation from liquid to gas.

Can there be such a thing as the application of heat to a substance without increase of its temperature? Evidently, that depends upon what happens to the heat. If this heat simply increases the rapidity of the motions of the molecules of the substance to which it is applied, then the heat of that substance increases. But if the heat energy applied to a substance is exerted in overcoming the force of cohesion of its molecules, as in transforming a solid to a liquid (or a liquid to a gas), then the heat energy applied to that substance is transformed, and 
does not cause an increase in the temperature of the substance. The heat applied to it is transformed into that potential energy which a substance acquires when it changes from a solid to a liquid, and which it gives up again in the kinetic form of heat when it changes back to a solid. This principle was illustrated in the freezing of ice-cream. The temperature of the freezing-mixture does not increase although the temperature of the substance frozen decreases greatly; the heat withdrawn from the cream is used in the change of ice and salt to liquid; it is "stored" in this liquid; it has become potential rather than kinetic. You have also learned that the temperature of boiling water does not increase no matter how much heat is applied to it, for the heat is used in the transformation of molecules from the state of liquid to the state of gas.

We can demonstrate this principle even more simply and clearly by placing in different vessels equal amounts of ice and water, and applying to them equal amounts of heat. In the case of the ice, the temperature of the water which results from its melting will not rise until all the ice is melted; all the heat applied is being consumed in overcoming the solidity of the ice; it ceases to be heat, having been expended in the work necessary for changing a solid to a liquid. But in the case of the water, its temperature will begin to rise from the moment that the heat is applied. By the time that the ice in the other vessel is all melted, the water, to which no more than an equal amount of heat is being applied, will have increased in temperature $80^{\circ} \mathrm{C}$.

This gives a simple means for computing the amount of heat consumed in the changing of ice to water; the amount of heat involved in changing any solid to a liquid 
(or the reverse) is called the heat of fusion of the substance. The heat of fusion of ice is eighty calories; i. e., eighty calories of heat are absorbed in the melting of each gram of ice; also for each cc. (gram) of water that freezes, eighty calories are given out to its surroundings. Here again we get an idea of why large bodies of water in cold weather have such a warming effect upon the surrounding regions.

Since the change of a liquid to a solid involves, as you have just noted, the giving off of heat, what heat effect would you expect in connection with the change of a liquid to a gas; that is, in connection with evaporation? The change of liquid to solid is a process of condensation; that is, a process of reducing molecular motion. But the change of a liquid to a gas is a process of expansion, a process of increasing molecular motion. Since the former process releases heat, it follows that the latter process absorbs it. This we find to be the fact. Evaporation is a cooling process; it absorbs heat from its surroundings. This you have already learned, both in this book and elsewhere. The added discomfort we feel on hot days when the atmosphere is humid (full of moisture) is due not only to the perspiration which stays on our skins; it is due even more to the failure to have heat drawn off from our skins by the process of evaporation. Hot climates where the air is dry are even more comfortable than cooler climates where the humidity of the air interferes with evaporation. In southwestern United States it is common to keep drinking water cool by placing it in porous vessels and hanging these up in the air; the water will become cooler than the air which surrounds it on account of the heat carried off in the process of rapid evaporation in the dry air. Canteens are usually wrapped 
in cloth for the same purpose of keeping the water within at a temperature which makes it agreeable for drinking.

Your attention has already been called to the exceptional character of the expansion of water when it freezes, and you have considered the effects which this exception produces that are beneficial to man. Now, if we begin with steam, we note that reduction of the temperature of water is accompanied by contraction, just as in other substances. In the change of steam to liquid there is a very considerable reduction of volume, and if you go on lowering the temperature, this contraction continues. At what point then does this normal contraction cease and the $a b$ normal expansion of water begin?" We find that this occurs at $4^{\circ} \mathrm{C}$; that is, at four degrees above freezing-point on a centigrade thermometer, water ceases to contract and begins to expand.

Now let us consider what effects this produces upon a body of water in cold weather. As the air over the surface of the water loses its heat, the heat of the water passes up into it. As the surface-water loses heat, it increases in weight and sinks toward the bottom, while the warmer and, necessarily, lighter water beneath rises to the surface. So, on account of these movements of the water induced by the differences in density which accompany changes of heat, the whole body of water tends to become equally chilled throughout. This process continues until the whole body of water reaches a temperature of $4^{\circ} \mathrm{C}$. Then, evidently, something different is sure to occur, inasmuch as at this point of temperature the water begins to expand instead of contract; it begins to gain in lightness instead of in weight. So the surfacewater which first cools below $4^{\circ} \mathrm{C}$. does not sink; it re- 
mains at the top and, if its temperature continues to fall to $0^{\circ} \mathrm{C}$., it changes to ice.

You see, therefore, that practically all of the water in a lake or pond must reach a temperature of $4^{\circ} \mathrm{C}$. before any ice is formed. Consequently, it is easy to see why deep bodies of water take so much longer to freeze over than do shallow ones. Also it is easy to see why lakes and ponds do not freeze solid to the bottom, and why fish and other forms of life get along quite comfortably under the ice. The ice forms a protecting barrier through which the heat of the water below it penetrates only very slightly. So the water under the ice remains at about $4^{\circ} \mathrm{C}$.; this temperature permits life to continue which would cease to exist if the freezingpoint were reached.

You have noted that changes in the temperature of the water cause movements or currents, as a result of which any reduction of temperature tends to become evenly distrib-

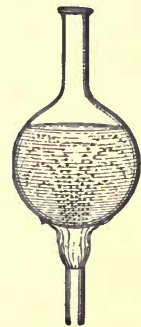

FIG. 57.-Convection currents. uted throughout the whole mass. (Would an increase of temperature at the surface of a body of water have the same effect?) Evidently, here is a means whereby heat is distributed or transported from one place to another. You have learned that heat migrates through solids by means of conduction. You now note that it may migrate through liquids (and the same is true for gases) by means of convection, for these movements of liquids or gases caused by their becoming warmer and therefore lighter than their surroundings, or colder and therefore heavier, are called convection movements or convection currents (see Fig. 57). It is due to convection that the warmer air is 
at the top of the room. It is also due to convection that great movements of air occur in the earth's atmosphere and produce thereby profound effects upon weather and climate (see Fig. 2); of this matter there will be more discussion in the chapter on seasons and weather.

\section{QUESTIONS}

I. Why is boiling water always at the same temperature?

2. What is the "heat of fusion" of ice, and how would you measure it?

3. Explain why evaporation is a cooling process.

4. Why do we feel more uncomfortable on hot moist days than on hot dry days?

5. Why will drinking water keep cool if put into a porous vessel?

6. Why does it take longer to freeze a deep body of water than a shallow one?

7. What are convection currents? 


\section{CHAPTER XX}

\section{THE ATMOSPHERE}

The Sun the Source of the Earth's Heat. - The sun is the great source of heat for the earth. Its heat comes to us through the atmosphere, and if it were not for the effects which the atmosphere produces upon this heat, the earth would be very different from what it is; indeed, if it were not for these atmospheric effects, life as it now exists would perish. It could not endure the great heat of day and the intense cold of night, which we should have were it not for the protecting and modifying effects of the atmosphere. Evidently, then, to understand the relations between life and heat, and all the other effects which the sun has upon the earth, it is quite necessary to have in mind a picture of the atmosphere.

Already you are familiar with a number of important facts about the atmosphere. You know that atmosphere and air are words which refer to the same thing. The principal difference in these words is that atmosphere is commonly used to indicate all of the air, while air is commonly used to indicate only part of the atmosphere. Thus we say that we breathe air. To say that we "breathe atmosphere" would express the same fact, but would express it awkwardly.

What the Atmosphere Is. - You nave learned that the atmosphere is a mixture of gases. You have learned that it has weight, exerting a pressure at sea-level of about 
fifteen pounds to the square inch. You have learned that this pressure is used by man in the performance of certain kinds of work. You have learned that this atmospheric pressure is less on mountain tops than it is at sealevel, and that this lessening of the pressure is gradual, being so definitely related to altitude that by means of a pressure recorder (the aneroid barometer) we may estimate the altitude wherever we are.

Density of Atmosphere. - This last fact about atmosphere indicates that the higher one goes the thinner it gets. What you know about the kinetic theory (see page 125) makes you realize that this thinning out of the atmosphere as you go up means that the molecules of the gases which compose it get farther and farther apart; the higher you go the fewer the molecules to the cubic centimeter, until presently, as is well known from the experiences of balloonists and mountain climbers, the air becomes so rarefied that it is difficult to breathe. In balloon ascents made for height, oxygen in metal containers is taken along for breathing purposes.

Balloons without passengers have gone up as high as eighteen miles, showing that even at that height the atmosphere is sufficiently dense to support them. The altitude record for balloons with passengers is between six and seven miles. At that height, air for breathing may be artificially supplied, but great discomfort results from the intense cold.

Extent of Atmosphere. - Other and very important evidence of the upward extent of the atmosphere is obtained from computing the height of meteors (shooting-stars). 
Meteors are solid bodies which come from the heavenly spaces beyond the earth's atmosphere. They move through space with great rapidity, as does the earth itself. If they approach near enough to the earth to be affected by its mass attraction (gravitation), they may be drawn into our atmosphere. When they enter it they are intensely cold; the temperature of the space from which they come has been estimated to be about $-459^{\circ} \mathrm{F}$. But as they plunge downward at tremendous speed they become red hot through friction, for now they are travelling through real substance instead of through empty space. So they glow and we see them as shooting-stars. Usually they are consumed by heat before they reach the solid surface of earth.

Meteors have been observed that were as high up as two hundred miles. So the outer limits of the atmosphere must extend beyond even that height, for meteors evidently do not begin to glow, and thereby become visible, until they have already passed far within the outer limits.

Now perhaps we can form a mental picture of this great "envelope" of earth, the atmosphere. We see that it is really a part of earth; that we live at the bottom of a great sea of air which stretches for many miles above us. Yet we know that most of the atmosphere, computed by its density, lies close to earth; half of it, by weight, lies under a height of 3.6 miles above sea-level, while threefourths of it lies under 6.8 miles. Above that level, it thins out gradually to nothingness, and we may conceive of its outer limits as like the fine spray from the top of a fountain; its particles bound off into space, and are then drawn back again by force of gravity. Beyond these vague outer limits of our atmosphere are the enormous 
empty spaces through which earth and the other heavenly bodies move in their orbits.

Relations Between Atmosphere and Heat. - Now the thing for us to do is to consider this atmosphere, and the substances which are in it, and then to see what effect it must necessarily produce upon the distribution of the heat which comes from the sun. Then we shall perceive that, like soil and water and light and heat itself, the atmosphere, through its effects on heat, as well as through its supply to us of the air we breathe, is one of these great facts of nature which has determined and continues to determine the nature of life. We shall see how small we seem to be as compared with these enormous facts and forces of nature which permit us to exist. We shall also see that the atmosphere through the effects which heat produces upon it is the chief thing which determines the distribution of water; similarly, through the effects which it produces upon heat it is a very important factor in the formation of soil. Soil formation and water distribution are, of course, two of the things upon which life depends. Thus, more and more, we come to realize that heat and the atmosphere are two great co-operating agencies whose relations determine the nature of our lives. Surely it is important that we should have some understanding of the relations which exist between them.

Let us remember also that air is below us as well as above us. It penetrates the soil and the rocks, it affects fertility, and the substances which compose it become dissolved in water and unite chemically with rock, an action similar to that which occurs when, through respiration, oxygen unites with substances in living bodies. 
Composition of the Air. - You have learned that air is made up, by weight, of four-fifths of nitrogen and onefifth of oxygen. These proportions, it should be noted, refer to $d r y$ air; the figures usually given are seventy-eight per cent nitrogen and twenty-one per cent oxygen. This leaves, you see, one per cent which is made up of other gases. Of these other gases, carbon dioxide is the most important to life, but it forms, by weight, only three-tenthousandths of the whole atmosphere. Other gases also exist in the atmosphere in small quantities.

Water vapor is a gas whose presence in air is very important to life, but, as you have noted, the amount of this gas varies so much from time to time and from place to place that it is usually regarded as something in the air, rather than as a part of the air itself, and it is dry air only which is considered when we discuss its constitution.

Air near the earth also always contains more or less of dust, and of organic matter in the form of bacteria and spores, and the presence of these in air also has important effects on life. Air is a medium by means of which both beneficial and harmful bacteria are spread. By means of it the spores of fungi and of other plants are carried about. A dust-like kind of spore called pollen is produced by flowers, and at certain seasons there is much of this in the air. This air-transport of pollen is of great importance to us in that by means of it the pollen of our most important crop plants is conveyed from flower to flower, a thing which is important in connection with the production of seeds.

You have seen the "motes" of dust that are visible when you look through a sunbeam. You have seen them dancing in it, and perhaps you have wondered if it could be 
true that all the rest of the surrounding air is likewise filled with these tiny particles. (These particles are very much larger than molecules, yet their behavior as you see them revealed in a bar of light suggests the behavior of the molecules of a gas as you have learned of it in studying about the kinetic theory.) The reason you can see the particles of dust in a sunbeam is that they reflect the light that strikes upon them; it is the dust in the air that diffuses or scatters the light of the sun so that there is light in shady places. Think how important this is. If it were not for the dust in the air, all shady places would be in darkness. The colors of the sky, of the sunset, and of the sunrise are all produced by the effects of the particles of dust and water in the air upon the light which strikes them. Also, when water vapor condenses into rain-drops, these dust particles act as points about which the water first condenses. Have you ever noticed the dust specks in a rain-drop even when it first strikes against a clean pane of glass?

Relations of Air to Life. - The importance of nitrogen to life you have already learned. The importance of oxygen is familiar to us in connection with the process of breathing. You know that in the air which we exhale from our lungs the oxygen has been largely replaced by carbon dioxide, oxygen being used in our bodies in connection with that essential life process called respiration. It is similarly used by all plants* and animals as well as by ourselves.

This raises an interesting question as to how the supply of oxygen which is constantly being used is constantly

* With the exception of certain bacteria. 
maintained. For it is constantly maintained, and the question of oxygen-supply for future generations never perplexes us as does the question of food-supply. Here again we find one of the links which binds animal life to plant life; here again we realize that we are partners in life with plants, and that our lives could not continue if this partnership were to be dissolved. For it is the plants which, more than anything else, maintain the supply of oxygen in the atmosphere.

You have learned the process of food manufacture by green plants in sunlight. The materials used in the first steps of this process are water and carbon dioxide; the water is obtained from the soil and the carbon dioxide from the air. (Now you see why that small amount of . carbon dioxide in the air is so important to life.) You know that in all manufacturing processes raw materials are transformed into finished products, and that in connection with this process all of the raw material is usually not consumed; the parts not consumed are wastes or by-products of the process of manufacture. This thing is also true of the process of food manufacture by plants; they use carbon dioxide $\left(\mathrm{CO}_{2}\right)$ and water $\left(\mathrm{H}_{2} \mathrm{O}\right)$ as raw materials. They use all of the carbon and of the hydrogen in their finished product (carbohydrate food), but they do not use all of the oxygen, and this excess of oxygen is returned to the air. It is a sort of waste or by-product in food manufacture, but it serves the very important purpose of keeping up the supply of oxygen which is needed for breathing. When you think that nearly all the land surface of the earth is covered, at least half the time, with green plants, and that this process goes on in all of them while the sun shines upon them, you can readily see 
that the total volume of oxygen which they give back to the air is very great.

But the answer to this question of oxygen-supply immediately raises another question, and so it always is in the study of nature; the answer to one question usually raises many others. If the plants use carbon dioxide in maintaining the oxygen-supply, how is the carbon-dioxide supply maintained? Perhaps you can think of the answer yourself? Think of all the burning and breathing that goes on in the world. From both of these processes carbon dioxide is given off.

\section{QUESTIONS}

I. What are the limits of the earth's atmosphere, and how have they been measured?

2. What is the composition of air?

3. Why can you see dust particles in a sunbeam?

4. Why is there any light in shady places?

5. What relation has dust to rain?

6. What maintains the supply of oxygen in the atmosphere? How?

7. What maintains the supply of carbon dioxide? How? 


\section{CHAPTER XXI}

\section{AIR AND WATER COMPARED. ATOMS AND}

\section{ELEMENTS}

You have learned that water, like all other substances, is composed of molecules. You have noted that a molecule of water is composed of hydrogen and oxygen, the chemical symbol indicating this composition being $\mathrm{H}_{2} \mathrm{O}$.

Now as to air. You may ask, is there such a thing as an air molecule, and if so, what is its composition? Already you know that air contains oxygen, which we use in breathing, and nitrogen, and a little carbon dioxide. So we ask, are these substances parts of air molecules, as hydrogen and oxygen are parts of water molecules, or do they exist in some other relationship?

The fact is that there is no such thing as an air molecule. Pure water is composed of just one kind of molecule, but pure air is composed of a number of different kinds. Water is what is called a compound, while air is a mixture.

Here we have come upon a very important fact. If we stop to consider it carefully, we shall get some important information as to how all substances are composed. Water a compound, and air a mixture! The thing for us to do is to see just what is meant by this word compound, and then to see why it doee not apply to air as well as to water.

Molecules. - To do this we must look a little further into the nature of molecules. A molecule is the least, 
particle into which any substance may be divided, and yet remain the same substance. You know that in air, oxygen, nitrogen, and carbon dioxide occur. Now the new fact to note is that air is composed of separate molecules of oxygen, of nitrogen, and of carbon dioxide $\left(\mathrm{CO}_{2}\right)$, which are equally distributed in accordance with the law of diffusion that you have already considered. In other words, if all molecules were so big that we could see them, and tell them apart one from another, we should see that water is composed of molecules which are all alike. But when we examine air, we find it to be chiefly composed of two distinct kinds of molecules, oxygen molecules and nitrogen molecules, and these would be symmetrically arranged so that you would find one oxygen molecule associated with every four nitrogen molecules. Then, about once in every twenty-five hundred molecules (not counting those of water vapor) you would find one of carbon dioxide.

Thus we see that a compound is a substance all of whose molecules are of the same kind, while a mixture is a substance whose molecules are of more than one kind.

Elements. - It is the work of chemists to analyze substances, and thereby to discover of what they are composed. In this process molecules are decomposed in order that their composition may be discovered. Now one of the most important and significant facts that all this work of the chemists has revealed is that there are only about eighty substances in the world which may not be reduced into simpler substances. They have analyzed thousands upon thousands of different substances, decomposing them as far as possible, and the result of all this 
work indicates that all substances whatsoever are composed of one or more of these eighty simplest substances. Just as all words are made up of various combinations of a few letters, so all substances are made up of various combinations of a few elements. So you can see that the translation of this word, analysis, "loose back," gives a good idea of the real nature of the process. It is a process of "loosing" molecules "back" to the elements of which they are composed. The opposite of analysis is synthesis, which means the "putting together" (by chemical combination) of simpler substances into more complex ones. Thus you may have heard of synthetic rubber, which means rubber manufactured by chemical processes out of simpler substances so that the product is practically equivalent to the natural rubber obtained from plants.

Note that new word, elements. It is important. All substances, then, are elements or compounds of elements. What are these eighty elements or simplest substances? With some of them you are already familiar. Hydrogen, oxygen, and nitrogen are elements. Others with which you are familiar are carbon, copper, gold, iron, lead, mercury, phosphorus, platinum, silver, sulphur, tin, and zinc. Evidently, then, elements may exist as liquids, solids, or gases. Which is the element named above which exists in liquid form?

Atoms. - Now to go back again to our water molecule. We have been told that it is composed of two parts of hydrogen and one of oxygen. These "parts" of which molecules are composed are called atoms. Thus the molecule of carbon dioxide is composed of one atom of carbon and two of oxygen. 
The fact that molecules of water contain two atoms of hydrogen to one of oxygen is indicated by the fact that when they are decomposed into these two elements (which, when liberated, take the form of gases) the volume of hydrogen obtained is just twice as great as the volume of oxygen. Water may be so decomposed by passing through it an

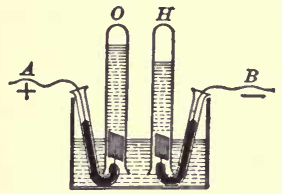

FIG. 58.-Diagram illustrating how water is decomposed by electrolysis; the hydrogen collects in top of tube $H$ and the oxygen collects in top of tube O.-After MILLIKAN and GALE. electric current; the process is called electrolysis. Study Fig. $5^{8}$.

\section{Chemical and Physical Changes.} - Any change in the nature of the molecule of a substance is a chemical change. All other kinds of changes are physical changes. The change of water to ice or steam is a physical change. The change of water to hydrogen and oxygen is a chemical change. Chemistry is the study of chemical changes. Physics is the study of physical changes. Both physical and chemical changes are constantly going on in living as well as in non-living bodies. Life itself is a constant procession of changes. Evidently, to understand living things, it is quite necessary first to understand something of physics and chemistry.

You have just noted that molecules are composed of atoms; thus the water molecule is composed of two atoms of hydrogen and one of oxygen. Molecules composed of few atoms (few both in number and kind), like the water molecule or the carbon-dioxide molecule, are said to be simple. But molecules composed of many atoms are said to be complex. The molecules of some substances are very complex, containing even hundreds of atoms. 
Now it is evident that, by chemical change, complex molecules may be reduced to simpler ones, or simple molecules may be built $u p$ into more complex ones. Already you have considered a number of cases of chemical changes. It will be well to reconsider these, and to determine in each case whether reduction or the building up of molecules occurs.

Perhaps the most familiar of chemical changes is the process of burning. You have learned that, in the burning of wood or coal, gases are produced. Two of these gases are carbon dioxide and water vapor. They result from the union of oxygen of the air with carbon and hydrogen, which, before the burning occurred, were in the molecules of the fuel. These fuel molecules are much more complex than the simple ones of water and carbon dioxide. Burning, therefore, is a case of chemical reduction. We shall consider it further in the chapter on combustion.

In Chapter $\mathrm{V}$ you learned that in washing your hands with soap in hard water, the soap "unites" with the mineral matter in the water, and that thereby a dirty sediment is produced. The word unites, used in this way, indicates that a chemical change occurs; that molecules, or parts of molecules, of different substances have united in the form of another kind of molecule. In this case the molecule of the sediment is more complex than the molecules from which it was derived, so this change is not a reduction but a building up. When a chemical change (or reaction) occurs which causes the production of an insoluble substance in a liquid (as in this case of the reaction between hard water and the dissolved soap), the insoluble substance is called a precipitate. So we may say that the 
use of soap in hard water causes a sediment to be precipitated, or "thrown down."

In Chapter XII, in studying the origin of soil, you learned that oxygen and water act on rock, producing changes known as oxidation and hydration. Rusting you noted to be a process which includes both oxidation and hydration; that is, the chemical union of oxygen and water with other substances. Here we have another case of reduction, similar to that noted in burning.

Then, in Chapter XIII, in considering the nitrogen-fixing bacteria, you learned that certain soil bacteria are able to act upon the nitrogen of the air, and to "fix" it in such form that it becomes available for the use of plants. This nitrogen-fixing process results in the production of substances called nitrates, whose molecules are much more complex than the molecules of atmospheric nitrogen; it is a building-up process.

Similarly, from the bacteria of the soil up to the highest living creatures, all life is based on a constant succession of chemical changes - actions and reactions, as they are called. By the process of digestion, the molecules of the food we eat are reduced to simpler substances which enter our bodies, and there through a long series of changes, these substances are built up into more and more complex substances, the most complex of all being protoplasm, which is the living substance itself.

So we must have food to build up and maintain our bodies. But we must also have air, whose oxygen is carried by our blood to all parts of the body. There it acts chemically upon the substances which have been built up from our food. This action (oxidation) is a reducing process, like the action you have noted in the process of burning. 
By means of it (as in burning) energy is released. This energy may take the form of heat or of motion. It gives us what we call the manifestations of life. The substances of our bodies, that are thus reduced through oxidation and their energy released, become of no further use to us; they are eliminated as excretions. Thus we see how very fundamentally chemical changes are a part of the processes of life.

\section{QUESTIONS}

I. What is the great chemical difference between air and water?

2. What is a molecule?

3. What is meant by "analysis" and "synthesis"?

4. What is an atom, and what relation does it hold to a molecule?

5. How is water decomposed?

6. Explain the difference between a physical change and a chemical change, giving examples of each.

7. Explain the chemical changes involved in the burning of wood.

8. Explain the rusting of iron. 


\section{CHAPTER XXII}

\section{HEAT AND THE ATMOSPHERE}

Now we have a picture in mind of the atmosphere, and we know something of the nature of heat. We know that it is a form of energy that tends to increase molecular motions (see Chapter XVI), and that what we perceive as heat or cold is simply the effect on us of different rates of these molecular motions. So now our problem is to consider the heat of the sun as applied to our atmosphere, to see what effects this atmosphere produces upon the distribution of this heat, and to realize what relations the resulting phenomena have to life.

You have learned that heat may be absorbed. So it is easy for you to realize that the amount of solar (sun) heat that reaches the solid and liquid surfaces of earth is much less than the original amount that comes to earth from the sun. For the heat "rays" coming to earth first encounter its gaseous surface; $i$. $e$., the outer limits of the atmosphere. In passing through the atmosphere much of the heat is absorbed, so that the amount of it which finally reaches the land and water surfaces (at the bottom of the great enveloping sea of air) is far less than that originally received at the atmospheric surface.

In view of what has just been said, why is it that, generally speaking, the higher up we go the colder it gets? You know that mountain tops, although nearer the source of heat, are generally colder than the land which lies be- 
low them. How can we explain this? This, like most other phenomena of nature, cannot be fully explained by just one thing. A number of things must be taken into consideration. We witness the effect, but to explain it fully, we must find a number of causes or "factors" in the problem. One of the causes of the coldness of mountain tops is the "thinness" of the surrounding air; its capacity to absorb and retain heat is much less than that of the denser air which lies below. Other "contributing" causes will occur to you as we study our larger problem. Similarly, the polar regions, even at sea-level, do not get warm, although at certain seasons they received great amounts of heat. Here the principal cause of coldness is evidently different from that in the case of mountain tops; it is that the heat received is so largely absorbed in the process of melting ice and warming very cold water, that the effects upon the temperature of the atmosphere are relatively slight.

Already you have learned that it is absolutely contrary to the nature of heat to stay in the same place. You learned this when you learned that heat is motion. Obviously, we cannot conceive of motion being at rest. To be heat, it must continue to be motion; the motion of molecules.

But, you may say, what of a thermos bottle or a fireless cooker? Are not these devices by means of which we confine heat and keep it in one place? Stop to consider. A thermos bottle consists of an inner receptacle surrounded (except for the opening) by a hollow metallic case. From the hollowness of this metallic case, before it was sealed, the air was withdrawn, thus producing a vacuum (see Fig. 59). Now a vacuum is a "non-conductor" of heat. 
Hence, liquids placed in a thermos bottle change their temperature only very slowly. If hot, their heat has no easy path of escape save through the cork, which is itself a poor conductor. If cold, the heat outside has similar difficulty in entrance, and so the contained liquid stays cold. Similarly, the fireless cooker depends upon the very slow conduction of heat by the materials which surround the central receptacle. Hence, well-heated food placed within

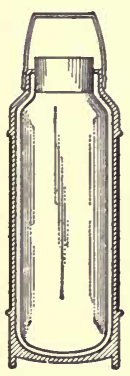

F I G . 59. -

The thermos bottle; notice the v a c u u m layer.

it continues to "cook," even in the absence of fire. In neither case, however, is heat actually compelled "to stay in the same place." The rate of its migration is, of course, greatly reduced, but the motion continues, even though largely confined. In fact, the "whole purpose of a thermos bottle is not to stop the motion of heat, but to preserve it, and it does this by confining it as much as possible to a limited space, thus preventing it from dissipating its energy."

Evidently, however, there can be no such confinement of the sun's heat in the air or in the soil or in the water or in whatever it is that absorbs it. After it has been first absorbed by air, or rock, or water, its journey here on earth has but just begun. To be, it must keep moving, and so it does keep moving about the earth, from one substance to another and back again, and in its movements it has profound effects upon all the life that inhabits the earth. It can be transformed, and it can pass by radiation out into space again, but it cannot be lost or destroyed or used up. It is energy, and you have learned that energy is indestructible. 
Transfer of Heat at the Earth's Surface.-Since heat is motion, it is better to speak of the transfer of it than of the motion of it. There are three ways in which heat is transferred, and all of these are important in connection with the natural distribution of it over the earth's surface. These three methods of heat transfer are radiation, conduction, and convection. Conduction and convection you have already studied (see Chapters XVIII and XIX). Radiation we will now consider.

Radiation. - It is natural to place radiation first in this list, because by this method heat travels from the sun to the earth; our original supply of it comes to us in this way. Radiation means movement outward equally in every direction; it may be represented by the radii of a circle, or, better, of a sphere. When we speak of the sun's "rays" we are expressing the idea of radiation. A radiator radiates heat out in every direction in a room.

Heat is not the only form of energy which travels by radiation. Light also radiates. Heat and light are then forms of radiant energy. (What is an example of energy which is not radiant?) Radiant energy travels in the form of invisible "waves," and it is a kind of energy transfer which does not require substance through which to move, as is proved by the fact that light and heat come to us through enormous spaces that are practically empty of molecules.

Now the importance of radiation in connection with the distribution of heat over the earth's surface is due to the fact that the sun shines on only half of the earth at a time. This is a very familiar fact, but we do not often stop to think what all the consequences of it are. One of the most important of them is that while half of the earth 
is absorbing heat, the other half is giving it off. While the sunny side of earth absorbs heat, the shaded side radiates it. The shadow of earth we call night, and the nights would all be intensely cold were it not for the giving off from land and water surfaces of heat which they absorb by day.

The capacity of air to absorb heat is obviously far less than that of land or water. What capacity it has depends largely upon the amount of moisture in it. Thus we see why in our dry southwest, or in the Desert of Sahara, there is much greater variation in temperature between day and night than there is in regions of greater humidity.

Now if day be longer than night, as in spring or summer, evidently the amount of heat absorption will be greater than the amount of heat radiation. The land, the water, and the "weather" all become warmer. But if night be longer than day, as in fall and winter, more heat is lost than is gained, and everything gets colder. So we see that the principal cause of the seasons is the variation in the lengths of day and night. But, you ask, what causes these variations of length? The answer to that we must postpone till the chapter on seasons.

Conduction. - This method of heat transfer you considered in connection with the freezing of ice-cream. Conduction requires the actual contact of substances of different temperature. It is by conduction that our hand is cooled when we touch ice, or warmed when we touch a stove or a radiator. In nature, conduction operates to transfer heat into air which is in contact with warmer land or water surfaces, and thus it is an important factor in the general distribution of heat which we are considering. 
You have already learned that land and water are better heat absorbers than is air. Therefore, it may not surprise you to learn that of the total heat of the air more is acquired by conduction and radiation back from land and water than is acquired by absorption directly from the heatrays of the sun. The air acquires heat from the sun only when the sun shines on it, but it is always in a position to acquire it from land and water.

Convection. - You learned of this process in studying what happens when a body of water freezes, and you noted then the convection currents of the atmosphere. They are caused by heat, and they in turn are the causes (though not the only ones) of winds and of the distribution of rain. Evidently, then, they are important factors in the environment of life.

It should not be at all difficult for you now to form a mental picture of the great convection currents in earth's atmosphere. You know that the surface of earth is hottest in the equatorial regions. Hence, the air over these regions will become warmer than the air of the regions to the north and south. So it rises, and, as it rises, cooler air from north and south comes creeping in to replace it. As the warm ascending air reaches higher altitudes, it cools, and then flows away toward the poles. Thus we have a constant great convectional movement or circulation of earth's atmosphere (see Fig. 2). This alone is simple enough, but we must remember that the whole matter of atmospheric movements is complicated by the rotation of the earth, and by other factors. These are matters to be taken up in the next chapters. 


\section{QUESTIONS}

I. Why is it colder on mountain tops than on plains?

2. Why is it colder at the north pole than at the equator?

3. Explain the thermos bottle.

4. In what ways is heat transferred?

5. How does heat travel from the sun to the earth?

6. What keeps us warm on summer nights?

7. Why is there much greater variation in temperature between day and night in the Desert of Sahara than there is in most other places?

8. What is the cause of the seasons?

9. How does the air get most of its heat? 


\section{CHAPTER XXIII}

\section{THE SEASONS AND THE SOLAR SYSTEM}

You have learned that a principal cause of what we call the seasons is the variation, at different times of the year, of the lengths of day and night. The longer the day, the greater the heat, and vice versa.

From this it appears to follow that the longest day of the year should be the hottest day. Similarly, we noted that it appears as though those points on the earth's surface nearest the sun (mountain tops) would be the hottest. But we found that other factors than nearness to the sun affect this matter, and that, as a matter of fact, mountain tops are cold. So as to the longest days. Other factors than length of sunshine affect the matter, and they are not the hottest days.

June $2 \mathrm{I}$, as you probably know, is, in the northern hemisphere, the longest day of the year, and yet most of the heat of summer comes after that date. Similarly, December 22 is the shortest day and, similarly, most of the cold of winter comes after that date. Evidently, the time of the greatest heat comes after the time of the greatest heating and, similarly, the time of least heat comes after the time of least heating.

You learned that, for certain reasons, the polar regions never become warm, although there may be a great deal of sunshine there at certain seasons; in fact, these regions have the longest days of all, since there, for months at a time, the sun never sets. For similar reasons, the region in 
which we live does not "warm up" to its warmest until after the longest day, or "cool off" to its coldest until after the shortest day. What are some of these reasons? If you remember what has been said of the relations of heat to soil and rock and water, you can solve this problem for yourself.

Solar System. - It is easy to see why the seasons result from changes in the length of day, but you cannot

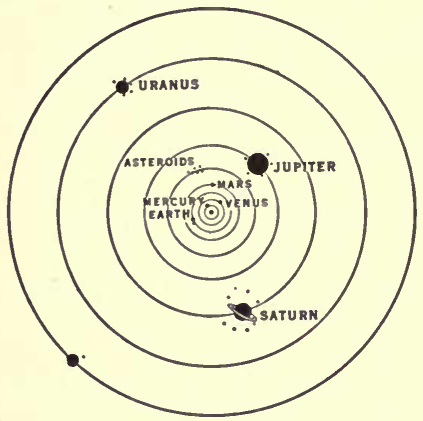

Fic. 60.-The solar system understand winy the days change in length unless you understand the solar system.

The solar system is composed of the sun and all the bodies which revolve about it, chief of which are the eight planets. Of these, the earth is one. All of the planets, except the earth, have names that were given them by the early astronomers in honor of ancient deities. In the order of their nearness to the sun, the planets are: Mercury, Venus, Earth, Mars, Jupiter, Saturn, Uranus, Neptune (see Fig. 60).

The planets revolve about the sun, following their orbits, and also rotate on their axes. In the case of earth, one complete rotation takes twenty-four hours, while a complete revolution takes three hundred and sixty-five days. Evidently, it is the earth's rotation which gives us day and night, while its revolution determines the length of the 
year. Let us remember, then, that as the earth makes its annual revolution about the sun, it spins as it goes, and each spin is what we call a day. Since the sun "rises" in the east and "sets" in the west, the direction of this spinning is evidently from west to east. At night we are in the shadow of the earth, but we go on spinning toward the east, till presently the sun peeps over the eastern horizon, and we say it is day.

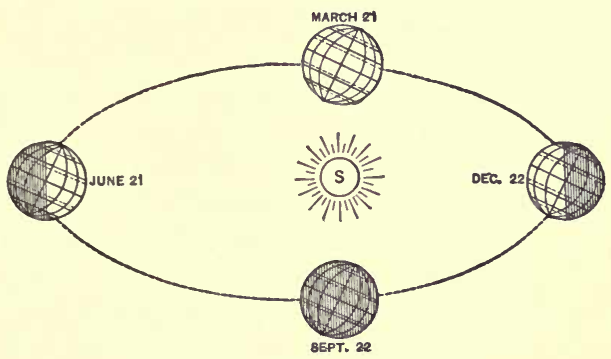

FIG. 6r.-Diagram of the earth's orbit.

The fact just suggested, namely, that earth and sun are not always the same distance apart, seems to give us a clew to the solution of the problem we are studying, the problem of variations in the amount of heat received on the earth. Consider then the shape of the orbit of the earth (see Fig. 6I). It is not a circle. It is a kind of curve called an ellipse, and when the earth, following this path, is farthest from the sun it is three million miles farther away than when it is nearest. However, the difference of distance is so small as compared with the total distance that evidently it can have but small effect on the amount of heat received on the earth. 
So this clew alone does not take us far. However, in considering it, you may have noted that the figure indicates that the axis of the earth is inclined. That is, as it spins, its axis does not intercept its orbit at right angles, but at an acute angle, and the position of the axis is the same throughout the year. Here is another clew we should use, for evidently this fact must have a great effect upon the way in which the earth's surface intercepts the sun's rays, and, consequently, upon the distribution there of solar light and heat.

Thus we have three great geometrical facts to consider in studying the distribution of solar effects upon the earth. These are its revolution, its rotation, and the inclination of its axis. Evidently, mathematics has an important part in the study of nature. The problem we are now considering is largely a problem in geometry, and the whole science of the heavenly bodies (astronomy) is largely a matter of mathematics.

Effects of the Inclination of Earth's Axis. - Let us remember that, in spite of the complication of our problems by this newly observed fact, the fact that one-half of the earth is always in the sunshine remains the same. The inclination of the axis simply results in such shifting about of this sunlit area that we are sure to be puzzled by it unless we think it out carefully.

Now you know that the sun at noon in summer is much higher in the sky than it is at noon in winter; you know that on a winter's noon the sun stands considerably south of the zenith, by which we mean the point in the heavens directly above your head wherever you happen to be (see Figs. 62 and 63 ). This evidently indicates that in our 
winter the north pole is tipped (inclined) away from the sun, while in our summer it is tipped toward the sun; in the southern hemisphere, the reverse is true. Thus we see not only why the sun gets higher at noon in summer than in winter; we also see why the sun in summer remains visible longer than in winter. Since in summer we are tipped toward the sun, while in winter we are tipped away from it, of course we see it longer in summer. Evidently,

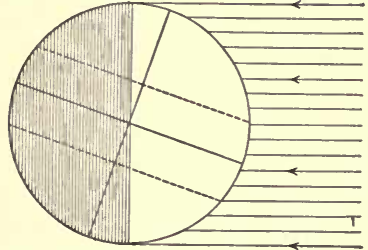

Fig. 62.-Diagram to show the direc: tion of the sun's rays in summer; the north pole is at the top.

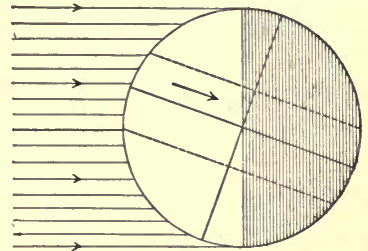

FIg. 63.-Diagram to show the direction of the sun's rays in winter; the north pole is at the top.

then, we have found out why the days of summer are longer than those of winter. We have found the cause of the seasons.

The Equinoxes. - Midway between the shortest and longest. days of the year come days when it is just twelve hours from sunrise to sunset. These days are March 21 and September 22. On these days, and these days only, the circle which bounds the sunlit half of the earth passes through both poles. So all over the world, on these dates, day and night are of equal length. These days are called the equinoxes (aequus, equal; nox, night); the one in March is called the vernal (ver, spring) equinox; the one in September, the autumnal equinox. Perhaps you 
have heard of equinoctial storms. The equinoxes come at stormy times of year and it was formerly believed that the equinox was the cause of these storms. It is now known that this is not the case, but the term is still used.

The shortest day of the year in the northern hemisphere is evidently the longest day of the year in the southern hemisphere; and the reverse is also true. But, as you have noted, the equinoxes come at the same time in both hemispheres. Also, you should note, that precisely at the equator, days and nights are always of equal length. Variations in length of day and night, and the consequent effects, evidently increase in proportion to the distance from the equator, until at last, precisely at the poles, variation ceases, and day and night are each a half year long. In the tropics, however, day and night are always of nearly equal length, and there is little variation in the angle at which the sun's rays strike the earth. Hence we find in this region much less variation in the seasons than we do to the north or south of them; the farther we go from the equator, the more marked the differences between the seasons become, until we reach the regions of perpetual ice and snow. Toward the poles the seasons become merged in one long winter, while toward the equator they merge in one long summer.

The Zones. - Doubtless you learned in geography that the earth is measured by two sets of lines which are indicated on all maps, and which give a geometrical method of locating places. The lines which run parallel to the equator are called parallels or lines of latitude; the ones which cut these at right angles and converge at the poles 
are called meridians or lines of longitude; both parallels and meridians are, of course, circular when complete, as on a globe. A degree (symbol, ${ }^{\circ}$ ) is the unit of length of these lines. It is $1 / 360$ of their total circumference. The degrees are subdivided into minutes (symbol, '), each of which is $1 / 60$ of a degree (see Fig. 64).

Now the northernmost parallel at which (on account of the inclination of the earth's axis) the sun ever reaches
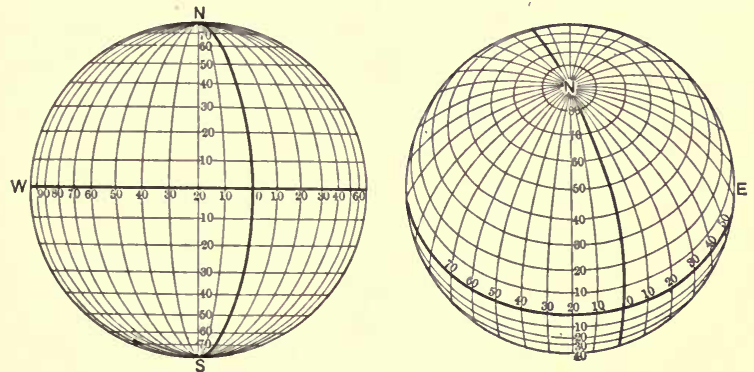

FIG. 64--Parallels and meridians.

the zenith is called the tropic of Cancer; the corresponding parallel of the southern hemisphere is called the tropic of Capricorn. These parallels are, of course, equidistant $\left(23^{\circ} 27^{\prime}+\right)$ from the equator, and the belt of the earth which lies between them is called the tropical zone. You see then that the sun seems to oscillate from one edge to the other of that belt of the heavens which lies directly over the tropical zone. Actually, however, it is not the sun that thus reels through the heavens; it is the earth that reels. When a moving train passes closely by a standing one in which you are seated, you get the impression that it is yours which is moving. Similarly we 
gain false impressions about the relations as to movement between earth and sun.

During that day, December 22, when the sun is over the tropic of Capricorn, it is evident that the region (circular in outline) around the north pole which remains in darkness throughout the twenty-four hours attains its largest circumference, for on that day the north pole is the farthest within the shadow of earth that it ever gets (see

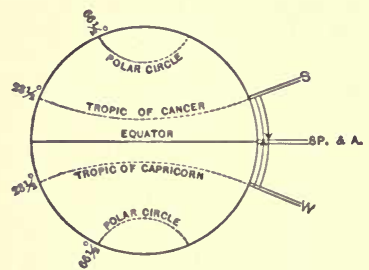

Fig. 65.-Diagram showing where the direct rays of the sun strike the earth at the various seasons (e. g., the sun is directly above the tropic of Cancer in summer, $S$ ).

Fig. 65). That parallel which throughout that day divides the northern area of darkness from the southern area of light, the last parallel toward the north which the sun's rays touch when it is thus in its most southerly position, that parallel forms what we call the arctic circle. Similarly, the limits of illumination,

when the sun is at its farthest northern point, mark the antarctic circle. It is a simple problem in geometry to show that the arctic circles must be just as far from the poles as the tropics of Cancer and Capricorn are from the equator.

Between the tropics and the arctics lie the great temperate zones, and it is in these that the seasons are most marked. In them all life responds to the changes of heat and cold, of rain or drought that accompany the seasons, and so closely interwoven are these causes and their effects that we have come to regard the seasonal changes in plant and animal life as parts themselves of 
spring and summer, of autumn and of winter. What are some of the things that we call "signs of spring," or "signs of winter"?

\section{QUESTIONS}

I. Why is our longest day not also our hottest day?

2. What is the "solar system"?

3. Describe the movements of the earth, and explain what relation they have to days and years.

4. In what direction does the earth rotate?

5. What is the cause of the seasons?

6. What are the equinoxes?

7. What are parallels and meridians?

8. What are the tropics? the arctic and antarctic circles? 


\section{CHAPTER XXIV}

\section{WINDS AND WEATHER}

In the phenomena we have studied thus far the relations between causes and effects have been rather simple. They have been cases in which certain causes produce certain effects which are not difficult to predict. But with wind and weather we shall find that it is different. In fact you already know that weather is a difficult thing to predict, for it is a result not of one but of many causes. It is so important to man to know what the weather is going to be that millions of dollars are spent by governments each year in doing all that science can do to foretell it. Yet their predictions often go wrong.

The work of a weather bureau consists, first, in securing daily reports from all over the country as to local weather conditions. Then, with such data in hand, it is possible to make forecasts (predictions) which are fairly accurate. For weather, like all other phenomena of nature, is not accidental, it is the result of certain definite causes. The difficulty in its prediction is that these causes can be ascertained only in a general way, and local weather conditions may be determined by purely local causes which conflict with the general causes. We shall see first what the general causes are, and then consider some of the local causes.

Weather Is the State of the Atmosphere. - We speak of it as warm or cold, as wet or dry. If we stop to consider, it is evident that we mean by this that the atmosphere 
about us is warm or cold, wet or dry. So we see that amounts of heat and amounts of water are the chief determiners of the nature of the weather, the atmosphere being the substance in which these determiners operate. Evidently, then, the study of weather is a study of local changes in the state of the atmosphere as to heat and as to water.

How are such changes brought about? In the first place, there is the warming of the atmosphere when the sun shines on it, and its cooling off (refrigeration) when the sun is not shining on it. This is a process which always operates with reference to the atmosphere as a whole. But evidently it seems frequently not to operate with reference to local conditions, for the sun often shines brightly during our coldest days. So we must look further.

Already you have noted that unequal heating of the atmosphere causes atmospheric movements (convection currents). You have also noted that heat received from the sun may be chiefly absorbed by ice and snow, and so have little effect on the atmosphere. These facts help us to understand why the air may be cold even in bright sunshine.

Evidently, then, the state of the weather is determined by atmospheric movements and by local conditions, more than by the direct action of the sun, since these evidently can overcome the direct effects of the sun. This is even more evident when we consider weather as to its wet and dry qualities, for the distribution of water by atmospheric movements is even more familiar to us than the distribution of heat. We have visible evidence of water movement in air whenever we see clouds moving across the sky. Heat movement in air, though not visible, is just as real as water movement, and when cold or hot winds strike 
us we are just as conscious of its reality. Why is it, by the way, that winds nearly always feel cool, even though the moving air may be warmer or just as warm as the air it replaces?

On a weather-map (see Fig. 66) you will note that certain areas are marked "low" and others "high." This refers to readings of the barometer. You remember that a low barometer indicates the coming of a change of weather, and, usually, a storm. This is very easy to understand when you remember that air or any other gas tends to diffuse equally in every direction. Evidently, this tendency of air to diffuse equally will cause it to move from areas of high pressure to areas of low pressure. For an area of low pressure is simply an area over which there is less air than there is over an area of high pressure.

But what is it, you ask, that causes air to thin out in certain places (low pressure) and to pile up (high pressure) in others? Heat is the answer. Variations in the amount of heat. How often in studying phenomena we come back to heat changes as the cause! In fact, nearly all changes in the atmosphere are due to heat; heat is the great explainer.

Now we might have said that variations in atmospheric pressure are caused by convection currents. But what causes convection currents?. Heat, of course. These currents, whether in water or in air, are simply expressions, as it were, of heat, tools in the hands of the sun's energy. This you learned when you studied these currents (see Fig. 2). You learned that the greater amount of heat received in the equatorial belt makes the atmospheric pressure there less than it is to north and south; that is, the greater heat near the equator causes the air to expand 


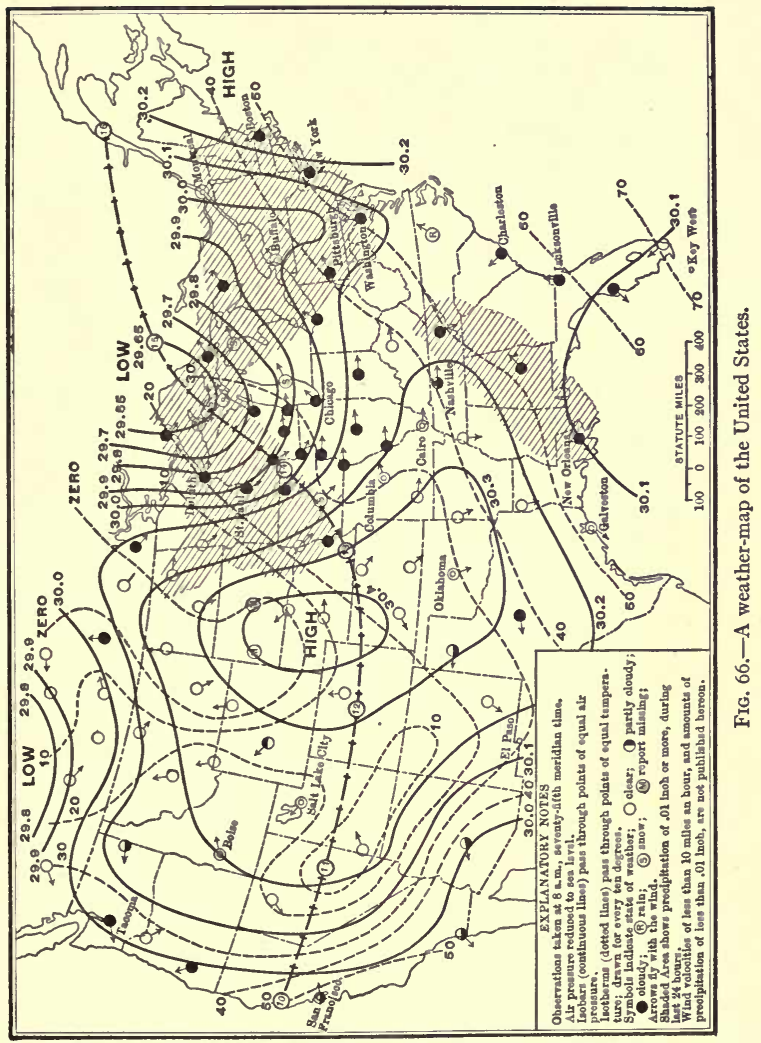


and rise, and then, as it condenses, to flow away toward the poles. This means that there gets to be actually less air per cubic foot over the hot-belt than there is over the regions north and south. So, in accordance with the law of diffusion, or as we say, to equalize the pressure, cooler air comes flowing in (at the bottom of the atmosphere) from north and south. We may call such flowings of air "convection currents" if we like, but they are more commonly called winds, the winds which flow toward the equator for the cause just indicated being called the tradewinds. They were so called originally because they were of great assistance to the trade carried on in sailing vessels, but they might well have been so called because they are part of a trade of air between one region and another.

Have you not noticed that a long spell of hot, dry weather is almost sure to be "broken up" by the coming of wind and rain? In this case, too, a sort of "trade" occurs. The longer the hot spell continues, the lower the pressure tends to become until at last it is as though the atmosphere could "stand it no longer," and winds, usually bringing rain, rush in to balance the pressure again.

We have noted that air temperature has a direct effect upon air-pressure, and that both have great effects upon the wind and the weather. Differences in pressure cause air movements, air movements are wind, and the winds bring the rain or snow. So we see in studying weather a whole chain of causes and effects. We also see, in this connection, the need the weather bureau has for making diagrams to indicate each day the states of temperature and pressure all over the country. For only by means of such facts as these "weather-maps" present, can the probable weather of the following day or week be foretold. 


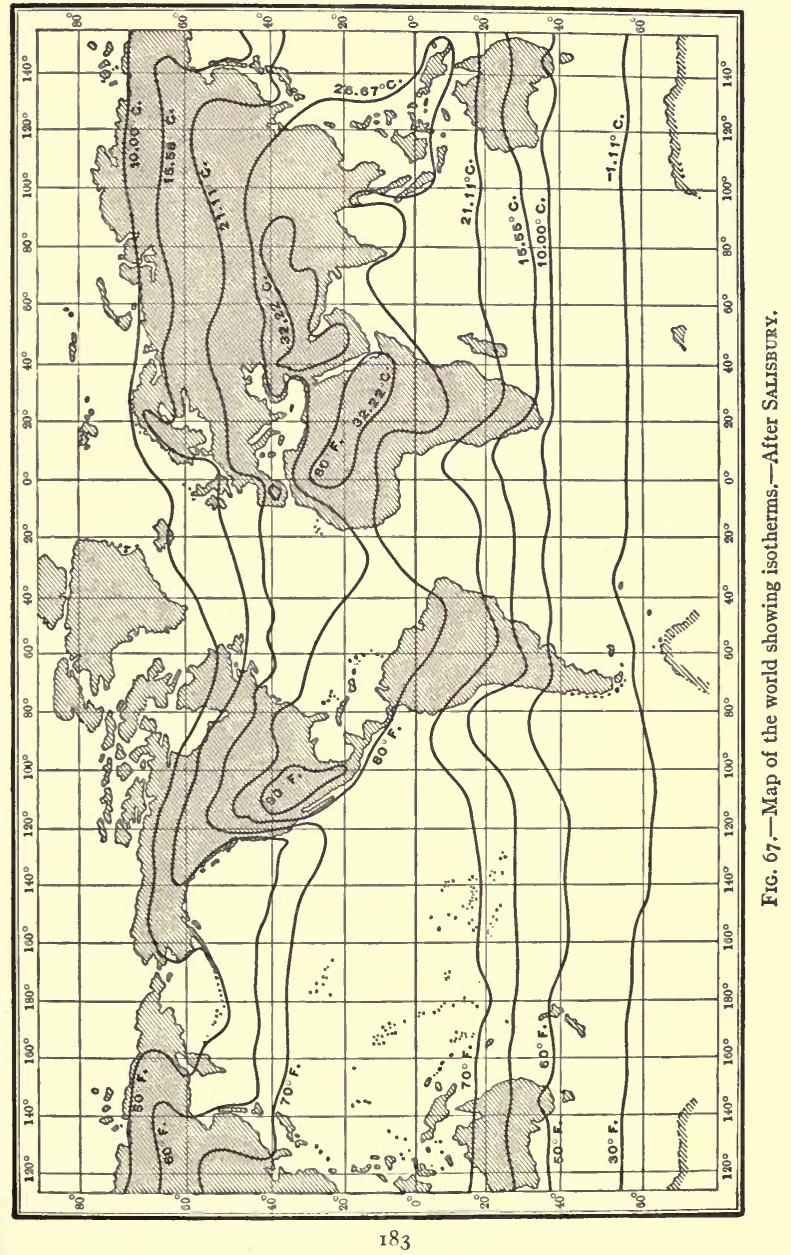


Weather-maps are marked by two kinds of lines. One kind records the variations in temperature over the country; the other records the variations in pressure. This is done by tracing across an ordinary map lines which connect points of equal temperature; or in the case of pressure, lines which connect points of equal pressure. Lines which connect points of equal temperature are called isotherms (see Fig. 67); those which connect points of equal pressure, isobars. The fact that isotherms and isobars do not correspond shows that other factors as well as heat affect the distribution of pressure. One of these is the fact that water vapor is lighter, per cubic foot, than air. So the more of water vapor there is in air, other things being equal, the lower the pressure. Hence we may expect to find a tendency for pressure to be less over the oceans than over the continents, and this expectation is borne out by a computation of the facts shown by Fig. 66 . The average pressure of the land areas figures out as more than the average pressure of water areas. But we must remember that the atmosphere is very mobile (movable), and that the earth is constantly spinning from west to east. As it spins, the gaseous outer part of it (atmosphere) does not quite keep up with the solid and fluid inner parts, especially in the equatorial region, where the motion of rotation is much faster than toward the poles. So it does not surprise us to find that areas of low or high pressure show a general tendency to move, and may not lie over the areas where they originated.

Also we note in Fig. 66 that, as expected, the pressure recorded in the equatorial regions is decidedly less than that to north or south.

As to temperature, we have noted that as altitude 
(remember mountain tops) and latitude increase, the temperature, generally speaking, increases. So it does not surprise us to learn (see Fig. 67) that the isotherms show a general tendency to run parallel to the parallels (lines of latitude). Nor need the bends (away from the parallels) of the isotherms surprise us when we remember the local effects that land and water and wind have on temperature. As to altitude effects, these are not shown on the maps. Allowances are made, when the reports are computed, so that the isobars and isotherms are drawn on the maps as though all the land were at sea-level. This is because altitude is so local a condition that to take account of it on weather-maps would only confuse a record which is meant to be general.

Fig. 68 indicates the general directions of the winds

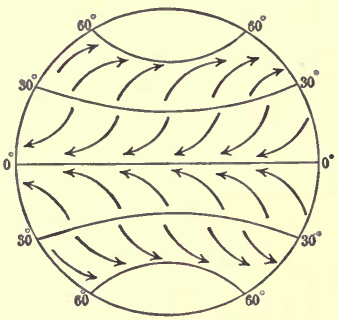

FIG. 68.-Diagram showing the general direction of the winds of the earth. of earth. This diagram is not difficult to understand if you keep in mind a picture of the rotating earth, and try to realize the effects which this rotation is certain to produce upon the atmospheric movements. At the equator the rotation movement is over a thousand miles an hour; to north and south it gradually diminishes until exactly at the poles it is zero. Now, of course, the atmosphere very nearly keeps up, in this rotating movement, with the rest of earth. Otherwise we should constantly have storms of enormous violence. As it is, even in hurricanes, the wind velocity rarely becomes greater than one hundred miles per hour. However, the rotation does 
have some effect, and it is this effect which is portrayed in Fig. 68. Remember (see Fig. 2) that the general convection circulation of the atmosphere is poleward from the equator for warmer air, and equatorward from north and south for cooler air. Now if it were not for the earth's rotation these great convection currents would move due north and south, paralleling the meridians, but, as it is, the rotation of the earth causes them to bend (blow) westward in low latitudes (where rotation speed is greater, and the water and land move a little faster than the air) and eastward in high latitudes. In other words, the atmosphere is bent westward at the equator, and this bending has an effect which extends clear up to the polar regions. So Fig. 68 represents what may be called the basic directions of the world's winds. But the air movements so determined are not so strong but that they may be overcome by local conditions. So they are often so modified and we may have even violent winds which blow in a direction opposite to that of the prevailing winds. Inasmuch as we live in the region indicated by the upper eastward-pointing winds, we should expect our prevailing winds to be westerly, or southwesterly; that is, from the west or south of west. Is this the case?

Judging from the diagrams, you would expect the equatorial region to be, comparatively speaking, a region of calms, the movement of the air being more upward than horizontal. This is the case. There is a zone of equatorial calms known as the doldrums.

Also, note that the trade-winds north of the equator blow from the northeast, while south of the equator they blow from the southeast. 
Land and Sea Effects on Wind. - You have learned that land absorbs heat more readily than water, and also gives it off more readily. So, other things being equal, land is warmer than water in summer and cooler than water in winter. This may produce a considerable effect upon air movements. Its tendency is to cause air to move landward in summer (to replace the ascending hot air there) and waterward in winter. The most striking case of this is the relation between the great tropical peninsula of India and the Indian Ocean which surrounds it. Here the prevailing winds change with the seasons in the manner just indicated. In this region these seasonal winds are called the monsoons. (The winds previously discussed, being affected by the rotation of the planet, are called planetary winds.)

Change in wind direction may also be effected by the temperature change of night and day between water and land. This effect is, of course, not so wide-spread as the seasonal change in such a case as India, but it is enough to give us along the shores of lakes and oceans frequent fluctuations in the direction of wind. It gives us what we call lake or sea breezes, or land-breezes. During a hot day and evening the air may move in from water to land (sea-breeze), and then, toward morning, if the land has cooled off more than the water, it may move waterward again (land-breeze).

\section{QUESTIONS}

I. Why do we study the weather?

2. How are weather-maps made and what do they tell us?

3. What causes low pressure and high pressure in the atmosphere?

4. What are the trade-winds?

5. What are isotherms and isobars? 
6. Why is atmospheric pressure lower over oceans than over continents?

7. Explain the general direction of the winds of the earth.

8. What are the "doldrums"?

9. Explain the effects of land and sea on winds. 


\section{CHAPTER XXV}

\section{ECONOMIC IMPORTANCE OF WINDS, RAINS, CYCLONES, CLOUDS, TORNADOES}

The economic importance of anything means its relationship to mankind, especially in connection with his material interests. A thing which is economically important may be beneficial to man, or it may be injurious, or it may be both. So it is with winds. They do much good, but they may do much harm. In both cases they are of much economic importance, and fortunately, they do more good than harm.

Windmills and sailing vessels are very ancient devices whereby man takes advantage of wind to get work done. But these, and all other devices in which the relationship to wind is under man's control, sink into insignificance as compared with the great natural effects of wind on mankind, effects over which he has no control and which do not depend in the least upon anything which he has devised. Of these natural effects of wind, the distribution of rainfall is the most important. It is wind which brings the rain. Could we get along without rain?

Uses of Rain and Snow. - The great fundamental occupation of mankind is agriculture. For agriculture at least twenty inches of rain per year is generally necessary. There are some exceptions to this, but not many. It is drought which the farmer usually fears more than any of his other enemies. 
Rain is needed, too, for man and beast as well as for the crops. In cities rain flushes our streets, lays the dust, freshens our lawns, and fills our cisterns. Though we may not use rain-water for drinking, we usually need it for washing.

Snow as well as rain is important for agriculture. A mantle of snow protects winter crops, like winter wheat, which are planted in fall and harvested in late spring or early summer. Both rain and snow are valuable aids to health. They cleanse the air of dust and bacteria. Have you never noticed how fresh and agreeable the air often is after a summer shower?

Variation in Amount of Rainfall. - The amount of rainfall, as you have learned in geography, varies extremely in different parts of the world. It depends, of course, upon the winds, but it also depends upon the regions from which the winds come, and upon the conditions which they encounter when they arrive. The only way in which the air obtains the water which falls as rain is by evaporation from the land and water surfaces below. So, to bring rain, a wind must come from a region where it could become moisture-laden. Then, to give this moisture up as rain, it must encounter conditions which will cause it to condense.

To illustrate this, let us take the case of the United States. Our prevailing winds are, as you have noted, from the southwest. They come to the California coast laden with moisture from the Pacific. In the winter months the California coast is cooler than the Pacific, so in those months these winds bring rain. The coolness which they encounter condenses their moisture into 
drops (precipitates it). But in the summer months the land is warmer than the sea, and the winds generally pass on without giving up their moisture. So the coast of California has distinct wet and dry seasons, just as is common in the tropics. Farther to the north, in Oregon and Washington, the rain is more abundant throughout the year, because the land there remains comparatively cool.

Soon these eastward-blowing winds encounter rising altitudes; they come to the first range of mountains. Since temperature falls as altitude rises, they may continue to deliver their rain. So there is plenty of rain and snow west of the Sierras and the Cascades. But once these mountain ranges are crossed, and the air begins to descend, it becomes warmer, and so tends to retain what moisture is left. Thus we see why the windward side of high mountains gets more rainfall than the leeward side, and we also see why the Great Basin is so arid.

When these winds after crossing the Great Basin come to the Rocky Mountains they may again yield moisture, but after they have crossed this second range, again they become dry, and the land which they then traverse (western Kansas and Nebraska) is of little agricultural value. But just beyond this, in the Mississippi basin, lies the richest agricultural region in the world, a region where rainfall is abundant and where farm lands are of great value. Why is this? Whence comes this rain? Surely there is not enough water left in the winds which have already traversed more than half the continent. No, the source of the moisture which makes the farms of our Middle West so fertile is not the Pacific Ocean. It is the Gulf of Mexico. But to understand how the winds blow 
up from the Gulf and bring these rains, it is necessary to understand something about cyclones.

A Cyclone Is a Wind Which Rotates. - The thing about which it rotates is an area on which the atmospheric pressure is either higher or lower than it is on the surrounding areas. When you hear the word cyclone you usually think of a terrific storm, but most cyclones are not terrific at all. The ones which are terrific are properly called tornadoes instead of cyclones. You have often seen cyclones, at least in miniature. On hot days you have seen little ascending whirlwinds of dust that rise, and move along, and get you all dusty if they happen to come your way. These are miniature cyclones.

Now the cause of this miniature cyclone is this. Some of the air, nearest the earth, has become heated (mostly by conduction) until it is decidedly lighter than the air which overlies it. At some point where the heating is particularly strong, this lighter air begins to rise, and breaks a passage through the cooler air above. Into this passage more of the low-lying hot air rushes; soon it is ascending from the ground in a whirling column which carries dust up with it, and moves along erratically before the breeze, becoming dissipated as its supply of hotter air becomes exhausted, and the pressures become equalized.

Cyclones similar in principle to these little whirlwinds occur on a great scale. They may involve hundreds or even thousands of square miles, and they may have much to do with the distribution of rain. Such cyclones center upon areas of low pressure; air is drawn inward toward its center and there passes upward. So, wherever we see on weather-maps centers (areas) of low pressure with higher 
pressures all about them, we may know that there the air tends to circle about this center, converging toward it, and moving upward as it reaches the center. We can also understand that this whole great rotating mass of air tends to move also in the direction of the prevailing winds which push upon it.

The arrows of Fig. 69 indicate the movement of air in such a cyclone as viewed from above, while those in Fig. 70 indicate these movements as viewed from the side, assuming that the prevailing winds are from left to right.

Another kind of cyclone is the anticyclone. Its center is a center of high pressure. In it the air moves downward and outward instead of inward and $u p$ ward. For the rea-
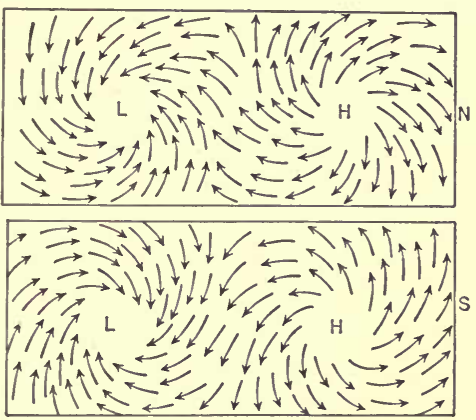

F1G. 69.-Diagram showing the direction of winds around areas of high $(H)$ and low $(L)$ pressure, when viewed from above; $N$ and $S$ indicate northern and southern hemispheres.-After SALISBURY.

son you have already learned, you can understand that cyclones in the southern hemisphere rotate in the reverse direction from those in the northern hemisphere; their rotation, whether the movement be inward or outward, is influenced by the earth's rotation as well as by the difference in atmospheric pressure.

$i$ It is a frequently observed fact that rain or snow commonly accompanies areas of low pressure, while clear 
weather commonly accompanies areas of high pressure. In view of what has just been stated you should be able to explain this fact. Remember that rising air is cooled and so tends to give up moisture, while as to descending air, the reverse is true.

Now, to go back to our case of the rains of the Mississippi Valley, it is a fact that areas of low pressure frequently originate in the region of the Gulf of Mexico, and, passing across it, move up the Mississippi Valley, and then are

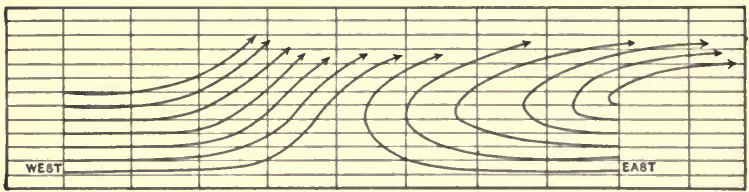

Fig. 70.- Side view of a cyclone as described in the text.-After Salisbury.

carried by the prevailing winds off to the east and northeast. By this means much air, carrying moisture from the Gulf, is drawn northward, and, as it goes, it cools and delivers this moisture as rain. Can you not see from this why it is that an east wind, throughout the Mississippi Valley, is considered a "sign of rain"? The cyclonic winds, which have just been described as the principal rain bringers in this region, first make their presence felt by an easterly or southeasterly breeze, which gradually veers around to the north and northwest as the "storm center" moves to the east.

Study of Weather-Maps. - Now you should be in a position to study and interpret such a weather-map as that given on page $I 8 I$, on which isotherms, isobars, direc- 
tion of winds, and cloudy, rainy, and sunlit areas are all indicated. This is the kind of weather-map which is issued daily by the government. Accompanied by the weather forecast, such maps are posted up in post-offices and other places all over the country. You will find it interesting and instructive to examine and try to interpret them.

Thunder-Storms. - Have you ever watched the approach of a thunder-storm? On some hot summer afternoon you may have seen dark clouds piling up in the west, and rapidly approaching. They seem to hang low over the earth, and to mount high in the sky, until they may fill half the heavens, and it becomes as dark as twilight. Then comes a gust of cool wind, followed by the first big drops. It is time now to run for shelter, for the storm is about to "break." Soon there comes a great downrush of rain. There are dazzling flashes of lightning, and thunder like the booming of many cannon. But soon the rain stops, the sky clears, and the clouds, white now with the sunlight on them, float away to the east. The air is cooler and the whole earth seems refreshed. In the eastern sky there may be a rainbow.

Such storms are usually quite local. They are due to what may be called an "overload" of moisture in the atmosphere, from which it finds relief through sudden rather than through gradual means. Since the hotter the air, the more moisture it absorbs, it is easy to see why thunder-storms usually occur in summer, on particularly hot days, more frequently by day than by night, and in the afternoon more frequently than in the morning. Lightning is the passage of strong currents of electricity through the atmosphere. Sometimes these currents strike down to 
earth and cause effects which are familiar. Heat lightning is the reflection on clouds of lightning which occurs below the horizon. Thunder is caused by vibration of the air due to the passage of lightning through it.

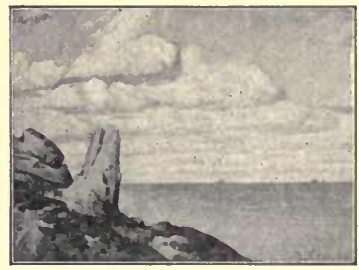

Fig. 71.-Cumulus clouds.

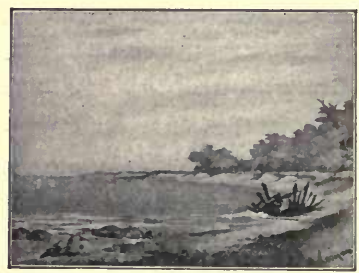

Fig. 73.-Cirrus clouds.

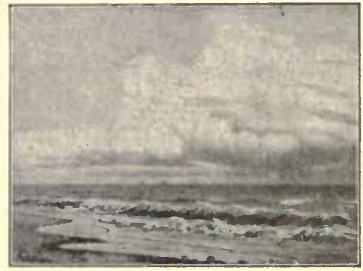

Fig. 72.-Cumulo-nimbus clouds.

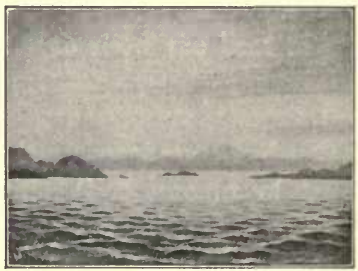

Fic. 74.-Cirro-stratus clouds.

After Cloud Chart, Hydrographic Office, Department of Navy.

Kinds of Clouds. - Cumulus clouds are the kind that seem piled up in the sky, with rounded, swelling contours above, and an almost horizontal base (see Fig. 7I). They are formed by rising water vapor, and their level bases indicate the height at which this vapor condenses to such a point that it interferes with the light, so that it becomes visible as cloud. Rain-clouds are the nimbus kind; they 
are dark and of irregular shape. The clouds of thunderstorms seem to combine the qualities of both these kinds; they are called cumulo-nimbus clouds (see Fig. 72). Cirrus clouds are feathery (see Fig. 73). They seem the smallest clouds, and are highest in the air; five miles or more. Usually they occur in large groups. When they are abundant, the sky is said to be a "mackerel sky." It is believed that this kind of cloud is composed of fine particles of snow and ice. Stratus clouds are the low-lying, horizontal clouds that seem to lie in layers (see Fig. 74). Of course there are many gradations between these various kinds of clouds, which really merge one into the other.

Tornadoes. - These destructive storms, usually called cyclones, are due to very strong convection currents with very small diameters. They are like the little dust whirlwinds, multiplied millions of times in power. Like the little whirlwinds, a tornado cloud has a funnel shape which spreads out more or less widely at the top. In the center of this funnel, due to the great uprush of air, the atmospheric pressure may be much less than normal atmospheric pressure. So we see why houses in the path of a tornado sometimes "blow up" from the inside. It is because the pressure of the outer air is temporarily removed, and the inner air in consequence expands with such violence as to rend walls asunder. Here is an excellent proof of the reality of this atmospheric pressure which we do not actually feel.

Tornadoes are rarely more than a thousand feet in diameter at the bottom, usually much less. So we can see why the path of destruction which they leave in their wake is narrow. Within this path, however, judged by the damage 
done, the wind may reach a velocity of four or five hundred miles per hour.

\section{QUESTIONS}

I. Why are rain and snow useful to man?

2. Why is there more rain in Oregon and Washington than in California?

3. Why is the Great Basin so dry?

4. Explain cyclones.

5. Explain the relation of rain to areas of low pressure and high pressure.

6. Why is there so much rain in the Mississippi Valley?

7. What is heat lightning?

8. What are the various kinds of clouds?

9. What are tornadoes? 


\section{CHAPTER XXVI}

\section{HEATING AND VENTILATION}

We have been considering the relations between atmosphere and man out-of-doors. But since most of us spend much of our lives indoors, it is important also to consider the atmosphere in its relation to our indoor life.

Houses. - Houses are an excellent invention. They and our clothing are the principal means whereby we satisfy the shelter need. It is difficult to tell which of these shelter providers was invented first. Primitive man probably began constructing or finding shelter among the rocks, or among the trees of the forest, just as soon as he began to clothe himself with the skins of wild animals or with rude garments made from the fibrous parts of plants.

Houses undoubtedly provide excellent protection from rain and wind and, usually, from cold. The only objection to them is that they may interfere (especially when artificially heated) with the supply of fresh air that we need. So we often hear it said that people stay indoors too much. We hear a good deal about the benefits of outdoor life, which means, besides exercise, plenty of fresh air and sunshine. These blessings indoor life cannot provide. Since man developed as an outdoor rather than as an indoor creature, his body is fashioned for outdoor rather than for indoor life; it pales and sickens if denied its heritage of fresh air, exercise, and sunshine. So there is 
virtue in sleeping either with the windows open, or out-ofdoors. Many modern houses have specially constructed sleeping porches, and these usually repay in health far more than they cost in money.

The health problem in house construction is evidently to provide adequate shelter, and at the same time provide as far as possible the health conditions of out-of-doors; it is to shut out the outdoor conditions which are disagreeable, and to admit those which are agreeable; it is to exclude cold and dampness, and at the same time to admit fresh air. But how are we to shut out the cold, without at the same time shutting out the air? They are, for practical purposes, one and the same thing. It is evidently a rather complicated problem. It is the problem of combining good heating with good ventilation. By ventilation is meant the delivery of fresh air and the removal of that which is impure. In warm weather, of course, this problem is simple, for then we can leave the doors and windows open as much as we like, closing them only to keep out rain and dust. But in cold weather this problem is always with us, and, to get satisfactory results, every member of the household should understand thoroughly the heating system which is used, and the rules which should be observed in controlling it.

Heating. - The log cabins of the early settlers were heated by the burning of wood in open fireplaces, and it was around the hearthstone that the family life centered. So the fireplace came to mean more than merely a place to keep warm. It was a place for rest and friendliness; a place for story-telling, and for the entertainment of a guest. It is a place which seems to soothe the heart of man, 
inviting friendliness and forgiveness, dismissing mistrust and hate. It is a place which makes it easier to tell one's thoughts, and people sitting together before the embers of a dying fire have come to know each other really better than in any other place in the world.

So it is easy to see why there is a great deal of sentiment about a fireplace, and why it is so pleasant a feature of a living-room. But, however good a fireplace may be for friendship and sentiment, it is not very good for practical heating purposes. It warms you well enough on one side, but on the other (unless there is some other source of heat) you are likely to be cold. Also, from the merely practical standpoint, a fireplace is a great waster of fuel. Most of the heat produced goes up the chimney. Yet even that has its advantages, for the warm and comparatively impure air which rushes up the chimney is replaced by fresh air drawn in from outside. Hence there is plenty of ventilation. Too much of it, if anything.

This suggestion as to waste of fuel indicates one of the principal factors in this problem. It is not difficult to get good ventilation so long as you don't care how much fuel you burn. If you keep letting the heated air out and fresh air in you will get plenty of ventilation, but it will be expensive to keep the house warm enough. So evidently the problem becomes to secure satisfactory ventilation with the least expenditure of fuel. The reason why many houses and other buildings are badly ventilated is that those in charge are thinking more about coal bills than they are about health. They care more about keeping heat in than about letting bad air out, and if you open a window they are apt to say: "Are you trying to heat all outdoors?" By the way, in "airing out" a room, why is it best to open 
a window both at the top and at the bottom, thus providing two openings?

After fireplaces came stoves, which are simply fire-holders so built that the consumption of fuel is economical and the transfer of heat is into the room rather than up the chimney. An important feature of the stove is the draft whereby air is admitted from below to provide the oxygen necessary for the burning of the fuel; the rate at which the fire burns may be controlled by the opening or closing of the draft. In the case of fireplaces, andirons are used to secure the needed draft of air from below. The draft (drawing) of air through the stove is also controlled by a damper, which is a movable plate by means of which the flue may be open or closed.

The closing of the flue, through which the hot gases from the fire flow, checks the draft, and so lowers the rate of burning. It also checks the heat from going up the chimney. So the damper is usually left open while the fire is starting, and then closed or partly closed when the fire is burning well. We should remember that wood and coal in burning give off gases, and it is the burning of these gases as well as the burning of solid fuel that produces the heat we feel. So we see that stoves have another advantage over fireplaces in that they give us the benefit of the heat from these burning gases more than fireplaces do.

A furnace is better than a stove in that, by means of it, the heat of a single fire may be conveyed over the whole house. It permits of greater economy in the consumption and in the transportation of fuel, as well as in the distribution of heat. A furnace, strictly speaking, is that part of a heating plant in which the heat is generated. For the conveyance of this heat to other points, 
various means are used; this conveyance may be by means of currents of hot air, of hot water, or of steam. (It is common to use the term furnace as applied to hot-air plants only, but there is no real reason why the term should be so restricted.)

The hot-air type is the cheapest type of heating plant to install, and has the further advantage of distributing heat more rapidly than other types. The chief objections to it are that it may also distribute dust, and that it may cause the air to become too dry to be comfortable. This latter objection may be considerably offset by keeping large pans of water under the registers through which the hot air comes into the rooms. You should

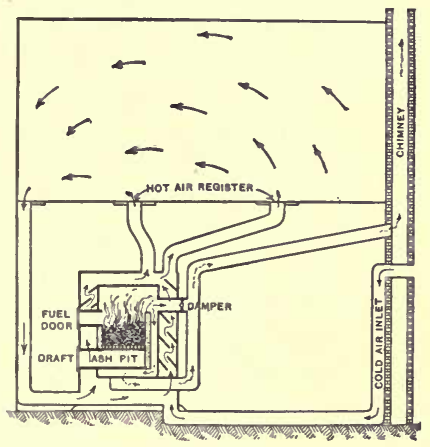

Fig. 75.-Diagram showing how a hot-air furnace works.-After MILLIKaN and GaLE.

remember that as air heats and expands it increases in power to absorb moisture. So, whatever heating system is used, provision needs to be made for keeping the air moist enough to be comfortable.

By studying Fig. 75 you can see how a hot-air furnace works. However, it is not quite as simple a matter as it seems. For one thing, there must be careful figuring to insure that enough fresh air enters the furnace to feed the hot-air pipes that lead away from it. You will note in the figure that only one cold-air flue enters the chamber 
(hot-air jacket) which surrounds the fire-box, while many flues lead away from it. Since air expands as it is heated, it is evident that the area of the cross-section of the feedflue does not have to be so large as the combined areas of the exit-flues; the right difference between them will be the difference between the volume of the

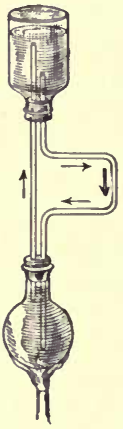

Fig. 76.-Diagram showing the principle of the hotwater heating system. Explain this. air when it enters the hot-air jacket and its volume when it leaves. Many hot-air furnaces do not work well for the reason that the feed-flue is not large enough in proportion to the exit-flues; often the efficiency of such a furnace will be greatly increased by adding another cold-air flue.

Then there is the question of whether the air which feeds the furnace shall be drawn from outdoors or indoors. That drawn from outdoors has the advantage of freshness. That drawn from indoors has the advantage of economy; it is already partly warmed; this arrangement has the advantage of insuring better circulation of air in the rooms from which it is drawn. Usually both of these sources of air are used; some is drawn in from outdoors, and some from the rooms above the furnace. This is the reason why you find in some rooms both cold-air and hot-air registers, the use of the former being simply to furnish an exit, the draft being into rather than out of it.

$A$ hot-water heating system, like a hot-air system, depends first on the distribution of heat by convection currents. The movements of convection currents of water may be nicely demonstrated by means of such an apparatus as that shown in Fig. 76; this shows clearly the principle of a hot- 
water heating apparatus. But let us note that, after the heat reaches the coils of pipe in the rooms above the furnace, it is then given off into the room by radiation; hence we call these coils of pipe radiators.

A hot-water system (see Fig. 77) requires that there be an open (expansion) tank at the top, so that, if steam forms, it may escape without bursting the pipes. When it does form, it causes "pounding" in the pipes, but it should not form if the furnace is properly controlled. Hot-water systems have the advantage of supplying an "even" heat; they also do not cause so much dryness of the air as do hot-air systems.

Steam-heating plants are operated on the same principle as hotwater plants, but they require a boiler in which the water is transformed to steam, and a pressuregauge which must be watched to

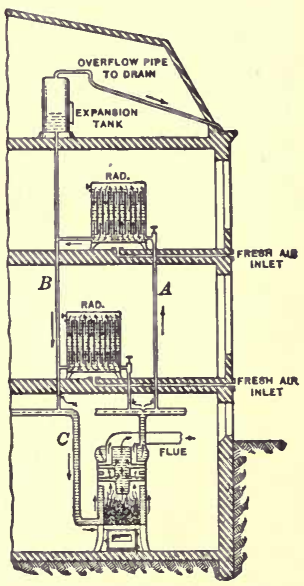

FIG. 77.-Diagram of a hotwater system. see that the proper amount of pressure is maintained. They are preferred in the heating of large buildings, or in the heating of several buildings by the same heating plant, for the reason that heat can be transported through pipes, for considerable distances, by means of steam more successfully than by means of hot air or hot water. Why is this so?

Sometimes combinations of heating systems are used. Thus the radiators of a hot-water or steam system may be 
placed in the basement in an enclosure through which air passes over them. This air, when heated, is delivered by flues to the rooms above. Very satisfactory results may be obtained by such an indirect system (see Fig. 78 ).

Ventilation. - You have already noted that the chief difficulty in ventilation is that it works at cross-purposes with heating; it is hard to ventilate a building properly

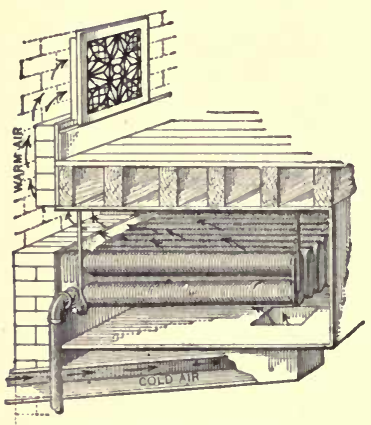

Fic. 78.-The indirect heating system. and at the same time to heat it sufficiently. In late years, however, it has been proved that, to make bad air good, it may not be necessary to change it. In other words, bad air may be made good by washing it and stirring it. This is done by driving it through a screen of falling water, whereby the disease-germs and other impurities are removed. Such ventilation systems have not come into general use, but they are successfully and economically operated in a number of places.

There is little doubt that the frequent colds that people catch in winter, and which so frequently lead to serious or even fatal illnesses, are largely due to poor ventilation. In badly ventilated rooms, especially in those used by the general public, disease-germs accumulate and multiply. Good ventilation would drive them out, or reduce their number below the danger-point. Bad ventilation particularly promotes tuberculosis, which is one of the 
greatest enemies of mankind. Doubtless you have heard of the fresh-air treatment for this disease. Doctors insist that tubercular patients shall have all the fresh air it is possible for them to get; this increases their power to resist and overcome the disease.

Ventilation was no problem at all when houses were loosely built and heated by fireplaces only. The heated air which rushed up the chimneys was quickly replaced by fresh air which came in under the doors and through other crevices. There were plenty of "drafts," which, though uncomfortable, probably did more good than harm. But now that man lives mostly in snugly built and usually overheated houses, he must give serious attention to his freshair supply. It is usually estimated that about two thousand cubic feet of fresh air per hour is desirable for each individual.

In private houses ventilation usually consists in simply opening the windows, and this may suffice if it is done often enough,

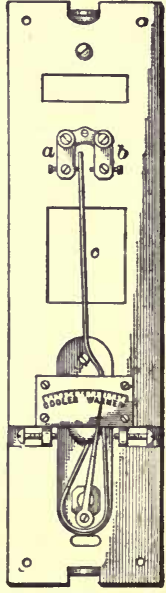

FIG. $79 .-$ The thermostat. and if circulation is provided by also opening some doors. But in the case of public buildings, especially in the case of public schools, there is need for the installation of special systems of ventilation. Very likely you have, noticed in your own schoolroom a large radiator in the wall through which fresh air blows into the room, and ducts through which bad air escapes. Large fans operated by electricity are commonly used to drive the air through such ventilating systems. Or the fans may be used to draw the bad air out of the rooms. The fresh air which is 
driven into rooms by a ventilating system is warmed first, but usually there is a heating system which is independent of the ventilating system, as well as co-operating with it.

A thermostat is a device for regulating temperature. It is a great convenience. You can set the hand of a thermostat at the desired temperature, and the heat-supply will be so regulated that this temperature will be attained and maintained as long as there is an adequate fire in the furnace. In the usual type of thermostat a small metal rod is attached to a curved strip of metal. The end of this rod lies between two electric terminals. If the temperature rises above what is desired, the rod, due to the expansion of the curved metal strip, at once comes in contact with one of the electric terminals, completing the circuit, and the heat-supply is thereby checked. If the temperature falls, the other circuit is completed, and the heat-supply is increased (see Fig. 79).

\section{QUESTIONS}

I. What is meant by ventilation?

2. How should a room be aired?

3. What are the advantages and disadvantages of a fireplace?

4. Why are stoves better than fireplaces?

5. What are the advantages and disadvantages of a hot-air furnace?

6. Why is the hot-water heating system better than the hot-air system?

7. What advantages have steam-heating plants?

8. What is the use of a thermostat? 


\section{CHAPTER XXVII}

\section{COMBUSTION}

If you have ever been the keeper of a furnace fire, you know that "firing" is not so easy as it seems. There is a good deal more to it than simply throwing in the coal and taking out the ashes. The fireman of a locomotive or of a steam-power plant, if he is efficient, must understand how to fire so as to secure the maximum of heat with the minimum consumption of fuel. This is a rather complicated matter and requires a thorough understanding of the laws of combustion.

There are various kinds of combustion. Burning is one kind. Rusting is another. The combustion of food within our bodies is yet another. Evidently, if these phenomena are examples of it, it must be a process which is important to understand.

What Combustion Is. - Combustion is the chemical uniting of a combustible substance with oxygen. It names a process which you have already considered under the name of oxidation. Oxidation names this process from the standpoint of oxygen; combustion names it rather from the standpoint of the substance which is oxidized.

That combustion is so common a process is due to the commonness of what we may call "oxygen-hunger." Many familiar substances show a sort of eagerness to change by uniting with oxygen whenever they have a chance. Since 
oxygen is a part of air, they evidently have plenty of chance to do this so far as the mere presence of oxygen is concerned. But, fortunately for us, the combustion of most inflammable substances requires more than the mere presence of air; it requires also more heat than is ordinarily present. Once the process is started, however, it may of itself generate enough heat to keep going until all the near-by combustible material has been consumed. All the fire departments and fire-insurance companies in the world are results of this simple fact. It explains why, when a fire gets started where we do not want it, we do our best to put it out.

You remember that the early scientists believed that fire was due to the escape from burning substances of a mysterious and invisible substance they called phlogiston. This phlogiston theory, absurd as it may seem now, has an important place in the history of science. It was only a little more than a hundred years ago that it was abandoned in favor of the modern theory of combustion.

The early scientists, though they misinterpreted the process of burning, did recognize that it and the process of rusting are similar processes. Iron-rust is iron plus oxygen in the form of a substance called iron oxide. This substance flakes away, and may finally disappear as dust, so we are apt to regard rusting as a process in which something is taken away from the iron. The iron does actually decay, but the thing for us to remember is that rusting, and much of what we call decay, are processes of oxidation, and that, as such, they involve the addition of something rather than the subtraction of something. In all kinds of combustion the resulting substances may be or become gaseous or liquid (iron-rust dissolves) and disappear, but the fact 
remains that the weight of all the substances resulting from combustion is exactly equal to the weight of the original substance plus the oxygen which has united with it.

Here, then, we have a statement of the modern explanation of combustion. It is an explanation which rests upon good evidence, for the products of combustion have repeatedly been carefully collected and weighed with results as indicated. You have already learned in your study of air that gas has weight which can be measured. So the gaseous, liquid, and solid substances which result from combustion, when all weighed, and their weights added, have always been found to exceed the weight of the original substance, the difference being the weight of the oxygen which has been taken on.

Inasmuch as the proof of this explanation of combustion depends upon very careful weighings, it does not surprise you to learn that this proof was one of the results which followed the perfection of balance scales, scales so perfected that they record the most delicate differences in weight. If the older scientists had had better scales, the right explanation of combustion would doubtless be much older than it is. So it has been with many of the greatest discoveries of science; they have resulted from the perfection of some mechanical device which enables man to get more evidence than he could get before. Thus the development of modern biology had to await the perfection of the microscope. To the physicist and chemist, delicate balances are quite as important as the microscope is to the biologist or the telescope is to the astronomer. One of the first discoveries made by the use of a delicate balance was that metal oxides, such as iron oxide, weigh more than the metals from which they are formed. In the light of 
this new evidence, the phlogiston theory was exploded, and the rest was comparatively easy.

Taking Care of a Furnace Fire. - Now to go back to the matter of taking care of a furnace fire. Two important things to accomplish are to get as much heat as possible out of the fuel used, and to prevent the formation of clinkers. These two things go together; you cannot succeed in the first if you fail to succeed in the second. A clinker is a mass which results from the fusion of coal which has been only partly burned; by its fusion it is so changed that it will not burn any more. This fusion of coal indicates that, due to overheating, coal may actually melt and run together before it burns up; the fused masses (clinkers) which result from this are useless for fuel, hinder the shaking down of ashes, and interfere with the draft.

So we see that to get the most heat out of coal we must not try to get it too fast; we must nurse the fire along; there is such a thing as giving it too much draft. The aim should be to provide a good circulation of air through the whole burning mass, so that it may become thoroughly oxidized in all its parts, and not fuse. Hence you may spoil your fire by giving it too much air from below; it is rather dangerous to leave the ash-door open. At the same time, this risk of too much air from below gives no excuse for letting the ashes accumulate. This will prevent access of air evenly to all parts of the fire; also, if the heap of ashes rises till it touches the grate-bars, it will (by adding to their heat through conduction) cause them to "burn out" (melt). Another thing which may cause clinkers is too rapid checking of the fire. When you 
close the draft, the check-damper should not be opened at the same time; not until a little later. For too rapid cooling off of the fire may also cause fusion. Another cause of clinkers is poor coal; sometimes you get coal which is so poor that even the most intelligent firing will not prevent clinkering. In such cases the coal-dealer should be compelled to give a rebate, or even to take the coal away.

It is evident that a good deal may be learned from taking care of a furnace. Just as a boy who takes care of a lawn intelligently will learn a good deal about botany, so, in taking care of a furnace, he has an excellent opportunity to learn something about physics and chemistry.

Some of the Products of Combustion. - Let us consider now what are some of the products of combustion. This depends entirely, of course, upon what it is that is being oxidized. You can get no products except those that result from the combination with oxygen of the materials which are already present. In the rusting of iron, you get only iron oxide. In the burning of wood or coal, you get a number of products; while in the combustion of substances within living bodies, you get an even greater variety.

Take the burning of a candle. By holding a saucer in the flame you can collect soot. Soot is carbon. It burns in the flame and becomes carbon dioxide. If you collect the gas given off from a burning candle, or from any other kind of burning, you will find that it is largely made up of carbon dioxide. Smoke is unconsumed carbon. The more smoke that a fire gives off, the less efficient it is in consuming its fuel; smoke indicates that some carbon, before it is oxidized, gets away from the range of sufficient heat to oxidize it. So smoke should be, 
suppressed, not only because it is a nuisance, but also because such suppression means greater economy in fuel consumption.

By holding a cold piece of iron in the flame, and removing it before it gets too hot, you can collect drops of water. This indicates that the candle contains hydrogen as well as oxygen, and that this hydrogen is being oxidized, thus forming water. Of course the heat causes this water to be given off as invisible water vapor.

Old-fashioned candles were made of tallow, which was derived from animal fat. The molecules of fat are composed of just three elements: carbon, hydrogen, and oxygen. Modern candles are usually made from substances derived from petroleum, but, like tallow, these substances are composed of carbon, hydrogen, and oxygen only. So evidently when we have collected carbon, carbon dioxide, and water from the burning of a candle, we have accounted for all the substances which compose it.

The flame of a candle is cone-shaped. The center of this cone, as you have proved by collecting carbon from it, is composed of substance transforrned by heat into a gaseous state, but not yet completely oxidized. It is oxidized when it reaches the surface of the cone, the part which is luminous. You can prove the presence of unconsumed gases in the center of a candle flame by introducing there the end of a small glass tube. If you hold a match at the other end of this tube, a flame will appear.

Energy Released by Combustion. - Thus far we have discussed only the substances resulting from combustion. But we are also familiar with the fact that, in combustion, energy is released. This energy, in cases of burning, we 
perceive in the forms of light and heat. In the rusting of iron we do not perceive it; it is too small in amount at any given time to be perceptible to our senses, yet it is measurable by means of instruments of precision which are used in physical laboratories. In the case of our own bodies, combustion releases energy which is manifested both by the heat of our bodies and by the motions of our muscles.

It may occur to you that this energy release should in some way confuse the results obtained by weighing the substances which result from combustion and comparing their weight with that of the original substance. But let us remember that energy is not a substance and cannot be weighed. Let us also note that we speak of the release of this energy rather than of its production, for energy, as you know, cannot be produced; it can only be transformed. So combustion is a process of energy transformation as well as of substance alteration. The energy which was confined or "stored up" in the combustible substance is released, and we may perceive it as light, heat, or motion.

\section{QUESTIONS}

I. What is combustion?

2. What is rusting?

3. Does rust weigh more or less than the iron which formed it?

4. What are clinkers?

5. What are smoke and soot?

6. Is smoke necessary?

7. What chemical elements are involved when a candle burns?

8. What transformation of energy takes place when wood burns? 


\section{CHAPTER XXVIII}

\section{LIGHT, COLOR, AND SOUND}

We have noted that combustion may result in light, heat, or motion, or in combinations of these. To heat and motion we have already given considerable attention. It is time now to study light and to learn something of its nature and behavior.

Light and Heat Much Alike. - The first thing for us to appreciate is that light and heat are much alike. They are both forms of radiant energy. Their apparent great differences are due to the differences in the effects they produce on us.

This sameness-of-nature or kinship of light and heat is indicated by many familiar phenomena. We know that heat may be very readily transformed into light; similarly, light may be transformed into heat. We know that white clothes are cooler than dark clothes, even though of the same weight; this is because white clothes reflect the light, while dark clothes absorb it, and transform part of it into heat. We know that sunlight striking through glass, as in greenhouses, causes increase of temperature even though the air outside may be cold; this is because the light-rays are absorbed after they pass through the glass, some of them are transformed into heat, and the heat-rays cannot escape by passing through the glass as the light-rays did. We know that in burning, both light and heat usually appear, and it is hard to tell where one 
stops and the other begins; they seem to merge; a flame seems to be both light and heat. All these, and many similar phenomena, indicate the close relationship of the two forms of energy.

What Light Is. - Now we come to the question, what is light? Heat we found to be molecular motion, the heat that we feel being the effect that this motion produces on us. But did it occur to you to ask, when studying heat, how, if it be molecular motion, does it get to us from the sun through the tremendous spaces which are practically empty, practically without molecules? Now you are in a position to understand this.

Heat, we can still say, is molecular movement wherever there are molecules to move, and, since our personal experiences are confined to spaces which are well filled with molecules, this, for practical purposes, does pretty well as a definition of heat. But we must also allow that heat passes through space which is empty of molecules. This we explain on the theory that heat is vibration, and that its passage through empty space is as vibrations of the ether. What ether is no one knows, but it is the physicists' term for whatever it is that occupies empty (molecularly empty) space. When these vibrations of the ether encounter the fringes of the atmosphere, they cause vibration of the atmospheric molecules. So we may properly say that, from here on, heat is molecular motion. These vibrations or motions which constitute heat are wave-like, and these waves, by means of fine instruments, are actually measurable as to their length and as to the speed with which they travel.

Have you ever tossed a stone into a pool of still water, 
and watched the ripples as they circle outward, getting fainter and fainter until they are imperceptible? Here is another case of the vibrations by which radiant energy is transmitted, and, since it is a case in which waves may actually be seen, it may help us understand the cases in which the waves cannot be seen. We see waves only on the surface of water, but invisible ones also travel downward through it.

We must not think of a wave as the motion of a mass; it is rather the motion of a motion as it travels through a mass, whether this mass be air, or water, or a sheet that you wave in your arms. So a wave on water is not a mass of water which moves forward; it is rather the effect of a vibration of water which produces undulations as it progresses.

Have you ever had your head under water when some one struck stones together near you? Then you know that sound-waves travelling through water produce on us an altogether different effect from that produced when they travel through air.

Now you can better appreciate the kinship between light and heat. For light and heat (and sound, too) are all simply vibrations of wave-like nature, which, considered from the standpoint of physics (that is, apart from the effects they produce on living things), are entirely of the same nature except for the difference in their wave-lengths. So you see that all forms of radiant energy are alike as to their essential nature; they differ only with respect to wave-length. They also differ with respect to the speed at which they travel and with respect to the effects they produce, but both of these things appear to be merely results of differences in wave-length. 
Now you can understand that the apparent merging of light and heat is more than an appearance; it is an actual fact, for there are waves of radiant energy of certain lengths that do actually produce upon our sense-organs the effects of both light and heat. Also you can see that, by interfering with the waves of light or heat rays, and thereby altering their length, heat may be changed to light, or light to heat. Similarly, as you have doubtless noted, the little waves on water change their length when they strike a rock or are otherwise interfered with.

So we may go back to our question, what is light? We find that it really isn't a thing, but it is an effect. That is, it isn't a thing any more than pain or pleasure are real things. It is simply an effect produced on us, through the instrumentality of our eyes, by waves of radiant energy of certain lengths. Eyes different from ours may get entirely different sensations of light from ours. Thus we say that a cat can see at night, while to an insect this undoubtedly appears to be a very different world from what it appears to us. You know that a tuning-fork across the room will respond to sound vibrations of a certain pitch which are set up by striking a note on the piano. Similarly, we may regard some of our sense-organs as instruments tuned up to certain pitches; to certain kinds of vibrations they respond, to others they do not. If there were no eyes to see, or ears to hear, or skin to feel, would the things we call light, sound, and heat then really exist?

Light-waves are shorter than those of heat, and travel faster. They are very much shorter than those of sound, and travel correspondingly faster. This fact you have witnessed many times. You have seen the steam rise from a locomotive-whistle before you have heard the 
whistle; you have seen the flash of a gun before you heard the report; and you have seen the lightning flash before you have heard the thunder. Sound travels at the rate of about eleven hundred feet a second, but light has the tremendous velocity of one hundred and eighty-six thousand miles a second. Yet, as you may have heard, so remote are some of the distant stars that it requires many years for their light to reach us.

Color. - Now light-waves themselves are not all of the same length. What we see as white light is simply the composite effect of light-rays whose wave-lengths are slightly different. It is possible to separate the rays which compose white light in such a manner that each kind of ray produces a separate effect. You have seen this result, and you have often marvelled at the beauty of it. You have seen it whenever you have looked at a rainbow.

A rainbow gives us what is called the solar spectrum, by which is meant a separation of the visible rays of the sun in such a manner that each kind produces its own effect upon the eye. These different effects we call colors. As you may have learned in using paint or water-colors, white is not a color, but is a "combination of all colors," while black is "the absence of color."

Now we are in a position to define color. Why is it that one object looks green while another may look red? It is simply because the surface of the green object is of such nature that it absorbs all the rays of light that strike it, except those which produce the effect of green. Similarly, a red object reflects only those which produce an effect of red. So we may define the color of an object as the effect produced on us by the light-rays which it reflects. For 
example, leaves look green to us not exactly because they are green (though it is quite right to say they are), but because the light which they fail to absorb and which they reflect back to our eyes produces an effect of green.

Surely you have noticed that the color of objects is not quite the same when viewed by artificial light as when viewed by daylight; thus, by artificial light it is hard to tell blue from green. Evidently, then, the color of an object depends to some extent upon the nature of the light that is shining upon it.

This suggests an interesting and significant fact. If gaslight, for example, produces light effects that are different from those produced by sunlight, does it not follow that the spectrum of gaslight will be different from the spectrum of sunlight? If an object which is blue in sunlight is not blue in another kind of light, does it not follow that the other kind of light lacks blue rays? For surely the object does not change its nature whenever it is changed from one kind of light into another; the change of color must be due to differences in the kinds of light.

Such thoughts as these led scientists to examine carefully the spectra produced by various kinds of light, and it was found to be a fact that every kind of substance capable of releasing light releases a kind which is different from all other kinds. Thus certain substances when they burn release light which contains no blue rays. Thus we see why an object blue by daylight may fail to be blue by artificial light.

Now since it has been found that every kind of substance when it burns releases its own kind of light, it follows that if the spectrum characteristic of a certain substance ke known, then it may be possible to tell what a substance 
is by merely obtaining the spectrum of its light. It is by this means that scientists have been able to discover important facts about the chemical nature of heavenly bodies. So far as their researches have gone, they have been unable to discover any element in the heavenly bodies which is different from the elements here on earth. Does not this suggest a common origin for all the heavenly bodies?

Reflection of Light. - We have noted that light may be absorbed or may be reflected. Light-rays, unless inter-

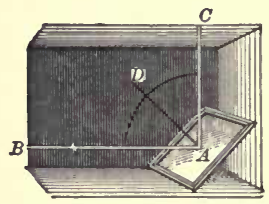

Fic. 80.-How does this diagram show that the angle of incidence is equal to the angle of reflection? fered with, travel in straight lines, and the principle of their reflection is the same as the principle which governs the rebound of a ball. That is, the angle of incidence is equal to the angle of reflection (see Fig. 80). We see this principle in operation when a billiard-ball rebounds from a cushion, or a tennisball from a concrete sidewalk, or we may study it very interestingly by observing the way in which mirrors reflect images.

Refraction. - There are other things than absorption and reflection which may happen to light-rays when they encounter surfaces. One of these is refraction, which means that the light-ray is bent. This explains why a spoon, or an oar, or anything else, looks bent when partly immersed in water. It seems to bend at the point where it enters the water. This is because of the greater density of water as compared with air; because of this difference in density, light passes through water in a direction somewhat altered 
from that of its passage through air; rays of light, as they pass from a less dense to a more dense medium, or the reverse, are modified in direction. So the light reflected back to our eye from the part of an object that is under water, changes slightly in direction as it passes from the surface of the water (see Fig. 8I). But our eyes see things only in straight lines; they do not make the correction which refraction requires

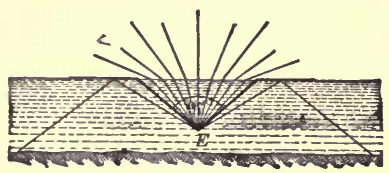

FIG. 81.-Diagram showing how the lightwaves fom object $E$, under water, are bent (refracted) as they go from water into air at various angles. in order to give us the right position of an object. We must make this correction with our brains, as boys do when shooting or spearing for fish.

Diffusion. - We should also note that light upon encountering rough surfaces is dispersed in all directions rather than being reflected in straight lines (see Fig. 82). Thus ground (roughened) glass reflects light irregularly rather
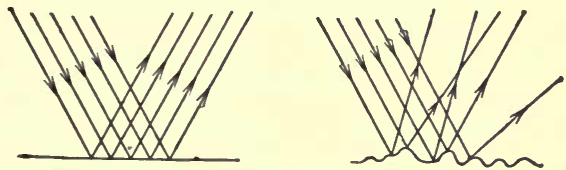

Fig. 82.-D:agram showing how smooth and rough surfaces reflect light.-After Millikan and Gale.

than in straight lines, or permitting it to pass through. Such dispersal or uneven reflection of light is called diffusion. We have noted the great importance of the diffusion of light by dust and water particles in the atmosphere. It is this diffused light which lights up the shaded places. 
Except for it, there would be stronger contrasts between sunlight and shadow. Such contrasts are characteristic of dry, clear air, as in Arizona or New Mexico.

Transmission of Light. - If the light which encounters a substance simply continues on its way without modification we say that it is transmitted, and we call the substance through which it is transmitted transparent or translucent, depending upon the extent to which light passes through it; if it does not transmit light, we call it opaque. Smooth glass is transparent, while a sheet of white paper is translucent. A substance may both permit transmission and cause reflection. This you have noted in passing showwindows which are in the shade; they reflect your image while at the same time permitting you to see through them.

So we may sum up by saying that the various things that happen to light are transmission, reflection, absorption, diffusion, and refraction. You will find that, in consequence of these various light phenomena, various effects are produced which are of great importance to all of us.

\section{QUESTIONS}

I. Why are black clothes warmer than white?

2. Why are greenhouses warmer than the air outside?

3. What is the difference between light and heat?

4. How can light be changed to heat?

5. How do the waves of light, heat, and sound compare in length and speed?

6. What is a rainbow?

7. Explain how color is produced.

8. Why does a stick look bent when partly immersed in water?

9. What is the difference between transparent and translucent objects? 


\section{CHAPTER XXIX}

\section{SOME EFFECTS OF LIGHT. PHOTOGRAPHY PHOTOSYNTHESIS}

Cause of the Spectrum. - You have learned that the rainbow is due to the separation of sunlight into its rays of different wave-lengths. You have also noticed that rainbows appear only when the sun is low enough in the sky that the effects produced by fine drops of water are reflected back to us from the other side of the heavens. Now that you have studied refraction, you can understand why drops of water may cause the breaking up of light into its spectrum. Each kind of ray is refracted in a slightly different manner from the other kinds, dependent upon the nature of its wave-length. Then, if there be behind the refracting surface another surface that catches and reflects back to us the rays that have thus become separated into their own kinds, our eyes receive the image of a spectrum.

You have seen rainbows in the spray of a fountain or lawn-sprinkler. The drops of water, just as in the case of a rainbow in the sky, act both as refractors and as reflectors.

Also you can see why a glass prism may produce a spectrum. Note that in the spectrum produced by a prism in the manner shown in the figure the colors occur in the following order, reading upward: red, orange, yellow, green, blue, indigo, and violet. This is because the red rays, whose wave-lengths are longest, are refracted least, while the violet rays, whose wave-lengths are shortest, are refracted most. This order of the colors of the spec- 
trum is useful to remember; you can do so easily by recalling the initials of the colors in the proper order, namely, roygbiv.

Lenses are bits of glass very carefully manufactured so as to be perfectly uniform in texture and then very care-

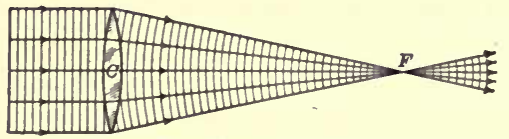

FIG. 83.-Diagram showing the effect of the convex lens on light-waves.

fully shaped by grinding them so that their refraction of light is geometrically perfect. A convex lens (see Fig. 83) refracts light so that it converges to a point (the focus) at the side of the lens opposite to the source of light. A concave lens refracts light so that it does not converge, but spreads (see Fig. 84). Now suppose that your eye is at the point marked $F$ in Fig. $8_{3}$, and that you are trying to look through the lens at an object on the other side of it. First you will so adjust the distance between your eye and the lens that the image of the object comes to a focus upon that part of your eye (the retina) that is sensitive to images, for otherwise the image will appear blurred or you cannot see it at all. Do you not see that the effect produced by thus look-

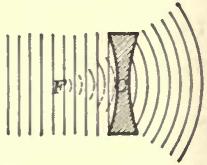

FIG. 8 4. - Diagram showing the effect of the concave lens on light-waves. ing at an object through a convex lens is to make it look larger; that is, to magnify it? If you remove the lens and look at the object with the naked eye, it at once looks smaller. A concave lens has the reverse effect. Thus you can see why convex lenses are used in the glasses for near-sighted eyes, while concave lenses are used for far-sighted eyes. 
A microscope (mikros, small; scopein, to appear) is an instrument to make "small objects appear," as the origin of its name very nicely indicates. That is, it permits us, by enlarging their images, to see objects which otherwise, on account of their smallness, we could not see. A compound microscope is one in which several lenses are used, and in which the object is examined by the aid of light which is reflected through it from below upward (study Fig. 85).

A telescope (tela, far) is an instrument which enlarges the image of remote objects and so seems to bring them near. You

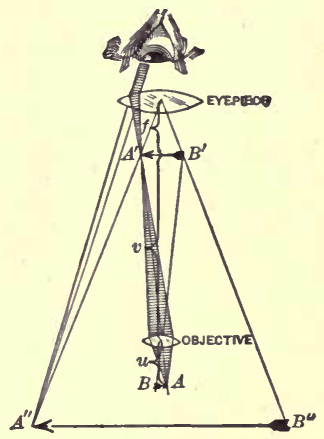

FIG. 85.-Diagram showing the principle of the compound microscope. can readily see that the perfection of both these instruments has depended upon the perfection of the art of lens manufacture.

Photography (photos, light; graphein, to write), or the "writing of light," depends upon various effects produced upon light and by it. It depends upon the refraction of

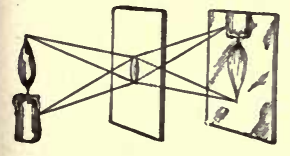

FIG. 86.-Diagram illustrating the principle of photographing. light by the lens of the camera, so that the light reflected from the objects to be photographed is focussed upon the sensitive plate or film upon which the image or "picture" is to be recorded. Since light from other sources would con- 
fuse the result (spoil the picture), the construction of the camera must be such that light enters it only from the objects which are to be photographed (study Fig. 86). The recording of the image depends upon the fact that light is absorbed by the substance (usually silver chloride or bromide) which coats the plate or film, and upon being absorbed it decomposes this substance. Thus the image of white objects appears black when the plate or film is developed, dark objects appear light, and gray effects are produced by objects which were intermediate between light and dark (colored). You can readily understand that this is because the light reflected from light objects destroys the chemical coating, while dark objects can produce no such effect because they do not reflect light. Also you can see why the developed plates or films are called negatives. Positives, in which the normal appearance is restored, are produced by placing the negatives over specially prepared paper, and exposing both to sunlight. The paper will then be altered as the negative was, but with reverse effects. This process is called printing the picture.

Candle-Power. - The intensity or strength of light is usually measured in terms of a unit called candle-power. As a basis for this system of measuring there must be, of course, a standard type of candle, uniform in all its details. The candle-power of an electric lamp may be measured as indicated in Fig. 87. Suppose the candle be set just one foot from the upright rod. Then we will move the lamp along line $a b$ until we find the point at which the shadow it casts on the screen is just equal in intensity (darkness) with the shadow cast by the candle. Suppose this point is just four feet from the rod. We know then 
that the lamp has sixteen candle-power, for light decreases in density as the square of its distance from the source. That is, if you are twice as far from a lamp as some one else, you are getting (at least directly from the lamp) only one-fourth as much light, which is easy to understand when you remember that the light is radiating out in every direction. So we see that an electric lamp which, at four

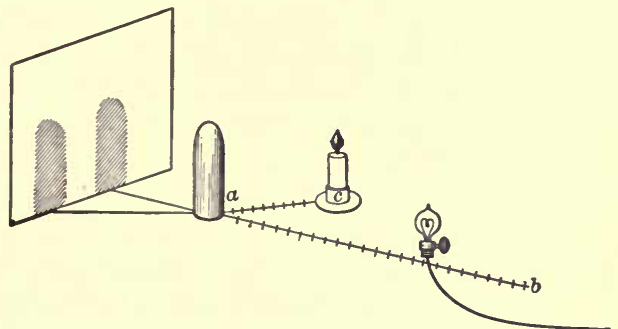

Fig. 87.-Diagram illustrating how candle-power may be measured, as explained in text.

feet, produces the same intensity of light or shadow as a candle at one foot, has a candle-power of four squared, that is, sixteen.

Photosynthesis. - You have noted the great importance to man of certain effects that light produces on him. Yet far more important to man than any of these is an effect which it does not produce on him; an effect which it produces directly upon green plants, but which, indirectly, is of vast importance to all other living creatures.

Blindness is one of the greatest of misfortunes, and yet one can live without seeing; that is, he can live without witnessing all the effects of light which we have been con- 
sidering, which, to perceive, one must have the power of sight. But even blind people could not live were it not for the effect of light upon green leaves. For every man must have food, and the basis of all food-supply is that manufacture of it which goes on in greer. leaves when, and only when, light is received by them.

This process of food manufacture in green leaves you have already learned. It is called photosynthesis, which, except for its length, is a very good name for it. It is a .word which explains its own meaning. The photo in it means light. Syn means together. Thesis means putting. So the whole word may be translated putting together in the light, and it refers to the power of the plant to put together in the light certain substances in such a way that they form food, food of the class known as carbohydrates, of which starch and sugar are examples. Photosynthesis is not all that there is to food making. The food which is made by photosynthesis may be afterward transformed into other kinds of foods. But photosynthesis is the only process by which food is made out of materials which are not themselves food. We ourselves have the power to transform foods from one kind into another, but we do not have the power to make food out of materials which are not food. This is done only by green plants. In the foods which they manufacture they store up energy which is derived from sunlight. 


\section{QUESTIONS}

I. Explain the rainbow.

2. What is a spectrum, and how is it produced?

3. How do convex and concave lenses affect light-rays?

4. What is the principle of a compound microscope and of a telescope?

5. How are photographs made?

6. What relation does light hold to food production?

7. Why are leaves green? 


\section{CHAPTER XXX}

\section{FOOD. THE NUTRITIVE CYCLE}

You have just noted that photosynthesis is the manufacture of only one kind of food - carbohydrate fcod. Evidently, it is important for us to find out what other kinds of food there are. We have been studying inorganic phenomena of nature, especially with reference to their relations to life. Now if we are to see how this inorganic realm of nature is related to life in the most important way of all, we must surely study food. For it is by means of food that the actual stuff of life (protoplasm) and the structures that it inhabits (bodies) are built up out of the inorganic materials of earth.

What Food Is. - So let us first ask ourselves, what is food? It is a popular rather than a scientific term, and does not have a very precise meaning. Ordinarily it refers to anything which, when taken into the body, contributes to the growth, energy, or repair of the body. So we may take this as our "working definition" of food. But in applying this definition, some questions arise. Is water a food? We shall have to admit that it contributes to the growth of the body. Is air a food? We shall have to admit that it is essential to the release of energy in the body. And yet air and water are quite different from the things we ordinarily think of as food - such things as tread, meat, and potatoes. 
Bread, meat, and potatoes are organic substances, while air, water, and salt are inorganic substances. So, if we are to regard the latter group as food, we evidently should recognize a great and fundamental distinction that exists between organic and inorganic foods; it is only the organic foods that can supply energy to living things or contribute to their living substance; "inorganic foods" are necessary to life, and yet they have an entirely different relationship to it from that of the organic foods; they provide the physical conditions under which life operates rather than providing anything which becomes a part of life itself.

To some writers this distinction seems so important that they use the word food as applied to organic substances only. Such usage makes the elementary study of food much clearer. Thus when you consider photosynthesis, you find that in this process green plants transform certain inorganic substances (water and carbon dioxide) into a certain class of organic substances (carbohydrates). Now shall we call both the product of this process and the raw materials it uses by the same name, i. e., food? If we do so, we shall be saying that plants manufacture food, and at the same time be saying that they get their food from the air (carbon dioxide) and from the soil (water). This is so confusing and inconsistent that it is evidently better to call only the finished product food, and to call the raw materials food-substance or food-material. Thus we not only make our meaning more clear, but we emphasize one of the two most fundamental changes which occur in what we call the cycle of life, namely, the transformation of inorganic substances into organic ones. The other great change is the transformation of organic substances back to inorganic, thus completing the cycle. 
Carbohydrates. - You have learned that photosynthesis produces carbohydrates, of which starch and sugar are examples. Carbohydrates are substances composed of carbon, hydrogen, and oxygen only, and in their molecules the atoms of hydrogen and oxygen always occur in the proportion of two to one, as in water. Thus the molecule of a common kind of sugar (there are many kinds) has the formula $\mathrm{C}_{6} \mathrm{H}_{12} \mathrm{O}_{6}$, which indicates that a molecule of this kind of sugar is composed of six atoms of carbon, twelve of hydrogen, and six of oxygen. The proportion of carbon in different carbohydrates varies, but that of hydrogen and oxygen always remains the same. Now in photosynthesis, for every molecule of water $\left(\mathrm{H}_{2} \mathrm{O}\right)$ used it is believed that a molecule of carbon dioxide $\left(\mathrm{CO}_{2}\right)$ is also used. Since the proportion of hydrogen to oxygen in these two kinds of molecules taken together is two of hydrogen to three of oxygen, it is evident that in the manufacture of carbohydrates from these substances (photosynthesis), there will be a considerable surplus of oxygen. This you have already learned in considering the maintenance of the oxygensupply in the atmosphere.

Most of our food contains more or less of carbohydrate. Carbohydrate foods are of especial importance as sources of the energy that we expend.

Fats. - The fats constitute another great class of foods. You have already learned in connection with your study of combustion that fat is composed of just the same elements as carbohydrate. The chief difference is that the proportion of oxygen in them is a great deal less than it is in carbohydrates. So fats have a greater oxygenhunger than have the other kinds of foods; they burn 
much more readily. Have you not seen how easily. the fat catches fire when steak is broiled? Fats are important in our diet especially for their fuel value; they help to keep us warm; we eat more of them in winter than in summer.

Proteins. - The third great class of foods is the class called proteins, and now we have reached a subject concerning which our ignorance is greater than our knowledge. For the science of chemistry has not yet revealed the exact composition of the molecules of proteins; we cannot write a chemical formula for them as we can for fats and carbohydrates. Why not? Simply because these substances are so complex that they defy chemical analysis. As soon as the chemist begins to work with them, their molecules "break down" into other substances. Then all he can do is to determine what are the elements which compose their molecules. As to the proportions of these elements in the protein molecule, or as to how they are arranged with reference to one another, he is quite at a loss to tell. So you see why we have no definite formulas for protein molecules; our knowledge of them is quite limited.

Yet we do know that proteins contain all the elements that carbohydrates and fats contain, and a number of others besides. Of these others, nitrogen is the most conspicuous. Indeed, it is so conspicuous that it is customary to speak of the proteins as nitrogenous foods, and of all others as non-nitrogenous foods. Other elements present in proteins in minor and varying amounts are phosphorus, iron, and sulphur.

Proteins are essential for the growth and repair of the body. They are the great tissue-formers. Our muscles 
are chiefly composed of them, and the muscles of animals (meat) furnish us our chief supply of them. They are also present in vegetable foods, especially in peas and beans. (Why especially in peas and beans?)

Protoplasm. - The proteins gradually merge into that mysterious, semifluid substance which Huxley first called the physical basis of life. We call it mysterious because we know so little of its origin or of its nature. With its behavior we are familiar. Its presence in all living things is observable, and all the "manifestations of life" seem to depend upon its activity. It responds in definite ways to changes in the conditions which surround it, yet some of its activities do not seem to be of the nature of responses; they seem to be self-initiated; at least scientists have never been able to determine the causes of such activities. So here, you see, we have a substance which is a sort of "holy of holies" of life, into which man with all his cunning has not yet been able to penetrate. In it are the mysteries of life, and whether it be in the lowliest plant or in the brain of the wisest man, it has, for aught we know, the same physical nature. At least it seems to be composed of the same elements, and no element has ever been found in it which is different from those found in the non-living world. When this substance comes to be known, if it ever is, the secrets of life will be known as they have never been known before. This is the substance which you have already learned to call protoplasm.

The Nutritive Cycle. - You should study carefully the diagram on page 237 , and try thoroughly to understand its significance. For nothing so completely indicates the 
dependence of life upon its environments as do the facts which this diagram represents. If you can form a clear picture in your mind of what is called the nutritive cycle (which is what this diagram portrays), then you have grasped some of the greatest and most fundamental principles of life.

Note first the absolutely inorganic nature of the materials with which the process of food construction is begun; the AIR

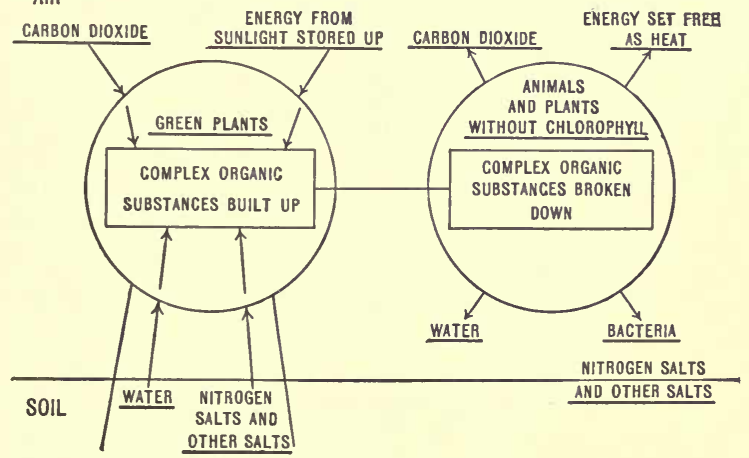

FIG. 88.-The nutritive cycle.

materials which the protoplasm of green leaves uses in the process, and by means of which this "living stuff" maintains and renews itself. These materials (carbon dioxide and water) existed on earth long before life began, and they exist on other worlds than ours.

But let us note at once that more than these raw materials, and the protoplasm which acts upon them, are necessary to the process. There must be light. It is from sunlight that green leaves absorb that radiant energy 
that they utilize in this process, and store up in its products in latent form, to be released again when these products are oxidized.

The protoplasm of green leaves produces a substance which acts as the means whereby the needed sunlight is absorbed. Evidently, then, it is this light-absorbing substance that makes the leaves look green. If the spectrum of sunlight is examined after it has passed through a solution of this substance, dark bands are found in it; these dark bands indicate what rays are absorbed by this substance; they show us just what are those rays of sunlight upon which our food-supply depends. This light-absorbing, green-appearing substance is called chlorophyll. It occurs in all green parts of plants in units of structure called chloroplasts, which are microscopic bodies composed of protoplasm and the chlorophyll which the protoplasm secretes. These chloroplasts are, then, the real organs of photosynthesis, and now you are in a position to understand the scientific definition of this process, which is as follows:

Photosynthesis is the manufacture of carbohydrates by chloroplasts in the presence and by the aid of sunlight, water and carbon dioxide being used, and a surplus of oxygen being given off.

Passing upward on the diagram beyond photosynthesis, we note the appearance of fats and proteins, the latter involving the addition of a number of new elements. Fat and protein formation do not require light, and may occur in animals as well as in plants, but always carbohydrates are necessary as a basis. All these processes are, of course, expressions of the activity of the protoplasm.

Oxidation of foods, involving the release of energy and 
the breaking down of their molecules into simpler compounds (waste substances), may occur at any point above the carbohydrate stage, as is indicated by the arrowed lines that run across the diagram from left to right. Yet some of the food, of course, is destined to continue in the process of elaboration until it becomes a part of the protoplasm itself. For the protoplasm itself is constantly breaking down and must constantly be renewed. Now you can see why it is believed to be true, as you have probably heard, that at the end of seven years every part and particle of the human body has been changed, so that nothing which was there seven years ago is there now; in most of the body the changes or replacements are even more rapid. Now, too, you can understand better what was meant by the statement that life is a procession of changes. Huxley said of protoplasm that it is like a whirlpool in that it is ever changing, yet still the same.

On the descending side of the circle you get new evidence of the immense importance of bacteria. Here they appear as the chief assistants to the process of oxidation in completing the cycle, in reducing dead and waste organic stuff to the inorganic state again. What would be the disadvantage to life in case the cycle were not complete at this point?

The Artificial Manufacture of Food.-Physics and chemistry are commonly considered to be those branches of science that have contributed most to man's convenience. But as you study this diagram and consider its significance, do you not see that the greatest invention of the future will be the invention of a biologist? Physics and chemistry will continue to contribute much to man's convenience, 
but biology (the science of life) will make the greatest contribution of the future to his welfare. Already biology has contributed much to the science of health and to the science of agriculture, but the great contribution which it may make in the future is the artificial manufacture of food. For do you not see that if man is once able to understand that process that goes on in every green leaf, and to duplicate it, then the food problem is forever solved? It is simply a question of taking certain simple and abundant inorganic materials and transforming them into carbohydrates. It sounds simple enough, and it is a thing which occurs constantly all about us, wherever light and green leaves come together, and yet man, with all his clever contrivances and "harnessing" of nature, has never yet been able even faintly to imitate the process of the leaf whereby it "harnesses" sunlight and thereby works the great transformation of inorganic into organic.

Of course this idea of the artificial manufacture of food is "urely speculation, and may never occur. Yet consideration of it should help us to realize how great is our dependence upon plants. They are partners in life with us, and we, with them, live only as we are related rightly to the great inorganic forces and substances of the universe, out of which somehow, mysteriously, we have come, in the midst of which for a very little time we live, and into which our bodies will surely be gathered again when we go. 
r. What is food?

\section{QUESTIONS}

2. What are carbohydrates and how are they produced?

3. What element is given off when food is manufactured by green plants, and why?

4. Which burn more readily, fats or carbohydrates? Why?

5. How do proteins differ from fats and carbohydrates?

6. Why do we call protoplasm "the living material"?

7. What is the process of photosynthesis?

8. What is the work of bacteria in the "cycle of life"? 


\section{CHAPTER XXXI}

\section{PLANT LIFE}

How Plants Work. - You have seen how light and heat and air and water and soil are related to our lives. Now, the green plants must be added to our mental picture before we can really understand how we live. We must see the green plants at work in the midst of these other things and understand how they work.

Think, then, of a young corn-plant. There it stands alive and at work in the midst of millions of others. Its leaves are spread to the sunlight while its roots burrow in the dark among the soil grains. Somehow, from soil and air, it gathers materials, transforms them into food, and stores this food in the swelling grains. This is the process we must try to understand. This is work that all green plants do. It is work that animals cannot do; they must depend upon plants for this great process of changing inorganic substances in to organic ones, the building up of food. Plant bodies, like our own, cannot take in solid materials. The substances that enter them must be in either liquid or gaseous form. So the corn-plant takes in liquids and gases. It also gives out gas in the form of water vapor that evaporates from its leaves. It cannot live without a constant income and outgo of materials. Neither can we.

Roots. - The roots burrow deeply in the soil, and, near their tips, they produce millions of delicate hairs called 
root-hairs (see Fig. 36). The root-hairs have thin walls. These thin walls are pressed closely to the soil grains, and through them the plant absorbs the liquid that it needs. This liquid is the water of the soil, and substances that are dissolved in it. The plant has no organs like ours in which the digestion of solids occurs before they are absorbed. It has to depend upon the water outside its own body to dissolve the substances that it needs to take in.

The gas-absorbing apparatus is at the opposite end of the plant. Here the leaves stand in the light, and, in the skin of the leaves, usually on the under surface, are thousands of small pores through which air passes freely. Up to these leaves passes the water that the roots take in, and thence it passes out into the air as water vapor.

The absorbing root-hairs need to be deep in the soil, for there is the water that they absorb. Only deeprooted corn-plants can keep on growing through a long drought; the shallow-rooted ones soon die. The leaves, on the other hand, to do their work, must be up in the air and the light.

So we see that there are three great relations with environment that every food-making plant must have if it is to live and grow. These three are the water-relation, the airrelation, and the light-relation. Of these three, the airrelation presents the simplest problem, and the waterrelation usually the most difficult. Lack of water kills more plants than all other causes combined. Lack of light also kills many plants. In forests millions of young plants die because they are overshadowed. In dense forests the light problem is more difficult than the water problem.

Now you can look with the mind's eye at all the green 
plants in the world, and you can begin to understand their various forms. For you know that all green plants are trying to do the same thing. They are trying to relate their root-hairs favorably to soil-water, and their leaves favorably to light and air. All of the plant that lies between root-hairs at one end and leaves at the other simply helps in getting these two things in good positions for their work. The deep-burrowing roots of trees are necessary to anchor the trunk and branches, as well as to reach unfailing supplies of water, and the trunk and branches are to get the leaves high in the air where they will not be overshadowed by other plants.

Leaves. - What happens in the leaves? Surely we should understand this. Through all but the winter months, the leaves of plants cover all the land, save where man has cleared them away, or where there is not enough water for plants to grow. They are so common, so beautiful, and so important to us that every one should understand their relation to our own lives, and the way in which they do their work. The skin of a leaf may be very harsh and tough, but inside it is always soft and tender. It is filled with a soft green pulp. This soft pulp is made up of many very small structures called cells. The bodies of all living things are made up of cells which exist in many forms and sizes. In this spongy, soft interior of a leaf the great work of food-making goes on. Three things are necessary to this work of food-making: (I) Sunlight is necessary, for it furnishes the energy used in this work. (2) Air is necessary, for it furnishes carbon dioxide, a substance used in the making of food. (3) Water is necessary, because it, too, furnishes materials that are used in foods. 
The green parts of plants (whether leaves or stems), whenever the light is shining on them, and whenever the necessary materials are present, keep working away at their task of food-making. Food-making is an elaborate process. The molecules of the substances out of which food is made begin in the leaf a long series of changes. Presently we find them changed to starch or sugar, and these are true foods of the carbohydrate class, as you have learned in physiology. It is this work of carbohydrate manufacture that requires light. Other kinds of food (fats and proteins) may be made out of carbohydrates in the absence of light. To make them out of carbohydrates does not require the energy that is necessary to make carbohydrates out of carbon dioxide and water.

Now you can understand how a plant lives. You know what roots, stems, and leaves are for. You know that they work together in the great process of food-making. After the food is made it may pass in liquid form to any part of the plant. Thus, in the case of corn, much of the food passes into the ear and fills the grains. The most important food plants in the world are the cereals - wheat, rice, corn, barley, oats, etc. In all these plants the food used by man is starch in the seeds. But how do the seeds help the plant in its life? This is another story, quite different from the story of root, stem, and leaf.

\section{QUESTIONS}

I. Explain the work of roots.

2. What are root-hairs, and of what advantage are they to the plant?

3. Describe the exchange of gases through the leaves.

4. What things are necessary for food-making by green plants?

5. What are some of the dangers to our crops? 
6. Why does a tree have a trunk and branches? Do trunk and branches work?

7. What are cells?

8. Name some of the most important food plants.

9. Does any plant furnish all the kinds of food needed? 


\section{CHAPTER XXXII}

THE STORY OF SEEDS

This is a story quite worth telling, and a story you can easily understand if you will try to put yourself in the place of the plant. Try to see what its problems are and how it solves them. The seed is the plant's answer to one of its greatest problems.

Plants that die each year as winter approaches are called annuals; plants that live on from year to year are called perennials. You can see that for the annuals there is the problem of how their young children can live over winter. The seed answers that problem. But perennials also have seeds. Let us see why.

Our food comes chiefly from seeds. The great crops of the world are crops

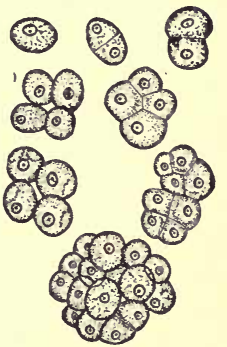

Fig. 89.-The "first" plants.-After J. M. CoutTer. of seeds. The food of farm animals is largely composed of seeds. What seeds do you know that are used in our foods? Any structure that contains seeds is a fruit, so the story of seeds includes the story of fruits. Write a list of the different kinds of fruits you have eaten. Is a tomato a fruit? Is a potato a fruit?

We must go back to the time when plants first began to live on the land. The very first plants lived in the water. They did not have roots, stems, and leaves. They were just tiny, round green balls, so small that you could not 
see one of them with the naked eye. Such plants still live. That green coating you sometimes see on bark, or where water drips on rock, is composed of millions of such onecelled plants (see Fig. 89).

Nutrition. - Think of the life-problem of such a plant. There it floats near the surface of the water on a bright, sunshiny day. To keep alive it needs sunlight and air and water and some of the substances dissolved in the water. All these things are abundant where it lives, and one might think that the little plant would have an easy time. This is true as long as summer lasts, but if this little plant lives where water freezes it must change its form to keep alive. This it may do by forming a thicker coat around itself, and sinking to the bottom. There it may rest for a long time and still keep alive (just as seeds keep alive) in the coldest weather. When spring comes it can come to the surface and start its active life again.

Just keeping alive is not all that there is to plant life. If it were, then the plants on which we live would never have come into existence, and we should never have come into existence. All through their history plants seem to have done everything in their power to spread, to spread everywhere that plants can live. There seems to be no place in the world where plants can grow but that, sooner or later, they find that place and grow there. This means that they must reproduce. It also means that in the long history of plants many different kinds have appeared, and so we find different kinds of plants in different kinds of places. We do not understand how the different kinds of plants have appeared, but we do understand that they all have come from the same ancient ancestors, and that 
the plant kingdom as we see it to-day is a result of the great tendency of plant life to spread and multiply.

To keep alive and to multiply, then, are the two great laws of plant life. The former we call nutrition; the latter reproduction.

Now, as plant life went on in those ancient days it kept improving. The two great problems of plant life have always been the same, but the plant's ways of solving these problems have changed. It is as though the plant kingdom kept inventing better ways of doing its work. All this took a great deal of time. Plants are changing now just as they changed in the past, but the changes are so gradual that we hardly notice them. Yet you know that the fruits we have in the market to-day are much better than the fruits our grandfathers had. This shows that plants change, and that these changes can be controlled by man. What we want o do now is to consider some of the ways in which plants have changed in the past, and we do this so that we can understand plants as we see them to-day.

Reproduction. - There was that ancient little plant that had to reproduce. It did it in the simplest possible way. It just divided into two. Then each of the two new plants (daughter-cells) divided again, and so on. It was very simple, and it is a method of reproduction that is still used. But it was not enough. Plants simply had to grow, and expand. Tiny, round, one-celled plants could never spread over the land. They would dry out too quickly.

We often find growing in running water plants that are composed of slippery green threads. They belong to the group of plants called alga. Surely you have seen them 
fastened to rocks or floating in the water when you have been in wading. These threads are one cell in thickness, but many cells in length, as may be seen under a microscope. In some of these cells many small bodies are found. These little things escape into the water where they swim around. They seem like little animals they are so active. Sometimes two of these little things unite. After they unite, they stop moving. They have formed a single cell, and

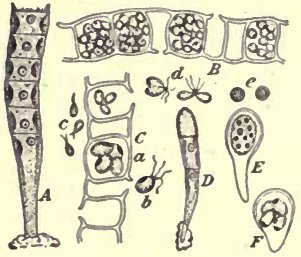

Fic. 90.- One of the algx, showing how the small reproductive bodies are formed within the cells; how they break loose and swim about $(c)$; how they pair (d) and form a single cell (e), which grows into a new individual $(D)$. - After J. M. Coulter. this cell presently will grow into a row of cells (see Fig. 90). This production of a new individual as a result of the union of two cells is the sex process, or reproduction, and we are going to see what this process has to do with the production of seeds.

Now you have seen two steps in the story of seeds. First, the little plant that reproduces simply by dividing. Next, the little plant that reproduces by the union of two cells. Now if these two cells that unite are of different sizes (as is true of most plants), we call the smaller one the sperm and the larger one the egg. This is important to remember, for all the higher plants and animals reproduce by means of sperms and eggs.

If you have ever been at the seashore you have been interested in the tides. Have you ever noticed the plants that lie on the mud at low tide? Probably the first plants that ever lived on land were plants that were left behind on the mud by the receding tides. Of course the greatest danger to a plant is the danger of drying up. All land- 
plants are protected from drying up by a covering through which water does not easily evaporate. So the plants that first lived on the land had to develop a kind of covering that their waterdwelling ancestors did not need.

To-day we find growing in damp places certain flat little plants that look as though they had rather recently come out of the water, and are just learning to

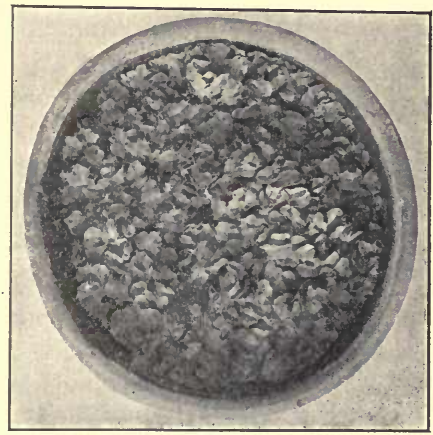

FIG. 91.-Pot of liverworts, the first land-plants.

live on the land. These plants are called liverworts, and their favorite home is in moist and shady places, especially

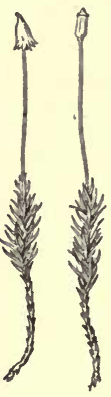

Fig.92,-Moss plants.After J. M. COULTER. on damp cliffs (see Fig. 9r). These plants show us the third step in our story. They produce eggs and sperms, and the sperms swim just as they do in algæ. But the eggs stay where they are formed. The sperms have to come to them. The union of the egg with the sperm is called fertilization. The cell that results from union of egg and sperm is called the fertilized egg. Now right here is the new point in the story. The fertilized egg does not grow into a plant like its parent. It grows into a clubshaped structure, and this structure contains hundreds of very small round cells. Presently the wall of this structure bursts and the small 
round cells escape. Each one of them, if it reaches a favorable place, will produce a liverwort-plant. These little round reproductive cells are called spores. Spores are reproductive cells that can grow directly into new plants. Eggs and sperms are cells that cannot grow directly into new plants; they must unite before the new plant is produced.

Mosses look more

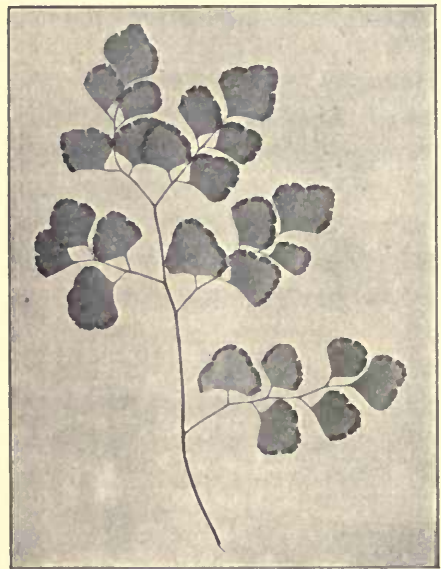

Fig. 93.-Maidenhair fern with brown spore cases at the edges of the leaves. like regular land-plants than liverworts do, but you nearly always find mosses where you find liverworts, and they have the same method of reproduction. They belong to the same great group of plants (see Fig. 92).

The fourth step toward seeds is represented by ferns. You all know ferns. Have you ever noticed that sometimes you find on the under surface of fern-leaves many small brown structures? (See Fig. 93.) These brown structures are made up of many little cases, and each one of the cases contains spores. Ferns do not have seeds. For their spreading abroad over the land they have to depend upon these spores. But you can see that these tiny spores have many disadvantages as compared with seeds. They are not protected by a thick wall and they do not contain 
much stored-up food. Unless they fall on a favorable place very soon after they are set free in the world, the spores of common ferns soon perish. Seeds, however, may live for many years.

The spores of ferns do not produce fern-plants. They produce a little flat green structure that looks like a little liverwort (see Fig. 94). This structure produces sperms and eggs. The sperm swims to the egg, and the fertilized egg produces the fern-plant.

Now let us see how this fourth step (fern) is different from the third step (moss and liverwort). In mosses the sperms and eggs are produced at the top of the

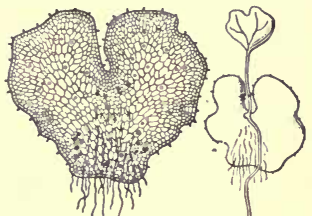

Fig. 94--Small plants produced by the fern spores; one of them is producing a new fern-plant. -After J. M. Coulter. little baby plants, while the spores are produced on structures that have no leaves (see Fig. 92). But in ferns the spores are on the leaves, while the sperms and eggs are pro-

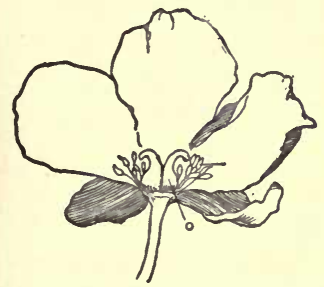

Fig. 95.-Diagram of a flower. $S$ is a stamen; $O$ is an ovary. duced by a small structure that has no leaves. These two things have been reversed. You see that in plant life there are two generations - the spore-bearing generation and the sperm-andegg-bearing generation. In the ferns it is the leafy generation that bears spores, and this is also true of seed-plants.

Now we are ready for the fifth step. This step is illustrated by a very graceful plant that is common in greenhouses. This plant is a distant relation 
of the common ferns, but it does not look like a fern at all. Its name is Selaginella (club-moss). This plant produces two kinds of spores, a big kind and a little kind. The big kind produces a structure that bears eggs only. The little kind produces a structure that bears sperms only. The sperms have to swim about to find the eggs. And

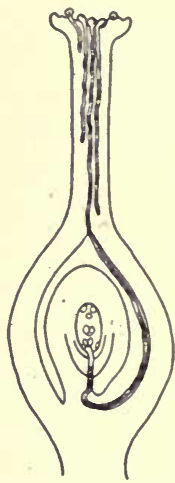

Frg. 96. - Longitudinal section of an ovary, showing ovule and pollen tubes.-After J. M. Coulter. still there is nothing that looks like a seed!

But the seed appears with the very next step. You probably know that flowers produce pollen. Pollen is a dust-like substance (commonly yellow), and you find it at the ends of those structures inside the flowers that are called stamens (see Fig. 95). Surely you have heard that insects (especially bees) carry pollen from flower to flower as they go about searching for food. Now, a grain of pollen is a spore. But we know that seed-plants produce two kinds of spores. Where is the other kind?

If you dissect a flower you will nearly always find at the very center of it, and at the bottom, the little structure that is going to become the fruit. If you cut open this structure you will find inside of it the very small structures that are going to become the seeds. These baby seeds are called ovules and the structure that contains them is called the ovary (see Fig. 96). It is inside the ovules that the big spores are produced, and they never escape. It is this that gives us seeds. The big spores produce eggs. These eggs are hidden away inside the ovules, and the ovules are hidden away inside the ovary. 
The pollen produces the sperms. How are they ever going to get to the eggs?

Look at the picture. Notice the slender, stem-like structure that rises from the ovary. You can find this in nearly every kind of flower. At the very top of this structure there is a rough and usually sticky surface. This is the pollen-catcher. Pollen may blow on it, or fall on it, or be rubbed on it, or be carried to it by insects. But, however it gets there, when it gets there it stops, and it begins to grow. It sends an invisible tube down through the stem-like part, and then into the ovary, and then into the ovules themselves. When the conditions are right, there is one pollen-tube for each ovule. These invisible pollen-tubes
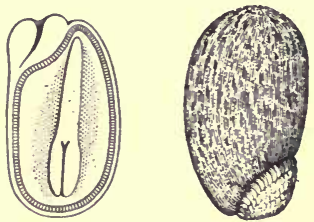

FIG. 97--Section of a seed, showing embryo inside, and tough coat outside.-After J. M. Coulter.

contain the sperms. Now you can see how the fertilization of seed-plants occurs, and now perhaps you can see what a seed really is.

The fertilized egg, lying there inside the ovule, begins to grow into a new plant. This little plant that is formed inside the seed is called the embryo. At the same time, the outer part of the ovule hardens and forms the tough coat of the seed (see Fig. 97). Between the coat and the embryo, food is stored for the use of the little plant when the seed begins to sprout. If you study botany you will learn more about the various groups of plants and the way they are related to each other. But, whether you ever study botany or not, you should understand something of the relationship between seed-plants and those that do not 
produce seeds. You should understand that they all have the same general problem of reproduction to solve. The seed-plants are the most successful plants in the world, and this is chiefly because the seed is the solution of the great problem of spreading out and multiplying.

\section{QUESTIONS}

I. What are the simplest plants?

2. Did the first plants live in water or on land?

3. How do the simplest plants reproduce?

4. What is the sex process of reproduction?

5. How do land-plants differ from water-plants?

6. What land-plants lived before there were any seed-plants?

7. How are seeds produced? 


\section{CHAPTER XXXIII}

\section{PLANT GROUPS}

In the last chapter you have had the story of the seed. This story began with the simplest plants, and it carried you through one group after another until the highest group was reached. It is important now to think of the plant kingdom as a whole, so that you will know the great groups when you see them.

Probably most.people think of plants as having leaves, stems, and roots, and producing flowers and fruits and seeds. This is true of our most conspicuous plants, and of the plants that are most useful to us. But you ought to know that the plant kingdom includes also plants without seeds or flowers; and even plants that do not have leaves or stems or roots. This is important for two reasons: first, you may see these more simple plants anywhere if you know about them; and second, it is from these simple plants that the higher ones have come.

Those who study plants (botanists) have divided up the plant kingdom into four great groups. These groups may be likened to the four stories of an apartment-house, rising one above the other until the highest story or group is reached. You should know, in a general way, the kinds of plants that live in these different stories.

I. The First Plants. - These are the plants that live in the first story. They are called the first plants because once they were the only kind of plants. They started the 
plant kingdom. These first plants are of two general kinds, and you have seen both kinds. One kind consists

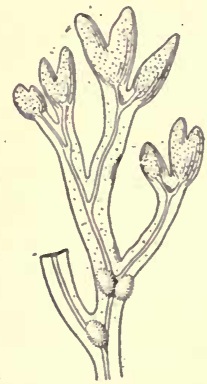

Frg. 98.-Seaweed.After J. M. Coulter. of what are called Alge. You have seen green, thready growths in the water, green "scum" in ponds, green stains on tree-trunks, etc. These are Algæ, our simplest green plants. They have no leaves or stems or roots, and produce neither flowers nor seeds. If you have visited the seashore, you have seen curious-looking plants thrown up on the beach by the waves. Some of them are brown or green and leathery; others are delicately branching and reddish. All of these are Algæ that have learned to live in sea-water, and to live also buffeted about by the tides and storms. Some of them are quite large, and they are commonly called "seaweeds" (see Figs. 98 and 99). In many places along the seacoast these seaweeds are thrown up on the beach in great numbers, and they have been found to be very useful as fertilizers. For this reason they are carted to the fields and spread over them like manure.

The other group is called the Fungi, and they differ from the Algæ in not containing any green material. For this reason they are unable to make their own food, and must get it from other plants or from animals.

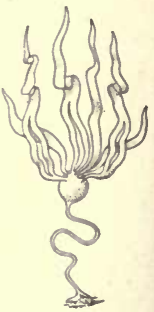

Frg. 99. - Seaweed. - After J.M.CoutTER. Some of them attack living plants or animals to obtain food, and when they injure them they produce what we call diseases. Many of our diseases, such as typhoid fever, diph- 
theria, tuberculosis, and pneumonia, are caused by the attacks of certain minute Fungi trying to obtain their food from our bodies. In doing this, they either destroy some of our body or give off substances that poison us. Some of these Fungi do not attack living bodies, but use for food dead bodies or material that has been made by living bodies. For example, you may have seen bread that has become "mouldy." This means that one of these Fungi has attacked the bread to get its starch (see Fig. 46). You know about yeast. It is one of these Fungi that attacks sugar, and in so doing gives off a gas that puffs up breaddough and makes it "light."

You will see that the Algæ are very interesting, because they are our first independent plants, independent because they are green and can make their own food. The Fungi, however, are more important to us because they so often produce diseases from which we suffer, and also diseases that injure our valuable animals and plants.

2. The First Land-Plants. - The second story of our plant apartment-house is occupied by the first land-plants. The Algæ live in water or in very moist places. They could not take possession of the land. But from the Algæ the first land-plants came. You have seen mosses, which are the most common members of this group. They are found very abundantly in shady and moist places, and some of them are able to live in very exposed places, as on bare rocks.

The plants that first learned to live on land, however, were not mosses, but the relatives of mosses known as liverworts (see Fig. 9I). You will find them in moist and shady places, sometimes clinging to rocks or tree-trunks, but sometimes growing flat on the ground. 
Neither liverworts nor mosses have flowers or seeds, but they made great progress in learning to live on land. The danger to plants in living on land was that they would be dried out and killed by exposure to air. If a fish is taken out of water and left in the air, it cannot continue to live. And so certain Algæ gradually learned how to

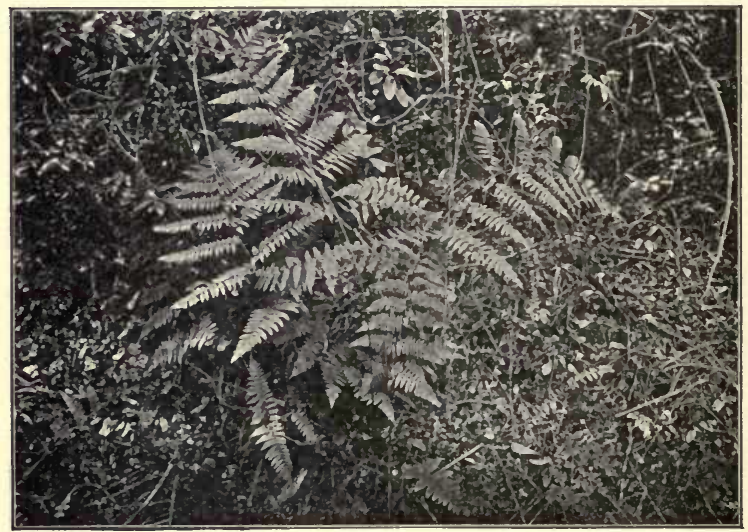

FIG. 100.-Ferns.

protect themselves from drying out. And when they learned, they were no longer Algæ, but became liverworts.

This second group of plants, therefore, took a great step in advance, and deserve to live in the second story. They made it possible for plants to begin to occupy the land surface.

3. The First Woody Plants. - These plants occupy the third story of our apartment-building. The most common 
of them you know very well, for they are the ferns. You know that ferns develop leaves and stems and roots, and they have much larger bodies than do the mosses and liverworts (see Fig. 100). In fact, you know that some of the ferns became trees, which you may have seen in greenhouses (see Fig. ror).

Why were ferns able to become larger than mosses? The answer is that they had developed something new, and that was woody fibres. These woody fibres not only make a more rigid body, but their chief value came from the fact that they carry water. It was like putting a system of

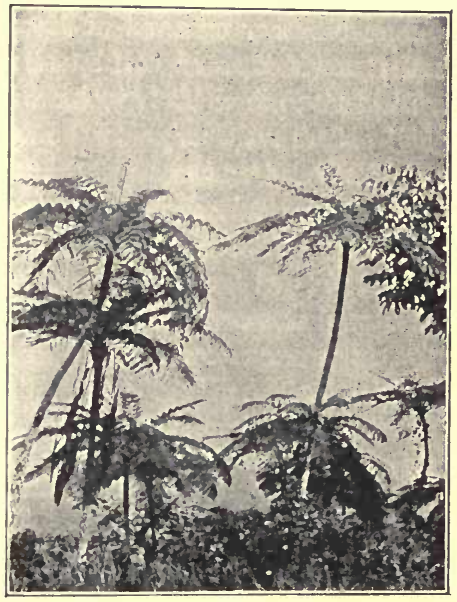

Fic. ror,-Tree-ferns. water-pipes into the plant. By means of these water-pipes the water entering through the roots can be carried rapidly and directly to leaves far above the ground. In this way plants could become larger, and trees became possible.

You will remember that you have seen yellowish or blackish dots on the under-surface of many fern-leaves. These are made up of little vessels that produce small bodies that are called spores. It is by means of these spores that new fern-plants are produced. There are no seeds yet. 
Relatives of the ferns are the club-mosses, which perhaps you have seen (see Fig. I02). Other relatives are the horsetails, which I know you have seen. They are curious

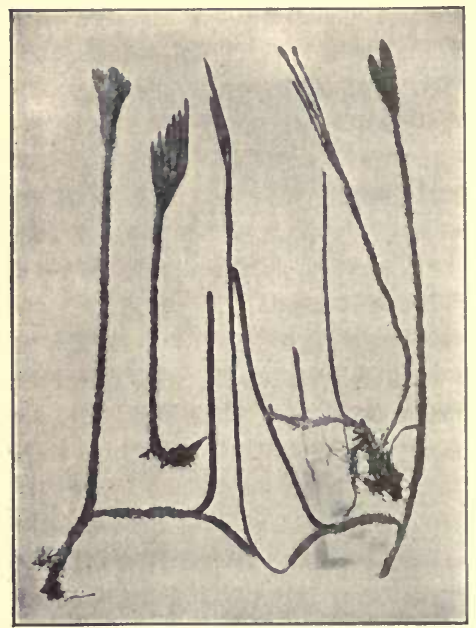

Fic. I02.-Club-mosses. leafless plants, and when they are pointed out to you, you will always recognize them (see Fig. 103).

\section{TheSeed-Plants.} - These are the plants that inhabit the highest story. They are woody, but they also produce seeds. The story of the seed is given in another chapter, and you know something about its structure. The seedplants are the most successful plants. This is shown by the fact that they have taken possession of so much of the land that they seem to cover it, where plants grow at all. They are also the plants that are most useful to us. When you think of the many ways in which we are dependent on plants, you will see that it is the seed-plants that supply these needs.

You should know the two groups of seed-plants. You know plants that belong to both of these groups. The pines, hemlocks; cedars, etc., belong to one group. You have 
probably heard them called "evergreens," because their leaves do not fall off in the autumn, and they remain green all winter. The name of the group is Gymnosperms, which means "naked seeds." The seeds are not enclosed in a case or fruit. You have seen a pine-cone, made up of hard, overlapping things called "scales." If you break off

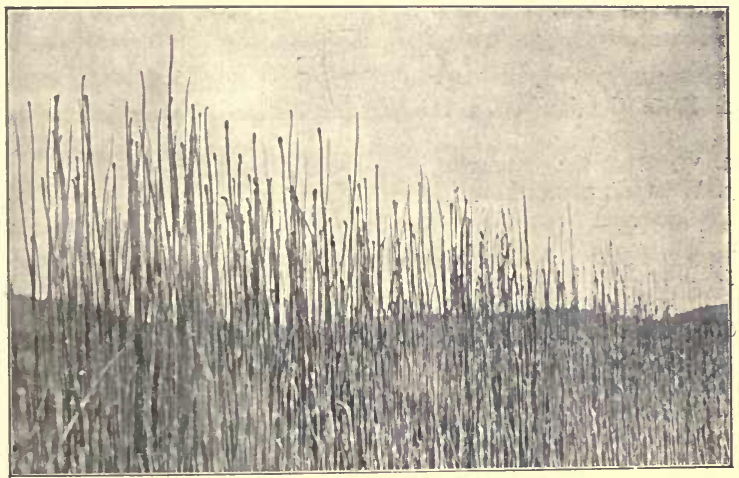

FIG. 103.-Horsetails.

one of these scales you will find one or two naked seeds fastened to its upper side near the base. Gymnosperms, therefore, produce seeds, but they do not produce flowers.

The other group of seed-plants is very much larger, and most of our seed-plants belong to it. It is called Angiosperms because the seeds are produced in a case or fruit. Angiosperms means "seeds in a case." You know that you have to split open a pea-pod to find the seeds; and that the seeds of apples are in the "core."

What people most notice about Angiosperms, however, 
is that most of them produce flowers. For this reason, Angiosperms are often called "flowering plants."

That Angiosperms are much more successful plants to-day than Gymnosperms is indicated by the fact that there are only about five hundred kinds of living Gymnosperms, while there are at least one hundred and forty thousand kinds of living Angiosperms.

\section{QUESTIONS}

I. State the important things that distinguish the four great groups of plants.

2. What are the differences between Algæ and Fungi?

3. What did plants have to learn in order to be able to live on the land?

4. Which one of the classes of plants has been the most successful?

5. What is the difference between the two groups of seed-plants, and are both groups useful to us?

6. Of what use is a flower to a plant? 


\section{CHAPTER XXXIV}

\section{RELATIONS BETWEEN PLANTS AND THEIR SURROUNDINGS}

Think of all the different kinds of plants that you might see in one short walk. Think of the microscopic plants that grow in water as compared with the huge trees of the forest. Think of the many forms of mushrooms, and of the strange plants of the tropics.

Evolution. - We wonder why there is all this great variety of forms that we see on every hand. This is one of the great problems of natural science. Scientists for many years have been at work upon it, but there is not yet any complete answer. You know that we do not believe that all the many kinds of plants and animals were separately created. We do believe that they have come from common ancestors. This great process is called evolution, which means change. It means the production of new things through the change of the old ones. It means that in ancient times as well as to-day no two forms were alike and that each new form was more or less different from its parents. You can see that with this sort of thing going on for some millions of years, there would surely be a great increase in the number of kinds of plants and animals.

As you look over a field of corn you are quite sure to see individuals that are different. Here is a fine plant, nearly ten feet high, and bearing two good ears. Not far away we 265 
find one much shorter and with only one good ear. Why this difference?

It is certain that the difference between these two plants is due either to a difference that they inherited from their parents, or to differences in their surroundings as they grew, or to both. In other words, all living things, animals as well as plants, are what they are because of heredity and environment. Heredity means what is inherited from parents; environment means all the conditions that surround an individual after birth.

You have been studying the environment. You know about the principal physical things (light, heat, air, etc.) that affect life. Now you should think of plant life as a great force in the world that is always trying to express itself (in nutrition and reproduction) in the presence of an environment that constantly acts upon it and affects it. This has been going on for such a very long time that we find plants usually quite well adjusted to their environments. This is to say, the shapes and structures of plants seem to be a good deal determined by their surroundings. We find very tough and hardy weeds growing in dry places, while soft and tender plants are found in moist and shady places.

Forests are the highest expression of the plant kingdom, and the most interesting study of plant life is the study of the woods in the spring when the leaves are coming out and the early spring flowers are found all over the floor of the forest. If you were to go into the woods some fine day in late April or early May, you might find the "spring flora" at its best. Then you could stop to think what the "woods" really means. In level country the woods usually means great age of the topography. The trees on dry bluffs and 
hillsides are never so large as those that grow in the older valleys. The greatest forests in the world are in the valleys of ancient, slow-flowing rivers. The greatest of all are in the valley of the Amazon.

In North America the number of kinds of trees is much less than in the tropics. There are about twenty kinds that every one should learn to know. They are quite easy to recognize if you will practise observing them very carefully when some one tells you the names. You must practise picking out the characters by which you will know them the next time you see them. Oak, maple, ash, elm, and hickory are trees you all should know, and there are several kinds of each one of these that you will soon learn to know if you take any interest in plants.

Now going back to the woods in April. Why is it that so many beautiful flowers are to be found there in spring, while in summer we find hardly any at all? Hepatica, violets, spring-beauty, bloodroot, trillium, Dutchman'sbreeches - do you know these flowers? In April and May you can find all of these and many more. But in July and August the woods are bare of flowers. Why?

This fact shows how very responsive plants may be to their environment. A woods is a sort of "plant society." In swamps, thickets, or meadows we find other kinds of plant societies. Every society, plant or human, has its more and its less prominent members. The trees are the prominent, controlling members of forest societies. The other plants have to adjust themselves to the great, successful trees. The trees are the forms that have made sure of the light and of the moisture. Their leaves are high in the air and their roots deep in the soil. The undergrowth must do the best it can with the light that filters through. 
Then there are the vines. They climb up the trunks of the trees. They have learned how to take advantage of the work of others. Sometimes in the forest you will find trees covered with vines, weighted down and killed by them.

In April and early May the leaves are not full on the trees. Light shines through to the forest floor, and this is the season that the little plants of the forest have made their own. In a few weeks they do nearly all their work of growth and of reproduction, and then rest until another season. Nearly all the early spring flowers arise from bulbs or other kinds of thickened underground parts in which food is stored. They do not come from seeds. They shoot right up, and often open their flowers even before the leaves are formed.

So, as you go about in the woods, you may find a hundred ways in which plants are closely related to their environment. But we do not find that there is just one rule of nature that explains how all these interesting results have been achieved. We know that heredity and environment, working together, have accomplished the results that we see, but we cannot say just what is due to one and what to the other. Certainly plants differ in this matter. Some are much more affected by their surroundings than are others. In this matter, you see, plants are almost precisely like people. We ourselves are the result of our heredity and our experience. We cannot alter our heredity, but we must make our experiences as desirable as possible. 


\section{QUESTIONS}

I. What is evolution?

2. What is the difference between heredity and environment?

3. Why do some plants grow in dry places and others in moist places?

4. Where are the greatest forests?

5. Why do vines climb up trees?

6. Why do we see certain forest flowers growing in the spring but not in the summer? 


\section{CHAPTER XXXV}

ANIMALS. VERTEBRATES

The study of animals is called zoology. We are not going to make a study of zoology now. That will come later. But, in order to fill out your picture of nature, you need a definite idea of the animal kingdom.

Just about half a million different kinds of animals have been described by zoologists, and about seven-tenths of these are insects. This has been called the Age of Man and Insects because in this age these two kinds of animals have been by far the most successful.

Branches of the Animal Kingdom. - The entire animal kingdom is divided into twelve branches. Of these there are two that you should understand. The other ten may wait until you study zoology. These two branches are the jointed-legged animals, and the vertebrates, or animals with skeletons. Of the former there are several classes, three of which you should know. A crayfish or a lobster is an example of one of these classes, the class called Crustacea; to another spiders belong; while a third is made up of that greatest of all classes, the Insecta. We shall study them in a separate chapter.

The Vertebrates. - Of the animals with skeletons (Vertebrates), there are five classes you should remember: fishes, amphihians, reptiles, birds, and mammals. These 
names all explain themselves, except perhaps amphibians, which means animals that can live either in water or on the land. Frogs and toads belong to this class. Turtles and alligators, as well as snakes and lizards, belong to the reptiles. Of course you know birds when you see them, but it may surprise you to know that birds are related to reptiles; that is, the first bird was a sort of winged reptile.

The last and highest class of the vertebrates are the mammals, to which we ourselves belong. Nearly all the domestic animals are also mammals, and many others that are wild furnish us with food or clothing. The name mammals refers to the mammary glands of the female that furnish milk for the young. The fur-bearing animals are all mammals. Fishes, birds, amphibians, and most reptiles lay eggs, but mammals give birth to their young alive.

Every boy and girl should try to get clearly and permanently in mind the way in which mammals are classified into different groups. This will help you greatly in organizing your knowledge. There is no more fascinating book than Hornaday's "American Natural History" in which you can read of the habits of all the important American vertebrates.

The mammals are divided into thirteen orders, four of which it is quite important to remember. First come the Primates, which means "first order." To this belong the apes, the monkeys, and man. Then come the carnivorous (flesh-eating) animals. To this order (Ferc) most of our interesting wild animals belong. This order is composed of five families: cats, dogs, bears, martens, and raccoons. Wild members of the cat family in America are the puma and the lynx, while wolves and foxes belong to the dog 
family. The marten family includes our small fur-bearers: otter, mink, weasel, wolverene, skunk, badger. You should learn to know all these animals by studying them in a museum or zoological garden if you have a chance.

The third order of mammals you should remember are the Rodents, or gnawers. Here belong rats and mice, and also squirrels, rabbits, and gophers. The fourth important order is composed of the hoofed animals-Ungulates. Cattle, deer, sheep, swine, and horses are the most important members of this great order.

Among mammals belonging to the smaller orders are seals, moles, bats, whales, and opossums. Now as you stop to think of all these forms you realize what a great and successful class the mammals are, and how they have spread all over the world.

Think then of the fishes in the water, the birds in the air, amphibians on both land and water, and you realize that these animals with skeletons have come to occupy the earth as far as large animals can go. All other great groups of animals are small in stature as compared with the vertebrates.

Now, having in mind all this wonderful population of vertebrates, let us think how they are built to do their work in the world. They must all move actively about in search of their food. Their skeletons form a solid framework to which muscles are attached, and the movements are all accomplished by muscular contractions acting on the bones.

But what is it that moves the bones? And what acts on the food and oxygen that enter the body? How are they changed so that they can be used? Perhaps you can answer these questions as to your own body, but do all these other vertebrates have lungs, hearts, nerves, blood- 
vessels, stomachs, and intestines the same as you? They all do except the fishes, which have gills in place of lungs.

As to reproduction, you learned in your study of plants that the sex method is used in some of the very lowest plants and in all of the high ones. But all plants also use other methods. In the higher animals, however, there is only the sex method. Sperms are produced by the males, and eggs by the females, and these must be united in the mating of the sexes. The fertilized egg grows directly into a new individual, and there is no resting-stage that corresponds with the resting-stage you have observed in seeds.

The great bulk of the body of all these animals, whether it be a fish or a frog, a bird or a mammal, is devoted to the work of securing food and making use of the food after it is obtained. In that respect they are just the same as plant-bodies, although they are so differently organized into definite organs.

The intelligence of animals is related to the size of their brains. All the vertebrates have bony skulls which protect the brains within them. As we progress from fishes toward man, we find the brain growing larger and larger, until in man we find developed that wonderful organ that makes all the difference between man and beast. It is only in brain-power that we excel the lower animals. They can excel us in all the other organs. Their hearts, muscles, stomachs, lungs, and sense-organs may all be better than our own. It is only in our more highly developed nervous tissues that we excel them. We can think, reason, and imagine. And this makes us responsible for our own acts. The lower animals are safely guided by their instincts. We are not. All our life long we must seek self-control. 
There is no insanity among animals, but insanity appears quickly among human beings where self-control is lost. We alone of all living things are responsible for our own acts. It is the price we pay for being at the top of the scale. We can be the happiest of all creatures. We can also be the most miserable. Suicide and crime are unknown except among more highly civilized human beings, and here we would not have them except for failure of the brain to do its work properly; failure to assert itself and be the real master of the body.

Another thing that increases as brain size increases is the length of time that parents care for the young. Take the fish. Here there is no care for the young at all. There is not even mating. The male discharges sperms in the water just as the female discharges eggs. Fertilization takes place entirely outside the bodies of the parents, and is very uncertain. Eggs and sperms are produced by millions. If they were not, the race of fishes would soon disappear.

When we come to snakes, however, we find real care of the young; while birds are placed next below mammals for no better reason than the attention they give to the rearing of their young. It is with human beings, of course, that this matter reaches its extreme form. Human parents are responsible for the protection and care of their children for many years. Of course this means that much fewer young are produced. So the investment of time and money and devotion to each one is greatly increased, and young people represent a very large investment by their parents and by society in general. It is truly a terrible thing not to take this investment seriously and responsibly. 


\section{QUESTIONS}

I. What is the largest class of animals?

2. What are the five classes of vertebrates? Give examples of each.

3. How do mammals differ from all other animals?

4. Name some of the classes of mammals, and give examples.

5. Is a whale a fish?

6. What methods of reproduction are there in the higher animals?

7. In what respect does man excel the lower animals?

8. How do different kinds of animals differ in the care of their young? 


\section{CHAPTER XXXVI}

\section{INSECTS}

Man's two greatest enemies are himself and insects. The best friends he has among insects are the cannibal insects, those that serve him by devouring other injurious forms. Bees yield us honey, and silk comes from the cocoons of a certain moth, but how gladly we should give up silk and honey if thereby we could escape the harm that other insects do to our crops and to our very lives! The common house-fly is the most dangerous animal in the world; it carries typhoid fever. And there is a kind of mosquito that spreads malaria from patient to patient. Altogether, we seem to be a good deal at the mercy of insects. Flies and mosquitoes we can drive out if we take the trouble to do so, but there are many insect enemies of our important plants that we do not know how to control. The gypsy and the brown-tail moths are very injurious to shade-trees, and millions of dollars have been spent in Eastern United States in trying to control them, and yet their ravages continue. Our annual financial loss due to insects is estimated as follows:

Cereals.

$\$ 300,000,000$

Hay and forage ....................... $66,500,000$

Cotton............................ 85,000,000

Tobacco............................. I0,00, 1000

Truck crops.......................... $60,000,000$

Sugar............................. $\quad 9,500,000$

Fruit............................ $60,000,000$

Farm products....................... II , $, 00,0 \infty$

Miscellaneous crops.................... I0, $10,0,000$ 
Animal products. . . . . . . . . . . . . . . . . . \$300,00,, 000

Natural forests....................... $\quad{ }_{100,00,000}$

Products in storage .................... 200,000,000

$\$ 1,212,000,000$

Twelve hundred millions in a year that might be saved if we knew just how to fight these tiny enemies instead of fighting them in the dark! It is like shooting into a forest to hit enemies we cannot see.

The study of insects is called entomology, and in the employ of the state and national governments there are many economic entomologists who devote their whole time to finding out how to fight these very injurious insects. As has been suggested before, one of the very best ways is to find another insect that is an enemy of the injurious one. Once such an insect is found, it is carefully bred until a great hostile army of them has been produced. Then these are set free to destroy the kind that is hurting the crops, or the fruit-trees, or whatever it may be. In California a certain kind of beetle (Vedalia) is kept in large colonies by the State Horticultural Commissioner. There is another kind of insect (cottony-cushion scale) that is very bad for the oranges. Whenever there is danger of an epidemic of the scale-insect, colonies of the beetle are sent to the "firing-line," and they promptly exterminate the cottony scale. This is a case in which almost perfect control has been worked out, but it took many years to do so, and the protecting insect was finally located in faraway Australia. Kellogg and Doane's "Economic Zoology" is a very good book in which to read about the different kinds of injurious insects and the ways in which they are combated. 
Quite apart from their importance in dollars and cents, insects are very interesting creatures to study. They have wonderful "life histories," and very much is yet to be found out about their behavior. You already know the life history of moths and butterflies, and you know of the wonderful behavior of ants and of bees.

Some insects appear to be the most intelligent of all animals lower than man, and yet we cannot be sure that

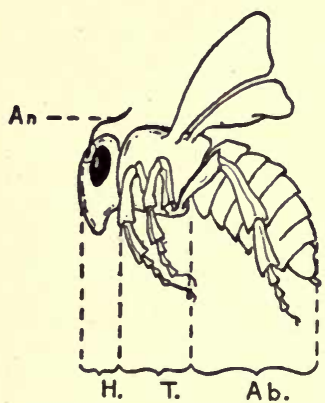

FIG. 104.-Diagram of the body of an insect; $H$, head; $T$, thorax; $A b$, abdomen; $A n$, antenna.

they are reasoning creatures. You see the world is a very different place to an insect from what it is to us. It breathes differently, sees differently, smells differently, and in practically every way has a plan of organization wholly different from our own.

The two great ideas about insects that you should have are (I) an idea about how they are constructed and how they live, and (2) an idea of the classification of insects; that is, an idea of the six great groups and of the important insects belonging to each.

All insects have their hard part outside and their soft part inside. They have no skeleton, as vertebrates have. There are three distinct parts of the body: head, thorax, and abdomen. To the thorax three pairs of legs are attached. The wings are also attached to the thorax. On the head are the compound eyes, composed of a great number of small eyes lying very close together. Just in front of the eyes arise the antenna, which are very impor- 
tant organs. They are used for feeling and for smelling, and, in some insects, for hearing (see Fig. 104).

On the lower side of the head we find the peculiar mouth. Insects do not have lips, tongue, and teeth in the ordinary sense. They have what are called mouth parts, and these six mouth parts are variously arranged in different insects. In a grasshopper they are arranged for biting. In a bug they are arranged for piercing and sucking. In a fly they are arranged for lapping (see Fig. I05).

One of the most surprising things about an insect is that it breathes with its abdomen. That is to say, along the side of the abdomen are found little openings called spiracles. These open into tubes called trachea, which branch and run to all parts of the body, even out into the wings.

Now think of the activity of an insect as compared with your own. How many times the length

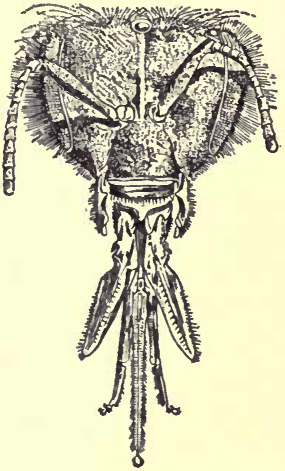

Fic. 105.-Drawing to show the complicated mouth parts of an insect. of its own body can a grasshopper jump? How many times can you? It is perfectly evident that insects far excel us in muscular activity in proportion to their size. A man would have no trouble jumping over the Woolworth Building if he could jump like a flea. The breathing-plan of insects has a good deal to do with their activity. It permits oxygen to get very quickly to all parts of the body. In other words, insects do not get "out of breath" the way we do. 
The blood of insects does not go through closed vesseis, as in man. It fills that part of the body-cavity not occupied by other organs. There is a true circulation, however, the heart being located just under the middle of the back. The digestive system is well developed, while there is a central nervous chain that passes along the lower side of the body.

Of the six great orders of insects, you should understand that two of them have incomplete metamorphosis, while four of them have complete metamorphosis. This long word, metamorphosis, names a very interesting fact of insect life. You probably know that a caterpillar changes into a moth or butterfly. It is this complete changing from one form into another in the life of an individual that is called metamorphosis. In a complete metamorphosis there are three stages. The egg hatches into a worm-like stage called larva. A caterpillar is a kind of larva. It is in the larval stage that insects do most of their eating. It is in this stage that they are so harmful to crops and to foliage. Larvæ eat almost constantly throughout their lives. After they have stuffed themselves and reached full growth, they pass into a resting-stage, the pupa stage. During this stage they undergo a quite complete change of form. When they emerge from it they usually have wings. They are now in the reproductive or egg-laying stage (see Fig. 106).

Early fall is the best time of year in which to study insects. In early September they are at the height of their activity. You can always find then representatives of the six great orders.

First, the grasshoppers. They belong to an order called Orthoptera, which means straight wings. Their metamor- 
phosis is incomplete. The eggs are laid in the ground, and they grow directly into young grasshoppers. Crickets also belong to this order. The members of it all have strong jumping legs.

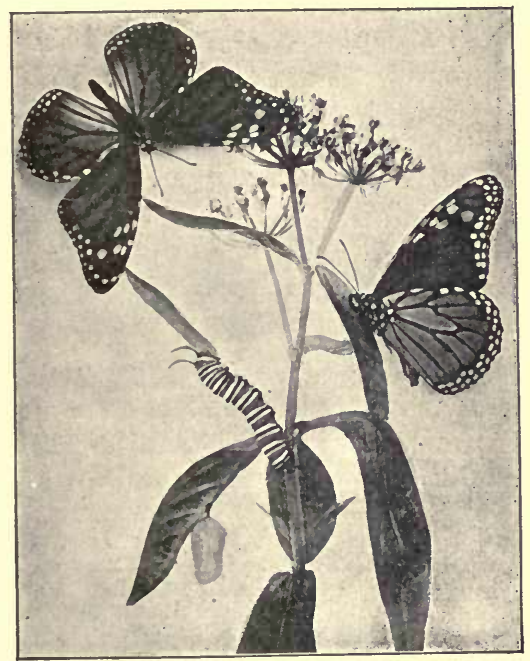

FIG. 106.-Metamorphosis of the insect.

Then the bugs. It is common to call all insects that are not well known "bugs." But, properly used, this is a scientific term that names just one order of insects, the Hemiptera. This word means half-wings, and refers to the fact that in many bugs the wings are very small. Some of them have no wings at all. Most of them have flat bodies that permit them to live in cracks and crevices. In September you are quite sure to find a good many bugs 
trying to get into houses for winter quarters. June "bugs" and potato "bugs" are not real bugs, but are beetles. Some bugs have a complete metamorphosis, but most of them do not.

The beetles are very numerous, but most of them stay hidden. You find them abundantly in rotting wood or under the ground. The so-called "pinching-bug" is one of the commonest forms of beetles. The outer wings of beetles are hard and are not used in flying. Hence the name of the order, Coleoptera, which means sheath-wings.

Then there is the great group of flies which includes mosquitoes. These, you know, are the great disease-carriers, and in that way do more harm to man than all other kinds of insects. They are called Diptera, which means two wings. You know that insects regularly have two pairs of wings, but in flies and mosquitoes there are only two wings. The second pair of wings (hind pair) found in other insects has been changed in the flies, being represented by two small rods called "poisers," because they are believed to help the insect to keep its balance when flying.

Then there are the butterflies and moths, which every one knows. The name of their order is Lepidoptera, which means scale-wings, referring to the fact that their wings and bodies are covered with scales that are usually colored. It is very common to see the brightly colored butterflies and moths flitting about flowers and sucking out the nectar.

The sixth order contains the bees and wasps and ants, and is named Hymenoptera, which means membrane-wings, referring to the thin, papery wings. It is much the largest order, and contains very important and interesting insects. 


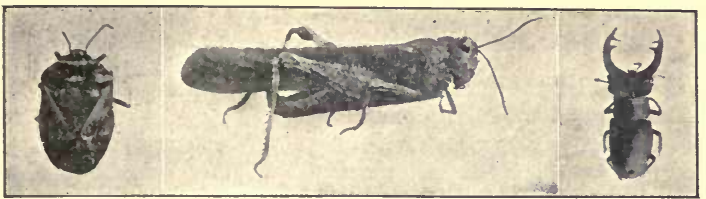

Bug.

Locust.

Beetle.

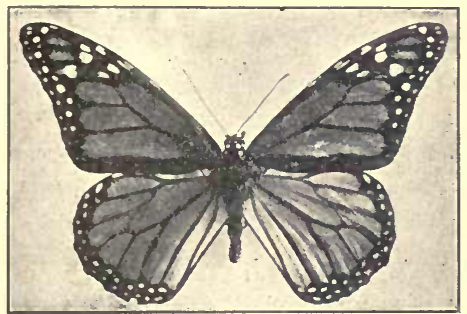

Butterfly.

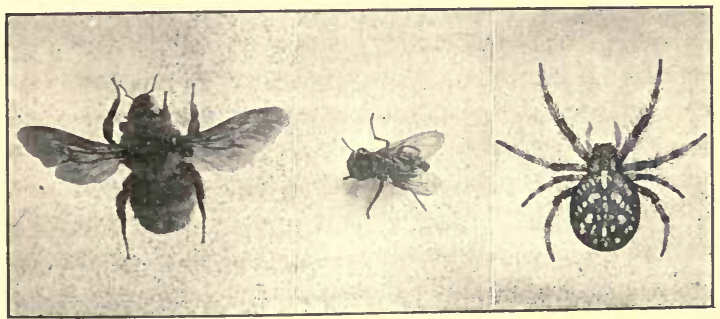

Bee.

Fly.

Spider.

Fig. 107.-The various orders of insects.

You know something of the habits of bees and wasps in building homes and storing food. The ants are everywhere and seem to be peculiarly intelligent, living in communities that are very wonderful in their organization (see Fig. 107). 


\section{QUESTIONS}

I. How are insects useful, and how are they harmful?

2. Describe the body of an insect.

3. How does an insect breathe?

4. How does the blood system of a man differ from that of an insect?

5. Describe the metamorphosis of an insect.

6. What are the different classes of insects? Give some examples of each. 


\section{INDEX}

Abdomen, of insects, 279

Aeration, 93

Air, I, I66, I67

- a mixture of gases, 43

- composition of, 15I, 156

- entering water, 42

- expansion of, 180,181

- movements of, 19

Air-pressure (see atmospheric pressure)

Algæ, 249, 258

Aneroid barometer, 58

Animals, 1, 270-275

- jointed-legged, 270

- vertebrates, 270

Antarctic Circle, I 76

Antennæ, 278

Anticyclone, 193

Archimedes $(287-2$ I2 B. C.) principle, 63,64

Arctic Circle, r76

Artesian wells, 33,52

Astronomy, I 72

Atmosphere, 3

- convection currents of, 167

- defined, I47

- density of, 148, 149

- humidity of, I43

— in indoor life, 199

- relation to heat, 150,167

- relation to sun, 162

- weather, a state of, 178

Atmospheric pressure, 55-62

- at mountain tops, 59

- at sea-level, 59

- cyclones, 192

- high and low, r8o

- measuring, 58

- relation to water vapor, 184

Bacteria, IOI-I04

Barometer

- aneroid, 58, 59

- high and low pressures, I 80

- mercurial, 59, 6I
Caloric, I 24

Calorimeter, I33, I34

Calory, 132, I43

Cancer, Tropic of, I 75, I 76

Candle-power, 228

Capricorn, Tropic of, I75, I 76

Carbohydrates, 230, 234, 238

Carbon, 159

Carbon dioxide, 43, 153, 154, 156, 158

Cells, 244

Centigrade thermometer, ${ }_{3} 30$

Chlorophyll, 238

Cistern, 46

Clay, 52, 84, 94, 96

Clouds, 4

- cirrus, 197

- cumulo-nimbus, 197

- stratus, 197

Coal, 3,50

Cold, I35-1 40

- freezing, 136

Color, 216-224

— rainbow, 220

- solar spectrum, 220

- waves, 220

Combustion, 209-215

- burning, 209

- energy released by, 2I4

- products of, 2I3

- rusting, 209

Condensation, I3, 16, I8, I43

Contraction, I 2, 89, I 29, I4I, I44

Convection, $145,167,180$

Convection currents, 167,180

Crustacea, 270

Cycle, of life, 233

- nutritive, 236

Cyclones, 192

$$
\text { - anticyclone, } 193
$$

Day, I69, I 74

Degree, of latitude and longitude, 175

Deposition, 25 
Dew, 18

Diffusion of gases, 44

- of light, 223

Digestion, 9

Doldrum, 186

Drainage, 83

Earth, as planet, 170

- axes and poles, 172

- crust, 52

- depth, 47

- inclination of axes, 172

— inside, 47

- movements of, 169-177

- orbit, 171

- revolution around sun, I70, I7I

Electrolysis, 158

Energy, II 7, 164

- combustion, 214

- conservation of, 137,138

- forms, II 7

- heat, a form of, 216

- kinetic, I18, 119, 142

- light, a form of, 216

- potential, I18, I19, I42

Entomology, 277

Environment, 266

Equator, 185

Equinoxes, I 73

- storms, 174

Erosion, 25, 28

Ether, 217

Evaporation, 5, 9, 10, 16, 143

- from leaves (transpiration), 35

Evolution, 265

- environment, 266

- heredity, 266

Expansion, I 2, 89, I29, I41, 143, I44

Fahrenheit (1686-1736) thermometer, 130

Fats, 234

Feldspar, 94

Fertilization, 251

Fertilizers, 107

Filters, 68

Fishes, 270

Fog, 18

Food, 5, 232-240

- carbohydrates, 234

- fats, 234

- inorganic, 233
Food, nitrogenous, 234

- non-nitrogenous, 235

- nutritive cycle, 236

- organic, 233

- oxidation of, 238

- proteins, 235

Freezing, 136

Frost, 18

Fulcrum, 112, I14

Fungi, 105, 106, 258

- mushrooms, 106

- puffballs, 106

- toadstools, 106

Fusion, heat of, 143

Galileo (1564-I642), I 24

Gas, 3,53

Glaciers, 35,36 - glacial till, 38

Gravel, 33, 52

Gravitation, II9, 120, 149

Gravity, 16, 21, 74, 75 (law of gravitation, 22)

Great Basin, I9I

Ground-water, 3 I

Hail, 19

Heat, I , 4, 9, I3, 49, I37-140, 145

- and atmosphere, 150

- calorimeter, 128

- conduction, 137, 166

- convection, $145,167,180$

- day and night, 169

- form of energy, 216

- measurement, I 28

- radiation, 165

- solar, 172

- thermometer, $124,128,130,131$

- variation, 141, 142, 180

- vibration, 217

Heating, 200-208

- fireplace, 200

- furnace, 202

- stove, 202

Heredity, 266

Houses, 199-200

Humidity, I 7, 143

Hurricane, 185

Hydration, $91,92,160$

Hydraulic press, 65

Hydrogen, $155,157,158,159$ 
Ice, $9,138,142,145$

- glaciers, 35,36

- sheet, 37

Inorganic (see substances)

Insecta, 270

Insects, 276,283

Inventions, 2

Iron oxide, 210

Irrigation, 80, 8I

Isobar, 184

Isotherm, 184

Kinetic theory, 125

Lakes, 32,46

Larva, 280

Latitudes, I 74

Lava, 49

Leaves, 244

Lenses, 226

Lever, I I 2, I I 4

Light, 1 , 4, 165, 216-224

- absorption, 22I

- diffusion, 223

- form of energy, 216

- intensity, 229

- rainbow, 220, 225

- rays, 222

- refraction, 222, 226

- reflection, 222, 227, 228

- solar, I 72

- spectrum, 220

- translucent, 224

- transmission, 224

- transparent, 224

- waves, 21 7, 219

Liquid, 3

Longitude, 274

Mammals, 270

- orders of, primates, 272

- rodents, 272

- ungulates, 272

Man, 273

Matter, 9 (see substances)

Mercury, 59, 60, 61, 62, I 28

Meridians, 175

Metamorphosis, 280

Microscope, 227

Minute, 175

Molecular motion, 139, 140, 141 , I63

Molecules, I 2, I3, I55-160

Monsoons, 187
Moraines, 38

Motion, 218 (see kinetic theory)

Mountains, worn down, 30

- rainfall, I9I

- range, $5 \mathrm{I}$

Natural science, $I$

Nature, I, 2

Newton, Sir Isaac (1642-1 727), I 20

Night, I69, I 74 - variation, 174

Nitrates, 160

Nitrogen, 43, 151 152, 156

-importance to plants, 103, 104

Nutrition, 248

Nutritive cycle, 236

Oil, 53

Orbit (of earth), I7I

Organic (see substances)

Oxidation, 91, 160, 16r, 238

Oxygen, 43, 15I-160, 209

Parallels, 174

Pascal (1623-62), 6I

Photography, 227, 228

Photosynthesis, 229, 230, 238

Phlogiston theory, 210

Piston, 75,76

Planets, 170

- axes, I 70

- movements, I 70

- revolution, 170

- rotation, 170

Plants, I

- algæ, 249, 258

- annuals, 247

- effect of sunlight, 230

- fungi, 258

- perennials, 247

- pollen, 254

- reproduction, 248,249

- stamens, 254

Polar regions, 169

Pollen, 254

Pressure, low and high, 2 I

Proteins, 235

Protoplasm, 160, 232, 236

Pulley, 113

Pump, 55, 56, 57, 61 , 66

Quartz, 94 
Radiation, 164, 165, 205

Rain, 4, 14

- thunder-storms, 195

- uses of, I 89

Rainbow, 220, 225

Rainfall, 189,190

- effect of mountains, I9I

- in Mississippi Valley, 194

- in United States, 31

Reclamation Service, 82

Reflection of light, 222

Refraction, 222

Refrigeration, 179

Revolution of earth, 172

Rivers, 24, 46

- deposition, 24

- erosion, 24

Rock, 50, 88

- disintegration, 92

- formation, 49, $5 \mathrm{I}$

- granite, 51

- layers, 32, 50, $5 \mathrm{I}$

- limestone, 49, 51,52

- sandstone, 5I, 52

- sedimentary, $5 \mathrm{I}$

- shale, 5 I

Roots, 243

Rotation of earth, I72, 185

Rust, 2 ro

Sand, 52, 84, 94

Sap, 4 I

- porous, 33

Saturation, 13

Seasons, $169-177$

- causes, 160-177

- changes of, 169

Sediment, 4 I

Seeds, 247-256

- algæ, 249

- fertilization, $25 \mathrm{I}$

- reproduction, 248,249

Siphon, 58

Smoke, 213, 214

Snow, 189, 190

Soil, I, 3, 52

- alluvial, 96

- eolian, 97,98

- fertility, I0I, 107

- food-supply, 107

- formation, 87

- grains, 84
Soil, layers, 32

- nature of, 99

Solar system, 169-177

Solid, 3

Solution, 40-45

Soot, 213

Sound, 216-224

Spectrum, 220, 225

Spores, 252

Springs, 32, 33, 46, 52

Stalactites, $47,48,52$

Stamens, 254

Stand-pipe, 68

Stars, 120,149

Steam, 9, 10

Steam-power, $70-78$

Strata, 33, 50, 52

Subsoil, 52

Substances, inorganic, 233,242

Sun, 147

- organic, 233,242

- centre of solar system, I70

- effect on atmosphere, 162

- revolution of earth around, I 70, I7I

- rising and setting, I $7 \mathrm{I}$

Telescope, 227

Temperature, I 28 (see "Heat and Cold," I35-140)

- of day and night, 169

- of land and water, 139

Thermometer, I 28, I 29, I30

- centigrade, I30

- Fahrenheit, 130

Thermostat, 208

Thunder-storms, 195

Topography, 35

Tornadoes, 197

Torricelli's experiment, 60,6 I

Trade-winds, 182

Transpiration, 35

Turbine, 72, 73

Vacuum, $16_{3}, 164$

Vapor, ro

Ventilation, $199,200,206,207$

Vertebrates, $270-272$

Volcanoes, 48,49

Water, 8, 16, 46, 67, 89

- air enters, 42 
Water, erosion, 25-27

- extent, 8

- filtered, 44

- ground-water, 3 I

- hard, 44

- irrigation, 80

- material dissolved, 44

- refraction of light in, 223

- soft, 44

- supply, 85

- suspension in, 44

Water-meters, 68

Water-power, 70, 71, 72, 74, 77

Water-pressure, $6_{3}, 64,65,66$

Water-table, 32

Water-works, 66, 67

Waves, color, 220

- length, 218

- light, 219

- sound, 218

- water, 218

Weather, $178-188$
Weather, atmospheric movements, I 79

- forecasts, 178

- maps, 182

Weather Bureau, 182

Weight, I 20-I $2 \mathrm{I}$

Wells, $32,46,52,53$

- á tesian, 33, 52

- oil, 53

Windlass, 55

Winds, 3 , 1 78-1 88

— basic directions, 186

- convection currents, 182

- doldrums, 186

- monsoons, 187

- movements of, 179

- planetary, 187

- prevailing, 186

- trade, 182

Zenith, 172

Zones, I $74^{-1} 77$

Zoology, 270 




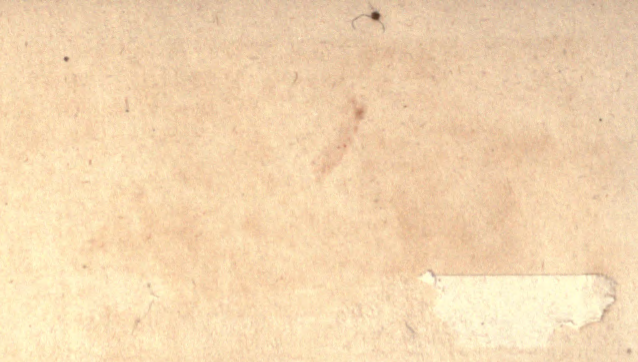

4

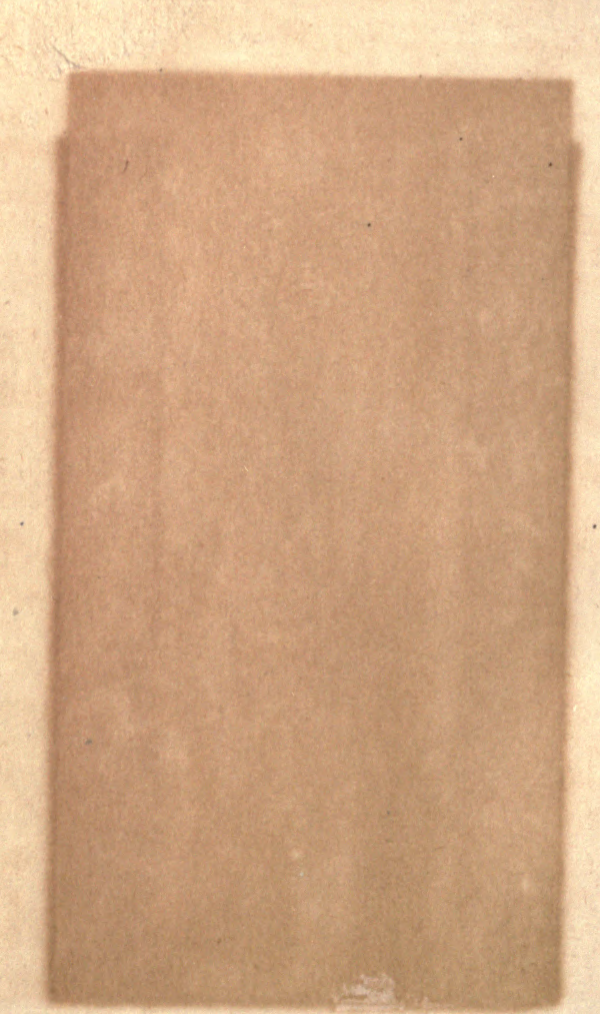



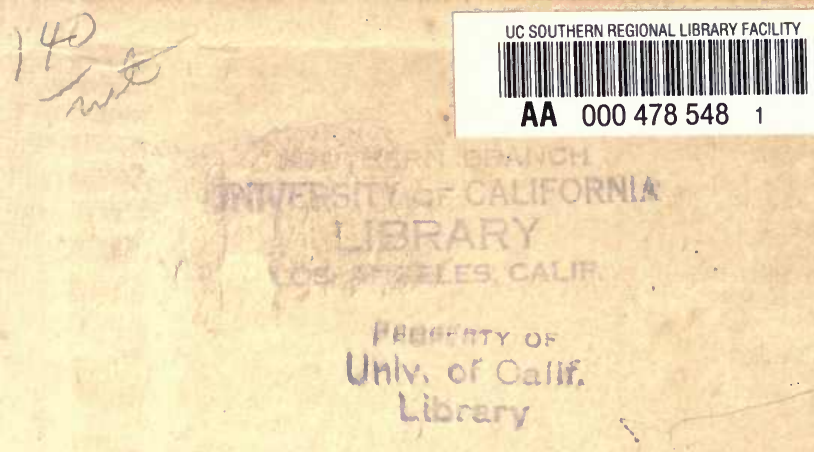
